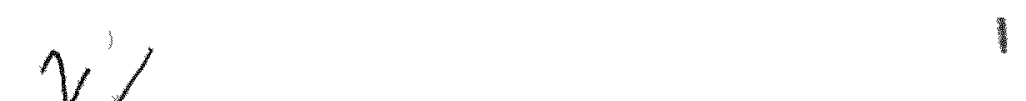

WHC-EP-0584

\title{
Status of Tank 241-SY-101 Data Analyses
}

Prepared for the U.S. Department of Energy Office of Environmental Restoration and Waste Management

\section{(W) Westinghouse \\ W Hanford Company Fichland, Washington}

Hanford Operations and Engineering Contractor for the

US Department of Energy under Contract DE AC06 87AL10930 


\section{LEGAL DISCLAIMER}

This report was prepared as an account of work sponsored by an agency of the United States Government. Neither the United States Goverament nor any agency thereof, nor any of their employees, hor any of their contractors, subcontractors or their employees, makes any warranty, express or implied, or assumes any legal liability or respensibility for the accuracy, completeness, or any third party's use of the results of such use of any informatron, apparatus, product, or process disclosed, or represents that its use would not infringe privately owned rights. Feference heren to any specific commercial product, process, or service by trade name. trademark, manufacturer, of otherwise, does not necessarly constitute or imply fits endorsement, recommendation, or favoring by the United States Government or any agency thereof or its contractors or subcontractors. The views and opinions of authors expressed herein do not necessarty state or reflect those of the United States Government or any agency thereot.

This report has been reproduced from the best avallable copy. Avallable in paper copy and microficho.

Avaltable to the U.S Department of Energy and its contractors from

Office of Scientific and Technical Information

P.0. Bóx 62

Oak Ridge, TN 37831

(615) $576-8401$

Avallable to the public from the U.S. Department of Commerce National Technical Information Service

5285 Port Royal foad

Springtiald, VA 22161

(703) 487.4650

Printed in the United States of Amantca

OISCLM-1 CHP (1-91) 


\section{DISCLAIMER}

This report was prepared as an account of work sponsored by an agency of the United States Government. Neither the United States Government nor any agency Thereof, nor any of their employees, makes any warranty, express or implied, or assumes any legal liability or responsibility for the accuracy, completeness, or usefulness of any information, apparatus, product, or process disclosed, or represents that its use would not infringe privately owned rights. Reference herein to any specific commercial product, process, or service by trade name, trademark, manufacturer, or otherwise does not necessarily constitute or imply its endorsement, recommendation, or favoring by the United States Government or any agency thereof. The views and opinions of authors expressed herein do not necessarily state or reflect those of the United States Government or any agency thereof. 


\section{DISCLAIMER}

Portions of this document may be illegible in electronic image products. Images are produced from the best available original document. 


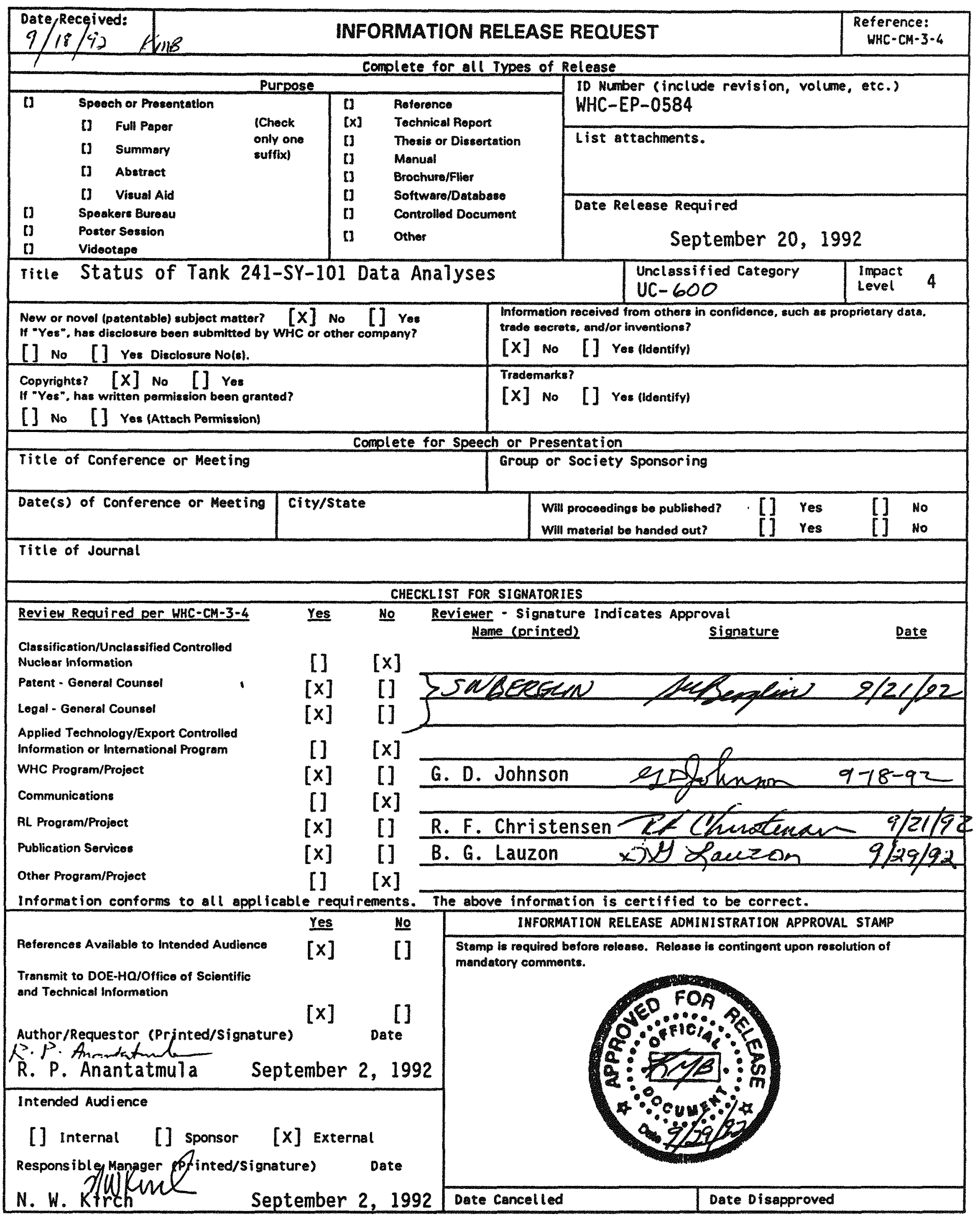




\section{Status of Tank 241-SY-101 Data Analyses}

R. P. Anantatmula

Date Published

September 1992

Prepared for the U.S. Department of Energy Office of Environmental Restoration and Waste Management

\footnotetext{
Q. Westinghouse

P.O. Box 1970

Hanford Company Richland, Washington 99352

Hanford Operations and Engineering Contractor for the

U.S. Department of Energy under Contract DE-AC06-87RL10930
} 
Document Title:

Prepared by:

Approved by:

Approved by:
Status of Tank 241-SY-101 Data Analyses

R.P. Anoutatiunte

R. P. Anantatmula, Principal Engineer

Tank Waste Technology Applications

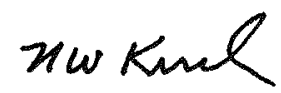

N. W. Kirch, Manager

Tank Waste Technology Applications

$9 / 23 / 92$

Date

$9 / 23 / 92$

Date

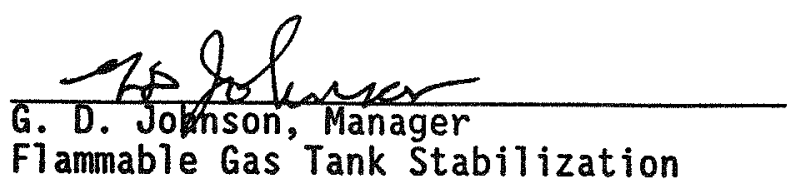




\title{
STATUS OF TANK 241-SY-101
}

DATA ANALYSES

\author{
R. P. Anantatmula
}

\begin{abstract}
The Waste Tank Flammable Gas Stabilization Program was established in 1990 to provide for resolution of a major safety issue identified for 23 of the high-level waste tanks at the Hanford Site. The safety issue involves the production, accumulation, and periodic release from these tanks of flammable gases in concentrations exceeding the lower flammability limits. This document deais primarily with tank 241-SY-101 from the SY Tank Farm. The flammable gas condition has existed for this tank since the tank was first filled in the time period from 1977 to 1980. During a general review of waste tank chemical stability in 1988-1989, this situation was re-examined and, in March 1990, the condition was declared to be an unreviewed safety question. Tank 241-SY-101 was $\mathrm{placed}$ under special operating restrictions, and a program of investigation was begun to evaluate the condition and determine appropriate courses of action. This report summarizes the data that have become available on tank 241-SY-101 since it was declared as an unreviewed safety question and updates the information reported in an earlier document (WHC-EP-0517). The report provides a technical basis for use in the evaluation of safety risks of the tank and subsequent resolution of the unreviewed safety question.
\end{abstract}


WHC-EP-0584

This page intentionally left blank. 


\section{CONTENTS}

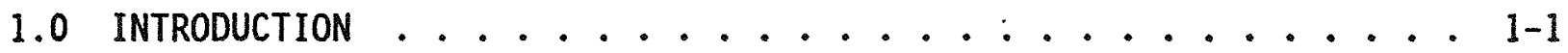

2.0 DESCRIPTION AND OPERATION OF TANK 241-SY-101 . . . . . . . . 2-1

2.1 DESCRIPTION OF TANK 241-SY-101............ 2-1

2.2 OPERATION OF TANK $241-S Y-101 \ldots . . . . . . . . .2-8$

3.0 MONITORED DATA PARAMETERS AND METHODS ........... 3-1

3.1 SURFACE-LEVEL MEASUREMENTS ............. 3-1

3.2 TEMPERATURE MEASUREMENTS ............. $3-2$

3.3 GAS COMPOSITION ..................... 3-2

3.4 TANK PRESSURE $\ldots \ldots \ldots \ldots . \ldots . \ldots . \ldots$

3.5 VENTILATION FLOW RATE ............... 3-5

3.6 RELATIVE HUMIDITY .................. 3-5

3.7 ACOUSTIC NOISE . . . . . . . . . . . 3-6

3.8 VIDEO IMAGES . . . . . . . . . . . . . 3-6

3.9 COMPUTER SYSTEMS USED IN DATA ACQUISITION $\ldots \ldots \ldots$

3.10 DATA REQUIREMENTS FROM TANK MEASUREMENTS ......... 3-7

4.0 GAS RELEASE EXPERIENCE $\ldots \ldots \ldots$. . . . . . . .

4.1 GAS RELEASE EVENT OF APRIL $1990 \ldots \ldots$. . . . . .

4.2 GAS RELEASE EVENT OF AUGUST $1990 \ldots \ldots \ldots \ldots$. . . . . .

4.3 GAS RELEASE EVENT OF OCTOBER $1990 \ldots \ldots$. . . . . . 4-4

4.4 GAS RELEASE EVENT OF FEBRUARY $1991 \ldots \ldots \ldots . \ldots . \ldots 4-4$

4.5 GAS RELEASE EVENT OF MAY $1991 \ldots \ldots . \ldots . . . . . . .44$

4.6 GAS RELEASE EVENT OF AUGUST $1991 \ldots \ldots$ 4-10

4.7 GAS RELEASE FOR DECEMBER $1991 \ldots \ldots$............ 4-11

4.8 GAS RELEASE CHARACTERIZATION ............. 4-11 4.8.1 Amount of Gas Released in an Event ......... 4-11 4.8.2 Current Understanding of the Gas Composition .... 4-11

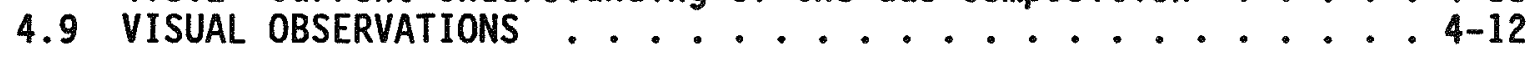

5.0 CORE SAMPLING DATA REQUIREMENTS ............... 5-1

6.0 CORE SAMPLE ANALYSIS RESULTS ............. . 6-1

6.1 PREVIOUS DATA ...................... 6-1

6.2 CURRENT SAMPLING DATA $\ldots \ldots . \ldots 6-1$

6.2 .1 Analytical Data on Crust Samples ........ 6-2

6.2 .2 Physical Properties of Core .......... 6-3

6.2 .3 Chemical Constituents .......... 6-.16

7.0 CHEMISTRY RESEARCH .................. 7-1

8.0 MODELING ACTIVITIES . . . . . . . . . . . . 8-1

8.1 BACKGROUND . . . . . . . . . . 8-1

8.2 MODELING OF GAS GENERATION AND ACCUMULATION $\ldots \ldots$

8.2.1 Gas Generation ............. 8-2

8.2.2 Gas Accumulation and Release $\ldots \ldots$ 8-4

8.3 MODELING OF THE ROLLOVER PHENOMENON ........ 8-5

8.3.1 The TEMPEST Modet ............ 8-5

8.3.2 The GOTH Model .............. 8-6 


\section{CONTENTS (continued)}

8.4 ROLLOVER FEATURE MODELS . . . . . . . . . . . . 8-8

8.4.1 Rayleigh-Taylor Instability ............ 8-8

8.4.2 Neutral Buoyancy Model of Rollover Initiation . . . . 8-9

8.4.3 The GOB Theory of Partial Rollover Gas Release . . . 8-11

8.5 MODELING OF HYDROGEN IN THE TANK DOME

SPACE AND VENTILATION SYSTEM ................8-11

8.5.1 FATHOMS Analyses ............... 8-11

8.5.2 Hydrogen Mixing Studies-Transient Reactor

Analys is Code Model.............. 8-12

8.6 PHYSICAL MODELING ........................... 8-...

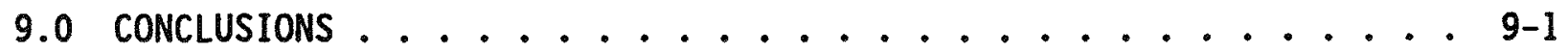

10.0 REFERENCES/BIBLIOGRAPHY . . . . . . . . . . . . . . 10-1 
WHC-EP-0584

\section{LIST OF FIGURES}

2-1 Schematic of Double-Shell Tank ............. 2-3

2-2 Tank 241-SY-101 Sample Riser Arrangement ........ 2-5

2-3 Double-Shell Tank Ventilation Details ......... 2-6

2-4 Double-Shell Tank Leak Detection System . . . . . . . 2-7

2-5 Tank 241-SY-101 Surface Level Data . . . . . . . . . 2-10

2-6 Historical Data of Tank 241-SY-101 Surface Leve1 . . . . . 2-11

4-1 Tank 241-SY-101 Apri1 19, 1990 Event Exhaust Gas Hydrogen Concentration ................ 4-3

4-2 Temperature Profiles of Tank 241-SY-101 Immediately Before the October 24, 1990 Event ........... 4-5

4-3 Temperature Profiles of Tank 241-SY-101 Immediately After the October 24, 1990 Event ............ 4-6

4-4 Temperature Profiles for Thermocouples 4 and 16 of Tank 241-SY-101 During October 24, 1990 GRE ......... 4-7

4-5 Comparison of Hydrogen Releases for Three Gas Release Events of Tank 241-sY-101 .............. 4-8

4-6 Comparison of Hydrogen Measurements from Tank Dome Space and Exhaust Header for the May 1991 Gas Release Event . . . . . 4-9

4-7 Gas Composition - 02 Tie Element Best Estimate . . . . . . 4-13

6-1 Measured Density of Tank 241-SY-101 Waste . . . . . . . 6-5

6-2 Supernate Density of Tank 241-SY-101 Waste . . . . . . . 6-6

6-3 Density of Solids from Tank 241-SY-101 Waste ......... 6-7

6-4 Variance of Viscosity with Temperature and Shear Rate for Segment 8 of Tank 241-SY-101 Waste .......... 6-9

6-5 Viscosity in the Convective Zone of Tank 241-SY-101 Waste . . . 6-10

6-6 Shear Strength Analysis Results of Tank 241-SY-101 Waste . . . . . 6-11

6-7 Percent Solids in the Convective Zone of Tank 241-SY-101 Waste . . . 6-13

6-8 Percent Solids in the Non-Convective Zone of Tank 241-SY-101 Waste .............. 6-14 


\section{LIST OF FIGURES (continued)}

6-9 Waste Height vs. Largest Particle Size

for Tank 241-SY-101 Waste ............. 6-15

8-1 Schematic Description of Tank 241-SY-101 Contents . . . . . . 8-3

8-2 Calculated Instability Index .............. 8-10 


\section{LIST OF TABLES}

2-1 SY Tank Farm Design Criteria . . . . . . . . . . 2-2

3-1 Tank 241-SY-101 Thermocouple Numbers and Locations . . . . . . 3-3

3-2 Tank 241-SY-101 Gas Monitoring and Analysis . . . . . . . 3-4

3-3 Data Parameter Requirements ..... . . . . . . . 3-8

4-1 Tank 241-SY-101 Slurry Gas Release Event Data . . . . . . 4-2

5-1 Analytical Data Requests for Safety, Modeling, and Engineered Remedies ............. 5-2

6-1 Comparison of Measured Density with Extruded Bulk Density . . . 6-4

6-2 Mother Liquor ................. 6-. . . . . .

6-3 Heat Load Estimated from Cesium-137 Inventory . . . . . . . 6-18

6-4 Cesium Inventories and Heat Load for Each Segment of Tank 241-SY-101 ................. 6-18

6-5 Composite Heat Estimation ............. 6-19

7-1 Proposed Mechanism of Thermal Degradation of Glycolate . . . . 7-3 


\section{LIST OF TERMS}

$\begin{array}{ll}\text { AMU } & \text { atomic mass units } \\ \text { ANL } & \text { Argonne National Laboratory } \\ \text { BOM } & \text { U.S. Bureau of Mines } \\ \text { CA } & \text { citric acid } \\ \text { CAM } & \text { continuous air monitor } \\ \text { CASS } & \text { Computer Automated Surveillance System } \\ \text { DSS } & \text { double-shell slurry } \\ \text { DST } & \text { double-shel tanks } \\ \text { ED3A } & \text { ethylelnediaminetriacetic acid } \\ \text { EDTA } & \text { ethylenediaminetetraacetic acid } \\ \text { FIC } & \text { Food Instrument Corporation } \\ \text { GMS } & \text { Gas Monitoring System } \\ \text { GRE } & \text { gas release event } \\ \text { HEDTA } & \text { N-hydroxyethylethylenediaminetriacetic acid } \\ \text { HEPA } & \text { high-efficiency particulate air } \\ \text { HMS } & \text { Hydrogen Mixing Studies } \\ \text { INEL } & \text { Idaho National Engineering Laboratory } \\ \text { LANL } & \text { Los Alamos National Laboratory } \\ \text { LFL } & \text { lean flammability limit } \\ \text { MMS } & \text { molecular mass spectrometer } \\ \text { NTA } & \text { nitrilotriacetic acid } \\ \text { HOACOH } & \text { hydroxyacetic acid } \\ \text { OSD } & \text { Operation Specification Document } \\ \text { OSR } & \text { Operation Safety Requirement } \\ \text { OVM } & \text { organic vapor monitor } \\ \text { PNL } & \text { Pacific Northwest Laboratory } \\ \text { PPE } & \text { Personal Protective Equipment } \\ \text { RT } & \text { Rayleigh-Taylor } \\ \text { TC } & \text { thermocouple } \\ \text { TFIC } & \text { Tank Farm Information Center } \\ \text { TRAC } & \text { Transient Reactor Analysis Code } \\ \text { TRU } & \text { transuranic } \\ \text { USQ } & \text { unreviewed safety question } \\ \text { VOA } & \text { volatile organic analysis } \\ \text { W.g. } & \text { water gauge } \\ \text { Westinghouse } & \text { Westinghouse Hanford Company } \\ \text { Hanford } & \\ \text { WTFGS } & \text { Waste Tank Flammable Gas Stabilization (Program) } \\ \text { XRD } & \text { X-ray fluorescence } \\ \text { XRF } & \end{array}$




\section{STATUS OF TANK 241-SY-101}

DATA ANALYSES

\subsection{INTRODUCTION}

The Waste Tank Flammable Gas Stabilization (WTFGS) Program was established in 1990 to provide for resolution of a major safety issue identified for 23 of the high-level waste tanks at the Hanford Site. The safety issue involves the production, accumulation, and periodic release from these tanks of flammable gases in concentrations exceeding the lower flammability limits. Two of these tanks, viz., 241-SY-101 and 241-SY-103, are in the SY Tank Farm and tank 241-SY-101 (known as 101-SY) is the highest priority tank for the WTFGS program. This document deals primarily with this tank from the SY Tank Farm. This condition has existed since tank 101-SY was first filled in the time period from 1977 to 1980. In the course of a general review of waste tank chemical stability in 1998 to 1989 , this situation was re-examined and, in March 1990, the condition was declared to be an unreviewed safety question (USQ).

The gases generated in tank 101-SY include hydrogen and nitrous oxide, which constitute a flammable mixture even in the absence of air. It is the combined presence of the nitrous oxide (oxidizer) and hydrogen that led to the designation of the USQ for tank 101-SY. The resolution of USQ requires the establishment of a valid safety envelope for the tank. This may involve the preparation of a free-standing safety evaluation including Operation Safety Requirements (OSR) for the SY Tank Farm.

Waste tank 101-SY is also identified as one of the tanks requiring special attention and restriction under Section 3137, Safety Measures for Waste Tanks at Hanford Nuclear Reservation, of Public Law 101-510 (November 1990).

Tank 101-SY was placed under special operating restrictions, and a program of investigation was begun to evaluate the condition and determine appropriate courses of action.

This report summarizes the data that have become available on tank 101-SY since it was declared as a USQ. The objective of this report is to provide a technical basis for use in the evaluation of safety risks of the tank and subsequent resolution of the USQ.

This report fulfills the requirement of Milestone 2011 of the fiscal year 1992 WTFGS Program. 
WHC-EP-0584

This page intentionally left blank. 
WHC-EP-0584

\subsection{DESCRIPTION AND OPERATION OF \\ TANK 241-SY-101}

\subsection{DESCRIPTION OF TANK 241-SY-101}

The double-shell tanks (DST) are located in the 200 East and 200 West Areas at the Hanford Site. The 241-SY (three tanks) Tank Farm is located in the 200 West Area while the 241-AN (seven tanks), -AP (eight tanks), -AW (six tanks), -AY (two tanks), and -AZ (two tanks) Tank Farms are located in the 200 East Area. The DSTs are designed and constructed to minimize the potential for leakage of radioactive liquids to the environment. The DSTs are similar in design with minor differences in operability. The SY Tank Farm design criteria are summarized in Table 2-1.

Each DST consists of three concentric structures as indicated in Figure 2-1. The outer tank structure is a reinforced concrete tank designed to sustain soil loading, dead loads, live loads, and temperature gradients. The reinforced concrete tank is lined with a carbon steel liner referred to as the secondary steel tank. The inner carbon steel tank is referred to as the primary tank. An annular space separates the two steel tanks. The primary tank is designed to contain the radioactive waste materials. The secondary tank can contain any liquid leakage from the primary tank.

The primary tank is $75 \mathrm{ft}$ in diameter and approximately $46 \mathrm{ft}$ high at the dome crown. The maximum content height is approximately $35 \mathrm{ft}$. The carbon steel in the bottom of the tank ranges from $1 / 2 \mathrm{in.}$ to 1 in. in thickness. The knuckle (the transition for the tank floor to tank wall) is a $7 / 8-i n$. plate. The primary tank wall thickness ranges from $1 / 2$ in. to $3 / 4 \mathrm{in}$. and dome is $3 / 8-i n$. thick.

The secondary steel tank lines the reinforced concrete tank and extends to the primary tank dome. The secondary tank is $80 \mathrm{ft}$ in diameter and varies in thickness from 3/8-in. to 1/2-in. plate. A 2-1/2-ft annular space between the primary and secondary tanks allows for installation of leak detection devices; and inspection equipment such as periscopes, television and photographic cameras; ventilation air supply; and exhaust piping and equipment for pumping liquid from the annular space.

The reinforced concrete structure is designed to withstand the most severe cumulative effect of operating and natural forces, including a breach of the primary tank with the resulting loads on the secondary steel tank and reinforced concrete structure.

An 8-in. slab of insulating concrete is sandwiched between the primary and secondary tank bottoms (refer to Figure 2-1). This slab provides protection for the reinforced concrete foundation from the heat generated inside the primary tanks. Slots in the insulating concrete route any leakage from the tank bottom to the annulus for collection and removal. 
Table 2-1. SY Tank Farm Design Criteria.

\begin{tabular}{|c|c|}
\hline Number of tanks & 3 \\
\hline Liquid storage capacity & $1.14 \times 10^{6} \mathrm{gal} /$ tank \\
\hline Primary tank diameter & $75 \mathrm{ft}$ \\
\hline Secondary tank dianeter & $80 \mathrm{ft}$ \\
\hline Earth cover (backfill) & $6.5 \mathrm{ft}$ \\
\hline Live loading on backfill over tank & $100 \mathrm{lb} / \mathrm{ft}^{2}$ uniform plus 50 tons concentrated load \\
\hline Internal vacuum & -5 in. w.g. maximum \\
\hline Internal pressure & 60 in. $H .9$. \\
\hline \multicolumn{2}{|l|}{ Waste characteristics } \\
\hline Temperature & $350^{\circ} \mathrm{F}, \max i m m^{*}$ \\
\hline Heat generation rate & $40,000 \mathrm{Btu} / \mathrm{h} /$ tank maximum \\
\hline pH & 8 to 14 \\
\hline Specific gravity & 1.7 maximum \\
\hline Seismic acceleration & $\begin{array}{l}0.25 \text { horizontal } \\
0.17 \text { vertical }\end{array}$ \\
\hline Wind loads & Uniform building code \\
\hline Design life & $50 \mathrm{yr}$ \\
\hline Tank wall temperature & $250^{\circ} \mathrm{F}$ maximum \\
\hline Primary tank construction material & ASTM - A 515 grade 60, carbon steel \\
\hline Secondary tank construction material & ASTM A 515 grade 60 , carbon steel \\
\hline Outer tank material & Reinforced concrete \\
\hline Process piping & $\begin{array}{l}\text { American National Standards Institute } \\
\text { B-31.1 criteria } \\
0.25 \% \text { slope minimum } \\
\text { pressure: } 400 \mathrm{Ib} / \mathrm{in} .^{2} \text { (gauge) } \\
\text { heat traced } \\
\text { encased }\end{array}$ \\
\hline Annulus ventilation system & $\begin{array}{l}700 \mathrm{ft}^{3} / \mathrm{min}, \text { maximum } \\
\text { double high-efficiency particulate air (HEPA) filtered } \\
\text { stack monitor/sampler }\end{array}$ \\
\hline Primary ventilation system & $\begin{array}{l}\text { 1,000, maximum } \\
\text { double HEPA filtered } \\
\text { stack monitor/sampler }\end{array}$ \\
\hline Air-lift circulators & Not appl icable \\
\hline Radiation exposure & Adequate shielding from coverblocks and earth cover \\
\hline $\begin{array}{l}\text { 1. ARH-2930, Functional De } \\
\text { K. H. Tanaka (November } \\
\text { SD-RE-TI-008, Compi lati } \\
\text {-SY Process Specificati } \\
\text { The tanks were analyzed for } s \\
\text { Even though wastes may enter the tank } \\
\text { the maximum tank wall temperature of }\end{array}$ & $\begin{array}{l}\text { Criteria - Saltcake storage Facilities - 241-SY Tank Farm, } \\
1973 . \text { ) } \\
\text { Basis Letters Referenced in } 241-A N,-A W,-A Y,-A Z \text { and } \\
\text { T. J. Venetz (January } 27,1982 . \text { ) } \\
\text { tural effects of thermal cycling and liquid level cycling. } \\
\text { to } 350 \text { of their temperature will fall quickly to less than } \\
\text { of by heat conduction and dilution. }\end{array}$ \\
\hline
\end{tabular}




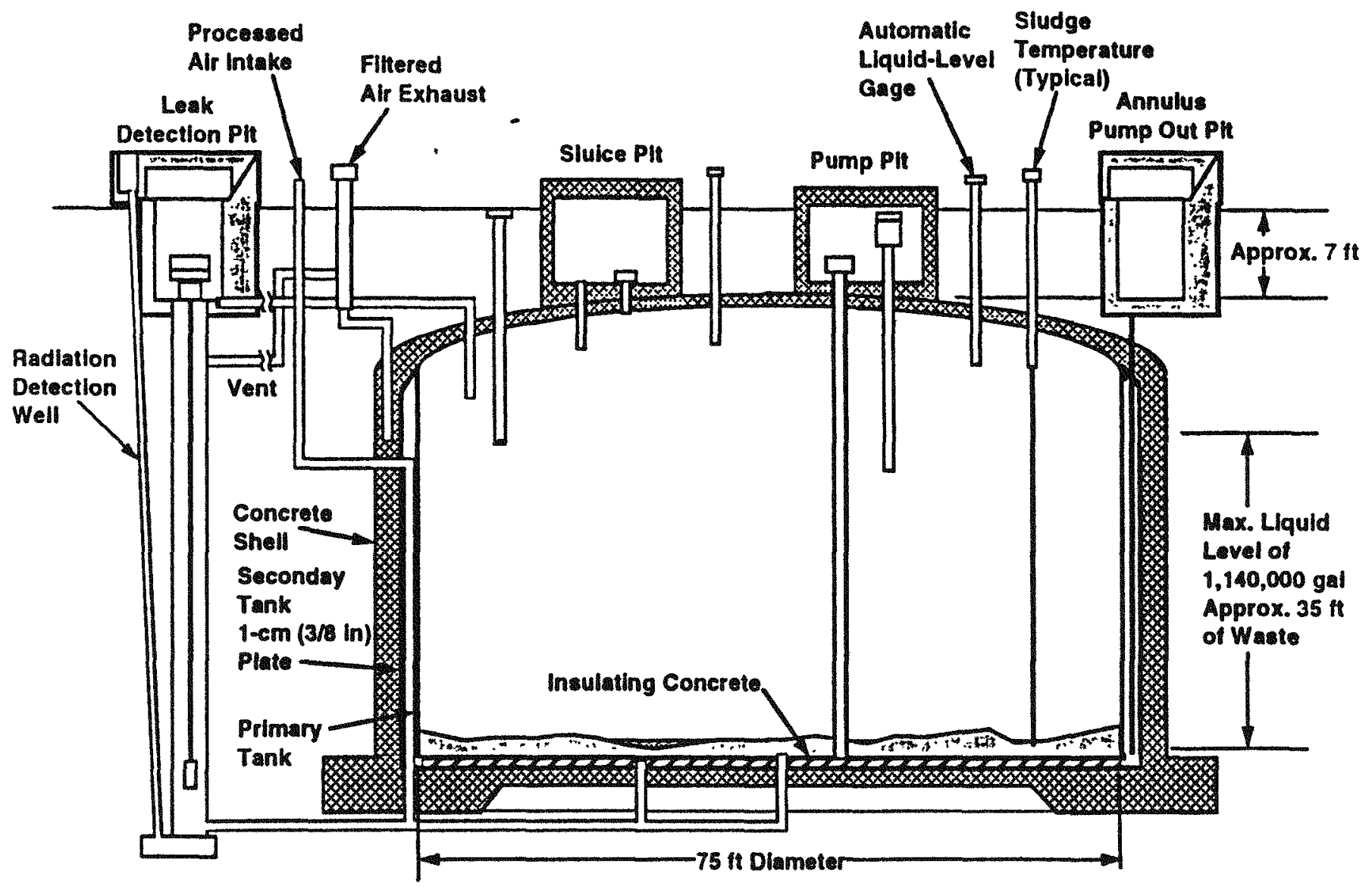


Each of the DSTs contain approximately 60 to 65 risers in the primary tank and annulus for monitoring and processing activities. A sample of a riser arrangement is shown in Figure 2-2 for tank 101-SY. The primary tank risers are used to measure liquid level, sludge level, temperature, and pressure. Risers also are used as observation ports.

Annulus risers are required for annulus pump out, ventilation air inlets and outlets, leak detection, annulus inspection, and construction access. All risers terminating above grade are located to permit crane access to process pits.

\section{Primary Ventilation System}

The ventilation system for each tank farm (refer to Figure 2-3) consists of two separate systems: (1) the primary tank system and (2) the annulus system. During normal operation, the primary ventilation system maintains a vacuum in the primary tank and prevents contamination spread.

Each primary ventilation system typically consists of a deentrainment pad to remove moisture; a heater to prevent condensation of the filters; a prefilter; two high-efficiency particulate air (HEPA) filters in series; a fan; and an exhaust stack with a flow measuring device, record sampler, and continuous air monitor (CAM).

Loss of power to the ventilation system shuts down the exhaust fans and monitoring equipment. During a loss of power, the tank vapor space pressure will equalize with atmospheric pressure in a process called breathing. Airflow during tank breathing will take the path of least resistance. Loss of instrument air to the tank farm causes the loss of vapor space pressure transmitters and associated alarms.

\section{Annulus Ventilation System}

The annulus ventilation system has three functions: (1) cools the tanks, (2) minimizes moisture condensation in the annular space, and (3) serves as a method of detecting leakage of radioactive waste from the primary tank.

An air inlet unit to each tank annulus ventilation system has a prefilter, a HEPA filter, and a manual butterfly valve. Outside air is drawn through the filters into pipes that extend into the tank annulus through risers and that are embedded in the insulating concrete. The air is discharged from the pipes into a plenum in the center of the insulating concrete. From the center of the insulating concrete, air flows radially outward to the annulus air slots in the insulating concrete, and is drawn out of the annulus the annulus exhaust fans.

\section{Instrumentation and Alarm Systems}

Instrumentation and alarm systems for each tank monitor operating parameters such as liquid level, temperature, leak detection, pressure, and area radiation levels (refer to Figure 2-4). A11 readouts are obtained at an instrument building in each tank farm and/or a nearby continuously manned facility. 


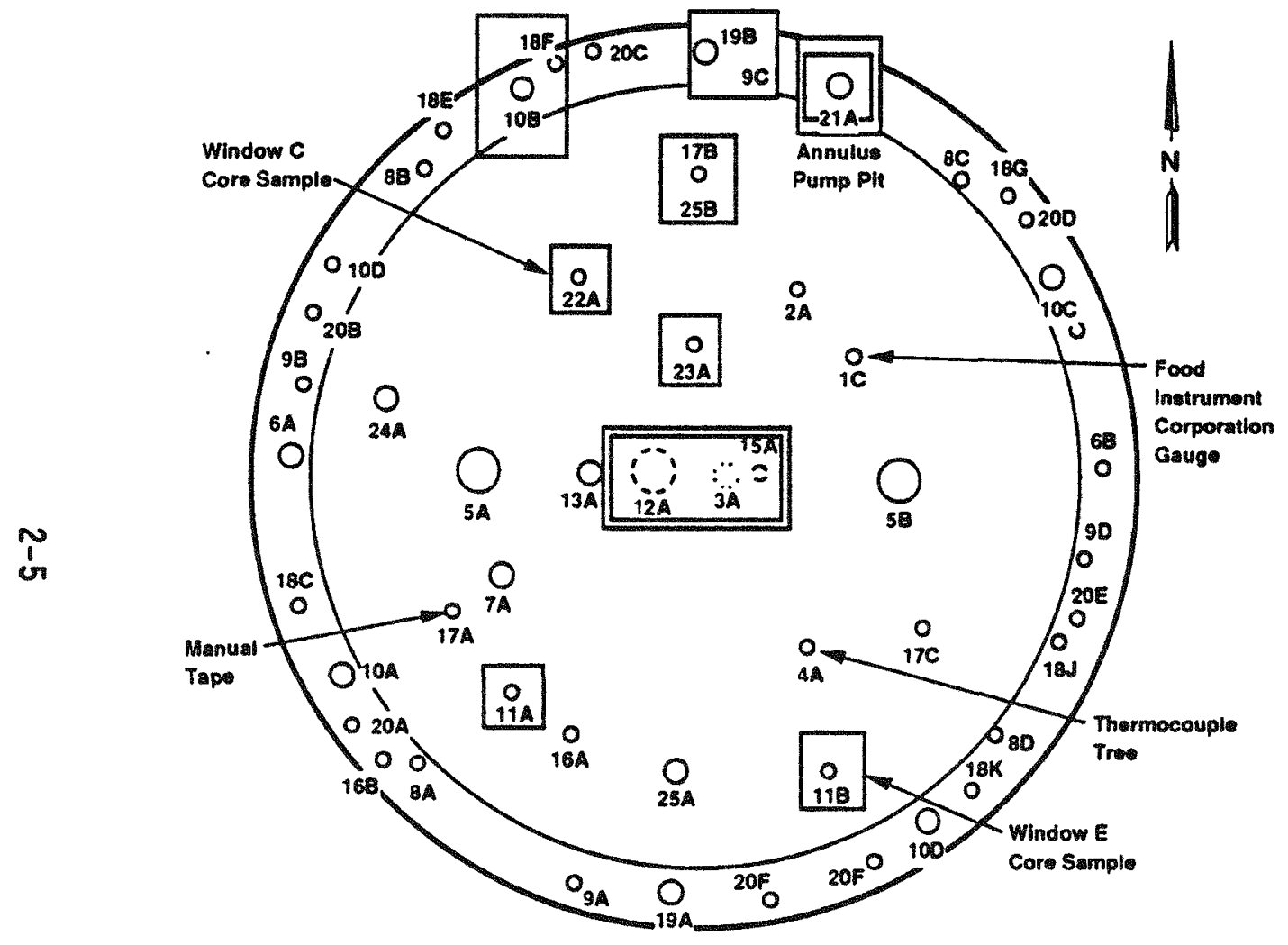

20C Transmitter Box 101-6

$18 F$ Annulus Inspection

178 Multifunction Instrumen Tree

108 Annulus Inspoction

$18 E$ Annulus inspection

22A Hydrogen Monltor

88 Annulus Alf Inlet

23A Sludge Weight

180 Annulus Prassure Gauge

208 Transmitter Box 101-3

24A Nontunctional

98 Annulus inspection

5A TV Lights

6A Annulus Access

$13 \mathrm{~A}$ Radar Gauge

$12 A$ Supernat Addltion

18C Annulus Inspection

$7 \mathrm{~A}$ Exhaust Pon

17 Manual Tapa

$10 \mathrm{~A}$ Annulus Exhaust Port

204 Transmitter $80 \times 101$.

168 Annulus Inspection

$11 \mathrm{~A}$ Spare

8A Annulus Air Inlet 16A Standard Hydrogen
Monitoring Systom

25A Nonfunctional

9 A Annulus inspection
198 Annulus inspection

9 Annulus Inspection Annulus Pump PII

$21 \mathrm{~A}$ Annulus Pump

25B Nonfunetional

$8 C$ Annulus Alr Iniet

2A Port Exhaust Drain

180 Annulus Inspection

200 Transmitter Box 101-1

$10 \mathrm{C}$ Annulus Air Inlet

$1 C$ FIC

184 Annulus Inspection

3 A Supernate Pump

15A Dropleg Nozzlo

5B TV Camera

78 Inlat Filter

68 Annulus Access

90 Annulus inspection

20E Transminter Box 101.2

18. Annulus inspoction

4 A Thermocouple

8D Annulus Air Inist

18K Annulus inspection

10D Annulus Inspectlon

118 Tank Pressure Port

186 Annulus inspection

20F Transmitter Box 101.3

19A Annulus Leak Detoctor 
To Building To Control Instrument Panel Poom

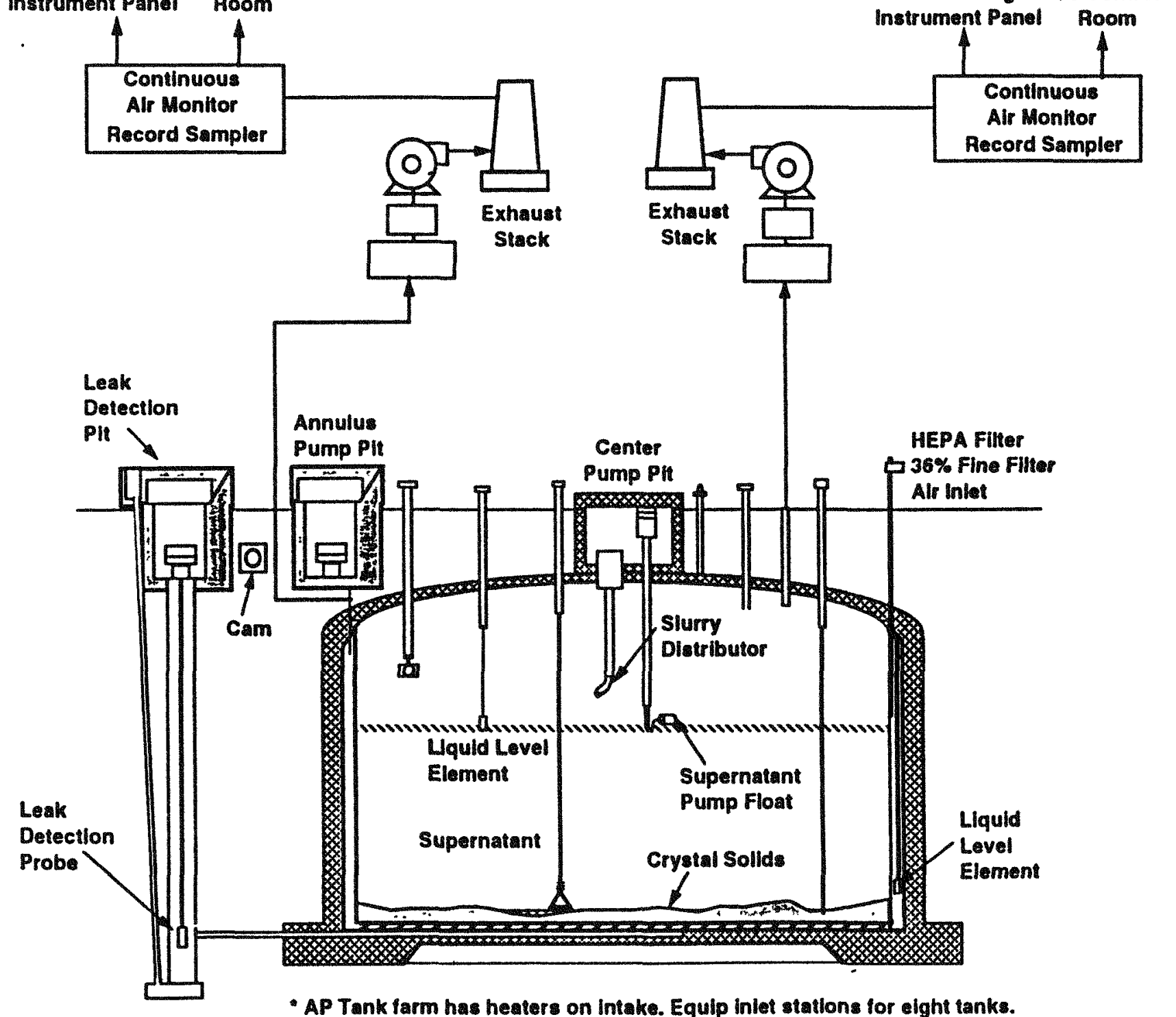

- AP has two leak detection welle On well tor two tanks. 


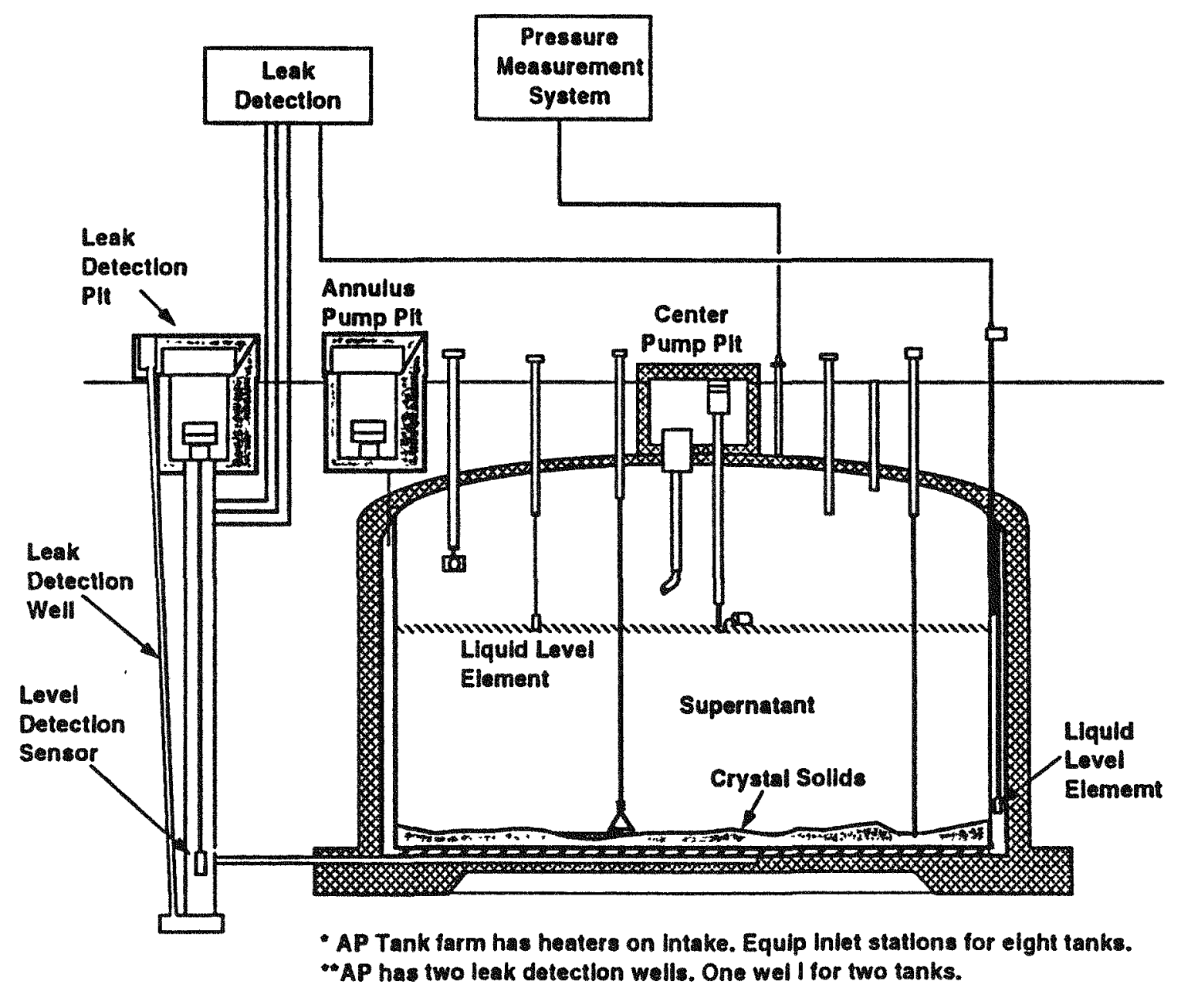

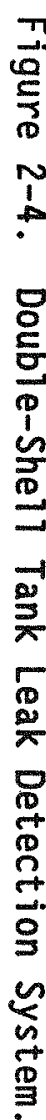


Each tank is equipped with an automatic liquid-level gauge (LIT/FIC) and backup manual tape (LIT). The gauge is located on a primary riser and consists of a plummet suspended on a tape, a tape reel, a sight glass, a control box, an air purge, and the water-flush sprays. In automatic operation, the plummet position is adjusted periodically to provide electrical continuity between the plummet and the liquid surface. The tape reading is converted automatically to an electrical signal for remote readout. The manual tape consists of a metal tape with a steel plummet that extends into the tank and a reel at the riser top. The liquid level is detected by electrical conductivity when the plummet contacts the surface. A radar surface level gauge, described later, has been added to tank 241-SY-101.

Sludge level detectors are installed to monitor the level of the solids in the tanks. The device consists of a weight suspended by a predetermined length of cable from a capped riser. Readings are taken manually by attaching a calibrated tape to the sludge weight cable, lowering the weight to the solids surface and reading the calibrated tape.

Each tank is equipped with approximately 100 thermocouples for monitoring temperatures throughout the concrete portion of the tank structure. A single probe containing 18 thermocouples is used to monitor waste temperatures at various levels in the primary tank. The thermocouples read out to the tank farm instrument building and the Computer Automated Surveillance System (CASS) monitoring room.

In addition to the leak detection provided by radiation monitors and conductivity probes, liquid level boxes are installed in the annulus.

Conductivity probes consist of a vertical tree of conductivity elements. Conductivity probes also are installed in the process pits and encasements. These areas normally are dry. The presence of liquid would activate the probe to indicate a leak and sound an alarm in the instrument building.

Leak detection wells collect leakage from the annulus. The liquid level in each leak detection well is monitored using specific gravity and weightfactor detectors and associated instruments. A radiation detection element is installed adjacent to each leak detection well to monitor radiation levels in the wells. A thermocouple is installed near the bottom of each well to monitor the temperature of the liquid in the well.

\subsection{OPERATION OF TANK 241-SY-101}

Construction on tank 241-SY-101 was completed in 1976. The first waste put into the tank was from the first double-shell slurry (DSS) campaign using the 242-S Evaporator in 1977. Double-shel1 slurry is the most concentrated material that the evaporators can produce. The degree of evaporation is limited only by the pumpability of the slurry. One hundred inches of this material was pumped into tank 241-SY-101.

From 1977 to 1980, the tank received complexed concentrate waste, which was placed in the tank at three different times. A total of $203 \mathrm{in}$. of complexed concentrate waste was placed on top of the heavier DSS. Complexed 
concentrate is a waste from the cesium/strontium recovery process in $B$ Plant. It is rich in complexants such as ethylenediaminetetraacetic acid (EDTA), $\mathrm{N}$-hydroxyethylethylenediaminetriacetic acid (HEDTA), citric acid, and hydroxyacetic acid ( $\mathrm{HOACOH}$ ).

The last material put into tank 241-SY-101 was from another campaign of DSS in the fall of 1980 . Water totaling 8,000 gal was added to the tank between September 1984 and May 1988 during water-lancing operations.

The volume of waste in tank 241-SY-101 was first noted to increase in 1977 after the first DSS was put into the tank. This phenomenon was termed slurry growth. After the last DSS campaign, the waste continued to grow and then dropped several inches, releasing gas. This cyclic growth and subsequent drop has continued.

Early laboratory studies simulated the growth behavior using synthetic waste containing the complexants EDTA and HEDTA ${ }^{\prime}$ as sources of organic carbon, and subsequently found the growth of waste volume in complexant-laden Hanford Site waste slurry to be due to gas generation caused by the oxidative degradation of the complexant HEDTA. The complexant EDTA was found to be stable in this slurry. The degradation proceeds according to first order kinetics in both $\mathrm{NaAlO}_{2}$ and HEDTA concentration and requires nitrate and/or nitrite to proceed. The reaction products include several gaseous species, principally $\mathrm{N}_{2}, \mathrm{~N}_{2} \mathrm{O}$, and $\mathrm{H}_{2}$.

Figures 2-5 and 2-6 show the cycling of the surface level of the tank during the operating history. Water and air lancing were used for a number of years in an attempt to control the gas releases in the tank. Lancing was stopped in 1989 when the surface level reached 423 in. This was greater than the 422-in. operating specification, which is used to prevent overfilling the tank.

External sampling of gases from tank 241-SY-101 was initiated in early 1990. In addition to hydrogen, analyses of the vapor samples since 1990 indicated the presence of nitrous oxide and nitrogen and small quantities of ammonia and other gases.

'EDTA: ethylenediaminetetraacetic acid, tetrasodium salt. HEDTA: $\mathrm{N}$ (2-hydroxyethyl) ethylenediaminetriacetic acid, tri-sodium salt. 

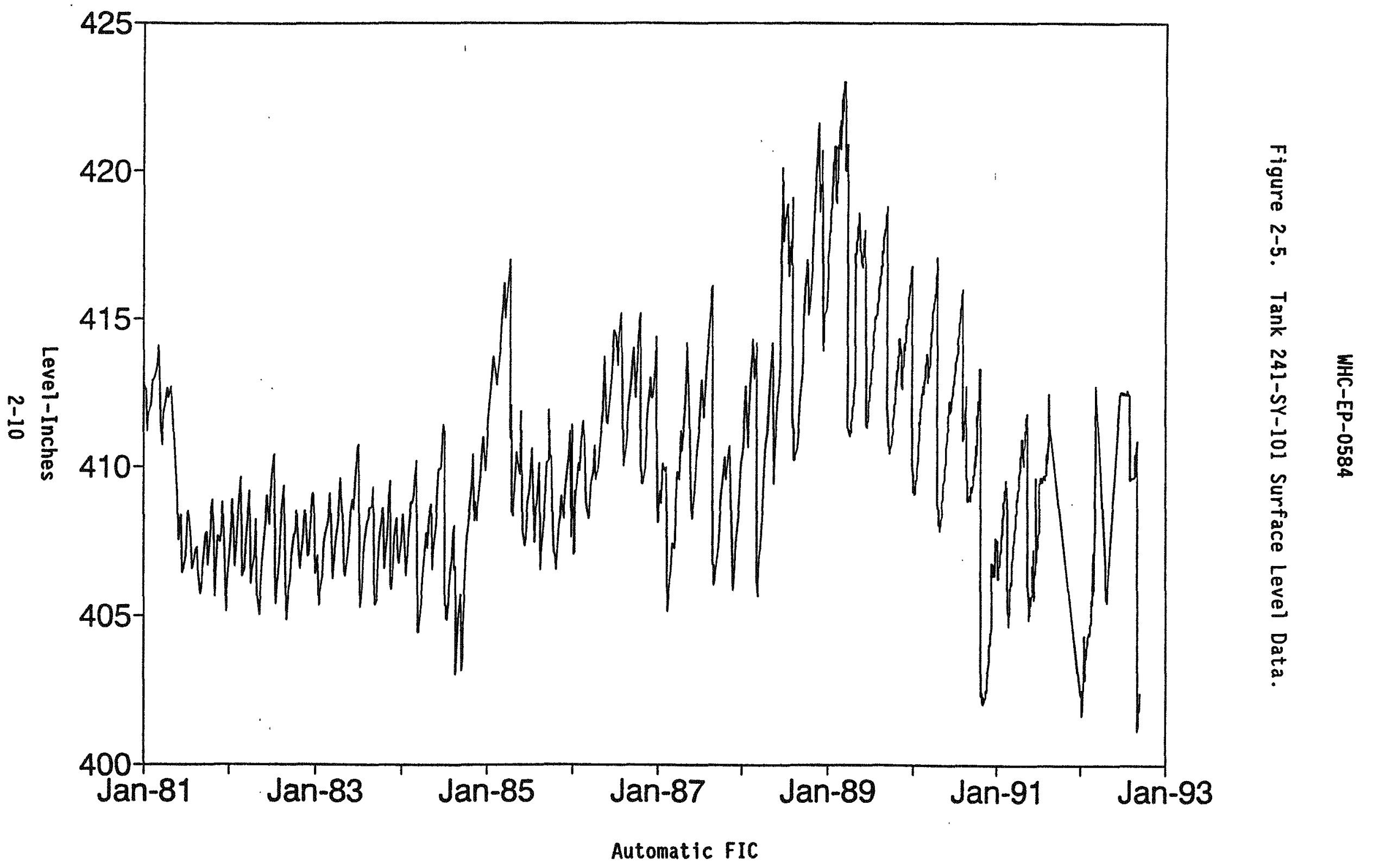


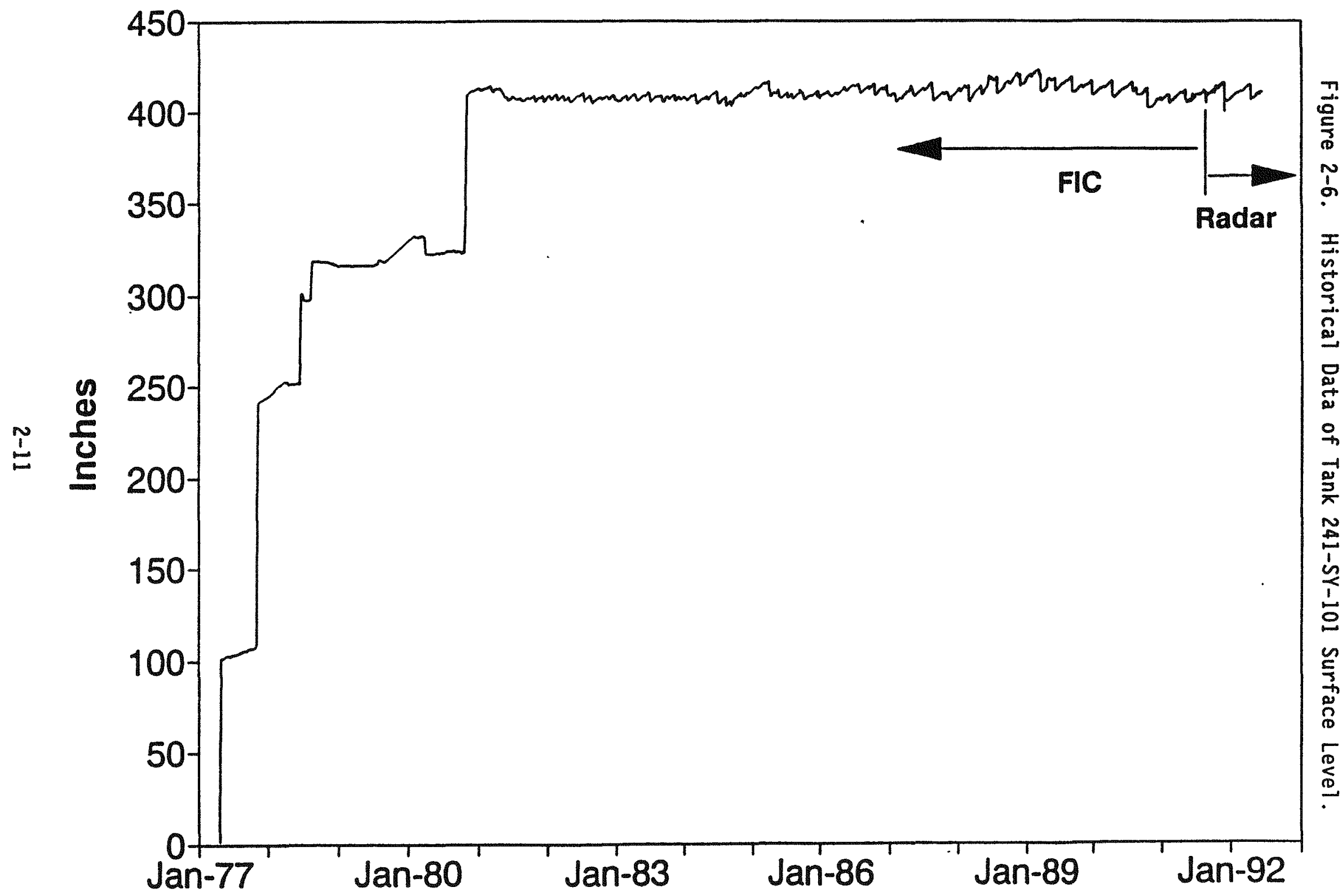

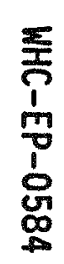


WHC-EP-0584

This page intentionally left blank. 


\subsection{MONITORED DATA PARAMETERS AND METHODS}

Several types of data are currently being monitored in tank 101-SY. Some parameters are measured by more than one method. The monitored data are the following:

- Surface-1evel measurements

- Temperature measurements

- Evolved gas composition

- Tank pressure

- Ventilation flow rate

- Relative humidity

- Acoustic noise

- Video images.

\subsection{SURFACE-LEVEL MEASUREMENTS}

The original purpose of measuring the surface level in the tank was to monitor for waste tank leakage and to verify when the tank was filled to the upper 1 imit. Leakage would be indicated by a drop in surface level. In tank 101-SY, increased surface level indicated a growth of the slurry caused by entrapment of generated gases.

There are three devices that measure surface level in the tank--two conductivity probes and a radar gauge. The automatic conductivity probe (manufactured by Food Instrument Corporation and known as the FIC) is located at riser 1C. The manual conductivity probe (manual tape) is located at riser $17 \mathrm{~A}$. The radar gauge, installed during window $\mathrm{C}$, is located at riser $13 A$.

Both the FIC and the manual tape work on the same principle, described here in a simplified manner. One electrical contact point is made at the probe, the other at the tank wall. The circuit is closed when the probe contacts the conductive surface of the waste. The surface level is determined by the amount of cable used to lower the probe to the level where the electrical contact is made.

The FIC (LE-101-1) automatically raises to break contact with the waste surface, then lowers to a holding position in contact with the waste. This raising and lowering of the probe occurs at a preset interval as defined by the CASS analysts. For normal operation, the cycle is repeated every 1.5 min; for enhanced operation, the cycle repeats every minute. The CASS is capable of polling the FIC for its measurement either at the preset interval or on request. The FIC itself does not transmit its reading until polled. The FIC can also be operated in a manual mode in the field.

The manual tape (LLE-FB-101) is lowered manually into the tank until contact is made with the surface of the waste crust. The reading is recorded on operations $10 \mathrm{~g}$ sheets. The minimum frequency for taking manual tape 
readings is set by the Waste Storage Tank and Leak Detection Criteria document (WHC-SD-WM-TI-357). Both the FIC and manual tape measurements are required daily. Generally, if the FIC is out-of-service, the frequency of manual tape readings is increased.

Several nonintrusive (noncontact) methods to determine the surface level have been considered as supplements to or replacements for the FIC and manual tape. An Enraf Nonius Model 872 Radar Gauge, manufactured in the Netherlands, was installed on the tank during window $C$. It is intrinsically safe and appears to be accurate ( $\pm 2 \mathrm{~mm}[ \pm 0.08 \mathrm{in.}])$. It averages the level over an area of the crust surface.

Readings from the radar gauge are shown on a digital LED display, located in the 241-SY-271 (271-SY) instrument building. The radar gauge is still in a test mode and readings are manually recorded on test data sheets by operators.

\subsection{TEMPERATURE MEASUREMENTS}

The temperature of the waste is obtained from a single thermocouple (T/C) tree located at riser 4A. Eighteen type $J$ thermocouples are bonded to a pipe that is located in a 4-in.-diameter riser. Thermocouple 1 is the lowest thermocouple in the tank, with higher numbered thermocouples higher in the tank. Thermocouple 17 is near the surface of the waste and thermocouple 18 is in the tank dome space above the waste. Table 3-1 provides the height of the thermocouples in the tank. Photographs taken in the tank show that the thermocouple tree is slightly bent, so the heights given are not necessarily precise.

From the thermocouple tree in the tank, thermocouple wire is run through two junction boxes to an 18-position selector switch (SS-101-1) located in the 271-SY instrument building. The thermocouples are read manualiy using a hand held digital thermocouple reading device. These readings are recorded onto log sheets, either daily, once a shift, or hourly, as directed by Process Memo. They have traditionally provided a record of the daily temperatures at the various heights in the tank. A parallel connection has been made from the thermocouple wires to a Wavetek data logger, al so located in the 271-SY instrument building. Information about the Wavetek data logger can be found in WHC-SD-WM-PLN-018, Rev. O (Leche1t 1991).

In addition to the thermocouples in the tank space, a thermocouple and temperature transmitter are located in the ventilation header space. The ventilation temperature data are logged to a Hewlett-Packard data logger located in the Gas Monitoring System (GMS) shelter. WHC-SD-WM-PLN-018 contains information about the Hewlett-Packard data logger.

\subsection{GAS COMPOSITION}

Gas composition is determined by a number of methods. Some are used on a continual basis and some are used only when an event is thought to be imminent until sometime after the event. The devices and systems used are discussed 


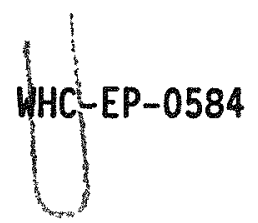

Table 3-1. Tank 241-SY-101 Thermocouple Numbers and Locations.

\begin{tabular}{|c|c|c|}
\hline $\begin{array}{c}\text { Thermocouple } \\
\text { number }\end{array}$ & $\begin{array}{l}\text { Instrument } \\
\text { number }\end{array}$ & $\begin{array}{c}\text { Nominal height from } \\
\text { tank bottom }\end{array}$ \\
\hline$T / C 1$ & TE-101-37 & 4 in. \\
\hline$T / C 2$ & TE-101-38 & 28 in. \\
\hline$T / C 3$ & TE-101-39 & 52 in. \\
\hline$T / C_{4}$ & $T E-101-40$ & 76 in. \\
\hline$T / C 5$ & $T E-101-41$ & $100 \mathrm{in.}$ \\
\hline$T / C 6$ & TE-101-42 & 124 in. \\
\hline $\mathrm{T} / \mathrm{C} 7$ & TE-101-43 & 148 in. \\
\hline$T / C 8$ & TE-101-44 & 172 in. \\
\hline $\mathrm{T} / \mathrm{C} 9$ & TE-101-45 & 196 in. \\
\hline $\mathrm{T} / \mathrm{C} 10$ & TE-101-46 & 220 in. \\
\hline$T / C \quad 11$ & TE-101-47 & 244 in. \\
\hline $\mathrm{T} / \mathrm{C} 12$ & TE-101-48 & 268 in. \\
\hline$T / C 13$ & TE-101-49 & 292 in. \\
\hline$T / C 14$ & TE-101-50 & 316 in. \\
\hline $\mathrm{T} / \mathrm{C} \quad 15$ & TE-101-51 & 340 in. \\
\hline $\mathrm{T} / \mathrm{C} \quad 16$ & $T E-101-52$ & $364 \mathrm{in.}$ \\
\hline $\mathrm{T} / \mathrm{C} \quad 17$ & $T E-101-53$ & $412 \mathrm{in}$. \\
\hline $\mathrm{T} / \mathrm{C} \quad 18$ & TE-101-54 & $460 \mathrm{in.}$ \\
\hline
\end{tabular}

briefly below. Table 3-2 is added for reference. Under the heading "Status," Online indicates the system is online at all times; Event Only indicates the system is placed into service to monitor for the event.

The Teledyne hydrogen monitor is located at the ventilation header and monitors for combustible gas in the ventilation system. The monitor determines hydrogen based on thermal conductivity. The monitor provides continuous output to a strip chart recorder and the Wavetek data logger.

Grab samples are taken at intervals determined by a Process Memo prepared before each event. They are analyzed in the 300 Area laboratory (mass spectrometer) and provide information about the gas composition. The samples are taken from a port in the ventilation line. The ventilation line port also feeds two gas chromatographs (one for hydrogen only, the second for other gases), the cryogenic sampler and an ammonia system. These instruments are installed on the tank farm when an event is nearing. 
WHC-EP-0584

Table 3-2. Tank 241-SY-101 Gas Monitoring and Analysis.

\begin{tabular}{|c|c|c|c|c|}
\hline Instrument & Location & $\begin{array}{c}\text { Cycle Time [Evont Cycle Time Shown } \\
\text { in Brackets] }\end{array}$ & Gas Components Analyzed & Status \\
\hline $\begin{array}{l}\text { Gas Monitoring System } \\
\text { Mase Spec }\end{array}$ & $\begin{array}{l}\text { Riser 17B, Near } \\
\text { Crust Probe }\end{array}$ & 5 minutes & $\begin{array}{l}\mathrm{N}_{2}, \mathrm{O}_{2}, \mathrm{H}_{2} \mathrm{O}, \mathrm{CO}_{2} \mathrm{~N}_{2} \mathrm{O} \text {. } \\
\text { Ar, } \mathrm{H}_{2}, \text { Other Gases }\end{array}$ & On-line \\
\hline $\begin{array}{l}\text { Gas Monitoring Systam } \\
\text { Hydrogen Monitor }\end{array}$ & $\begin{array}{l}\text { Aiser 17B, Near } \\
\text { Cruet Probe }\end{array}$ & $\begin{array}{l}5 \text { minutes, Normal Rate } \\
10 \text { seconds, Fast Rate; [Fast rate } \\
\text { start on increased preseure and/or } \\
\text { hydrogen] }\end{array}$ & $\mathrm{H}_{2}(\mathrm{Vol} \%)$ & On-line \\
\hline $\begin{array}{l}\text { Gas Monitoring System } \\
\text { Hydrogen Monitor }\end{array}$ & $\begin{array}{l}\text { Pieer 22A, Upper } \\
\text { Dome Space Probe }\end{array}$ & $\begin{array}{l}5 \text { minutes. Normal Rate } \\
10 \text { seconds, Fast Rate; [Fast rate } \\
\text { starts on increased preseure and/or } \\
\text { hydrogen] }\end{array}$ & $\mathrm{H}_{2}(\mathrm{Vol} \%)$ & On-line \\
\hline $\begin{array}{l}\text { Standard Hydrogen } \\
\text { Monitoring Syatem }\end{array}$ & $\begin{array}{l}\text { Riser 16A, Near } \\
\text { Crust Probe }\end{array}$ & Continuous; Strip Chart & $\mathrm{H}_{2}(\mathrm{Vol} \%)$ & On-line \\
\hline $\begin{array}{l}\text { Standard Hydrogen } \\
\text { Monitoring System }\end{array}$ & $\begin{array}{l}\text { Riser 16A, Near } \\
\text { Probe }\end{array}$ & Continuous: Strip Chart & $\mathrm{H}_{2}(\mathrm{ppm})$ & On-line \\
\hline $\begin{array}{l}\text { Teledyne Hydrogen } \\
\text { Monitor }\end{array}$ & Vent Header ${ }^{1}$ & $\begin{array}{l}15 \text { seconds, } 1 \text { minute, or } 10 \text { minutes; } \\
\text { [Set to } 15 \text { oconds in anticipation of } \\
\text { the event] }\end{array}$ & $\mathrm{H}_{2}$ & On-line \\
\hline $\begin{array}{l}\text { Grab Samples (Otf-line } \\
\text { Gas Analysia) }\end{array}$ & Vent Header ${ }^{1}$ & [Sample rate set by Process Momo.] & $\begin{array}{l}\mathrm{N}_{2}, \mathrm{O}_{2}, \mathrm{CO}_{2}, \mathrm{~N}_{2} \mathrm{O}, \mathrm{Ar}, \mathrm{H}_{2}, \\
\mathrm{He}, \mathrm{CO}, \mathrm{CH}_{4}, \mathrm{NO}_{x}\end{array}$ & $\begin{array}{l}\text { Event and } \\
\text { Baseline }\end{array}$ \\
\hline $\begin{array}{l}\text { Gas Chromatographs } \\
\text { (2) }\end{array}$ & Vent Header' & $\begin{array}{l}14 \text { minute and } 16 \text { minute cycle times; } \\
\text { installed in preparation for an event.] }\end{array}$ & $\begin{array}{l}\text { 1. } \mathrm{H}_{2} \text { epecific } \\
\text { 1. Other gases } \mathrm{N}_{2}, \mathrm{O}_{2}, \\
\mathrm{CO}_{2}, \mathrm{~N}_{2} \mathrm{O}, \mathrm{Ar}, \mathrm{H}_{2}, \mathrm{He}, \mathrm{CO}, \\
\left.\mathrm{CH}_{4}, \mathrm{NO}_{x}\right)\end{array}$ & $\begin{array}{l}\text { Event } \\
\text { Only }\end{array}$ \\
\hline Organic Vapor Monitor & Stack, Tank Farm & $\begin{array}{l}\text { [Inatall approx. I weak before ovent: } \\
\text { cycle time to to } 1 \text { minute] }\end{array}$ & $\mathrm{NH}_{3}$, Organics & $\begin{array}{l}\text { Event } \\
\text { Only }\end{array}$ \\
\hline
\end{tabular}

${ }^{1}$ The vent hoader gas sample port location is just upstream of the psychrometric port.

The organic vapor monitor (OVM) is installed at the SY Tank Farm stack by the Personal Protective Equipment (PPE) approximately 1 week before the anticipated event. It is a nonspecific monitor, but indicates ammonia. The readings appear to correlate well with Drager tube sampling, which are used at the stack to indicate ammonia.

A GMS was installed as a temporary system in April 1991. The gas is taken from vapor space sampling tubes located at three levels below riser 17B. The system instrumentation is housed in an instrument shelter on the SY Tank Farm near the riser. The GMS comprises three main subsystems:

(1) a molecular mass spectrometer (MMS) which analyzes the gas for its components with atomic mass units (AMS) between 2 and $50,(2)$ a hydrogen (in vol\%) monitoring unit, and (3) a differential pressure transmitter. The differential pressure transmitter is discussed in Section 3.4.

The sample tubing runs from the riser location to the instrument shelter. A gas sample is drawn into the tubing and analyzed by the MMS and the hydrogen monitor. The MMS communicates with a personal computer located in the shelter. Data are then transmitted as an ASCII file over an RS-232 line to the Hewlett-Packard (GMS) data logger. The hydrogen monitor provides a 4 to 20 milliamp (mA) current loop signal, which corresponds to 0 to 50 percent. 
The data are transmitted to the Hewlett-Packard data logger. The data logger is discussed in WHC-SD-WM-PLN-018 (Leche1t 1991).

Three additional hydrogen monitors were added to the tank within the past year. A second electrochemical cell (Whittaker) was added to sample from the gas probes in Riser 22A. Currently it is set to draw gas from the uppermost probe. The data from this device are recorded by the Hewlett-Packard data logger, which is part of the GMS.

The Standard Hydrogen Monitoring System (SHMS) is composed of an electrochemical cell (Whittaker) hydrogen monitor and a metal oxide semiconductor (MOS) hydrogen monitor. One is in place at Riser 16A and draws from the lowest gas probe. The data are recorded on a strip chart.

\subsection{TANK PRESSURE}

Two different pressure sensors are used on the tank. Pressure transmitter PT-101-1 monitors pressure at riser 11B. A pressure to current converter converts 3 to $15 \mathrm{lb} / \mathrm{in} .^{2}$ to 4 to $20 \mathrm{~mA}$ current signal, corresponding to -4 to 6 in. water gauge $(w . g$.$) . This current signal provides input to a$ Chessel strip chart recorder located in the 271-SY instrument building.

Digital readout is available and is recorded on $10 \mathrm{~g}$ sheets, if required. The 4- to 20-mA signal to the Chessel recorder is dropped across a 150-ohm resistor in series with a 100-ohm resistor, providing a 0.6 to 3 VDC output to the Wavetek data logger.

The other differential pressure transmitter is located at riser 17B. The output signal is 4 to $20 \mathrm{~mA}$, corresponding to -5 to $+20 \mathrm{in}$. W.g. The current loop signal is dropped across a 250-ohm resistor, yielding a 1 to 5 VDC input to the Hewlett-Packard data logger. Information about both data loggers is found in WHC-SD-WM-PLN-018.

\subsection{VENTILATION FLOW RATE}

The flow rate in the ventilation header is measured by a Voluprobe flow rate meter. The device transmits a 4- to 20-mA current loop signal to the Chessel strip chart recorder. The signal corresponds to 0 to 1200 cubic feet per minute ( $\mathrm{ft}^{3} / \mathrm{min}$ ) of flow. This signal is dropped across a 150-ohm resistor in series with a $100-0 \mathrm{hm}$ resistor to provide an output signal to the Wavetek data logger of 0.6 to 3 VDC.

A second, high-range flow transmitter is connected to a strip chart recorder. Its main purpose is to be able to monitor the flow during a gas venting, when the flow rate may approach or exceed $1200 \mathrm{ft}^{3} / \mathrm{min}$.

\subsection{RELATIVE HUMIDITY}

A single relative humidity probe is installed in the ventilation header of tank 101-SY. The 4- to 20-mA output signal corresponds to 0 to 100 percent relative humidity. The current loop signal is dropped across a 250-ohm resistor, yielding a 1- to 5-volt input to the Hewlett-Packard data logger. 
WHC-EP-0584

\subsection{ACOUSTIC NOISE}

Acoustic noise is no longer being monitored on tank 101-SY. Before event B in February 1991, an acoustic monitoring system was installed on the tank in a test mode. Microphones were positioned at three heights in the tank annular space. The output signals were recorded on a strip chart and by a videotape recorder used in an audio only mode. These devices were located in a small building, commonly known as the "acoustic monitoring shack, "outside the fence at SY Tank Farm. The shack, which has no climate control, also houses the Hewlett-Packard data logger.

After testing the system for several months, including during both events $B$ and $C$, it appears that the system will not accurately predict an impending gas venting or provide useful data on the actual event. The system was powered down and removed from the acoustic monitoring shack several days after event $C$. Future monitoring of this type is not currently planned.

\subsection{VIDEO IMAGES}

A color TV camera and lights were installed at riser 5A on May 19, 1991, following event $C$. The camera failed within the first few weeks after installation from radiation damage. It was removed from riser $5 \mathrm{~A}$, but the lights were left in place. Before the end of window $C$, a radiation-hardened black-and-white camera and lights were installed in riser 5B. The second set of lights has enhanced the ability of the camera to provide clear images of the tank interior.

Equipment associated with the camera is located in a small climate controlled traijer outside the fence of the SY Tank Farm. The trailer houses the pan and tilt camera controls, a video record/playback unit and a unit which prints still pictures from the video tape. The videotapes are the $1 / 2-i n$. VHS format. A nitrogen purge system ensures that an accidental spark from the camera does not ignite any flammable gas inside the tank.

The camera can be run at normal speed, or can be set at varying intervals to perform time-lapse photography. Videotapes are removed from the video trailer and copies are made and distributed as required. Copies of the tapes are made by Audio Visual Services. Copies can be checked out of the Tank Farm Information Center (TFIC).

The camera has been used in tank 101-SY to record GREs. More recent1y, the camera has been used to record event $G$ and is currentiy used to monitor and record in-tank activities during window $G$. The camera will remain in the tank to monitor mitigation activities.

\subsection{COMPUTER SYSTEMS USED IN DATA ACQUISITION}

Tank 101-SY has four main computer systems associated with data acquisition. Two are used for all tank farms, while the other two are specific for tank 101-SY. A description of the data acquisition system, archiving, and data analysis and reporting is given in WHC-SD-WM-PLN-018, Rev. 0 (Lechelt 1991). 


\subsection{DATA REQUIREMENTS FROM TANK MEASUREMENTS}

The data obtained from the various monitoring systems are required for several reasons. More data are needed to better understand the tank behavior (i.e., before, during, and after an event.) Understanding the tank contents and behavior will be useful in predicting future events and in planning for remediation. While much is still unknown about the causes of the tank behavior, review and analysis of available data will allow work to be performed on the tank during the safety window following an event.

For the purpose of this document, data for tank 101-SY are divided into four categories, defined by the need for the data. Table 3-3 provides a listing of each type of data currently available. The table indicates the categories to which each type of data belong. Some monitoring systems provide data that can be described as experimental (i.e., what the data will show and whether it will be helpful are unknown). These data types are placed in the category most likely to apply. The categories correspond to the column headings in the table.

- Data needed to meet OSRs, Operation Specification Documents (OSD). or other requirements or procedures. This includes data taken for trending and historical purposes.

- Data needed to predict future events. This includes historical data on past events and the data taken since the most recent event.

- Data needed to understand or report the gas release event (GRE). This includes the data needed to determine physical and chemical changes in the contents of the waste or gases. Also included are the data used to declare a window open following an event.

- Data needed to determine whether the tank parameters are inside the safety window. Data in this category are monitored after the event (during the window) to ensure that tank parameters remain within the criteria established to allow work to proceed on the tank. 
Table 3-3. Data Parameter Requirements.

\begin{tabular}{|c|c|c|c|c|}
\hline $\begin{array}{l}\text { Data Category: } \\
\text { Parameter: }\end{array}$ & $\begin{array}{l}\text { Meet OSR/OSD or } \\
\text { other requirements } \\
\text { or procedures }\end{array}$ & $\begin{array}{l}\text { Predict } \\
\text { future } \\
\text { events }\end{array}$ & $\begin{array}{l}\text { Understand/ } \\
\text { report } \\
\text { events }\end{array}$ & $\begin{array}{l}\text { Parameters } \\
\text { inside } \\
\text { window }\end{array}$ \\
\hline Temperature $18 \mathrm{~T} / \mathrm{C}$ Tree Data Sheets & Yes & No & No & No \\
\hline Temperature $18 \mathrm{~T} / \mathrm{C}$ Tree Wavetek Data Logger & No & Yes & Yes & Yes \\
\hline $\begin{array}{l}\text { Temperature } 1 \mathrm{~T} / \mathrm{C} \text { in Ventilation Header HP } \\
\text { Data Logger }\end{array}$ & No & No & Yes & No \\
\hline Surface Level FIC CASS Computer & Yes & Yes & Yes & Yes \\
\hline Surface Level FIC Data Sheets & Yes & No & No & No \\
\hline Surface Level Manual Tape Data Sheets & Yes & No & Yes & No \\
\hline Surface Level Radar Gauge Data Sheets & No & TBD & Yes & TBD \\
\hline $\begin{array}{l}\text { Gas Composition Gas Chromatograph }-\mathrm{H}_{2} \\
\text { Laboratory }\end{array}$ & No & No & Yes & No \\
\hline $\begin{array}{l}\text { Gas Composition Gas Chromatograph - Other } \\
\text { Laboratory }\end{array}$ & No & No & Yes & No \\
\hline Gas Composition Mass Spectrometer Laboratory & No & No & Yes & No \\
\hline Gas Composition Cryogenic Laboratory & No & No & Yes & No \\
\hline $\begin{array}{l}\text { Gas Composition GMS - Hydrogen Monitor Data } \\
\text { Logger }\end{array}$ & No & No & Yes & No \\
\hline $\begin{array}{l}\text { Gas Composition GMS - Mass Spectrometer Data } \\
\text { Logger }\end{array}$ & No & No & Yes & No \\
\hline $\begin{array}{l}\text { Gas Composition Organic Vapor Monitor Data } \\
\text { Logger }\end{array}$ & No & No & Yes & No \\
\hline Gas Composition Drager Tubes Laboratory & No & No & Yes & No \\
\hline Gas Composition Amnonia Bubbler Laboratory & No & No & Yes & No \\
\hline $\begin{array}{l}\text { Gas Composition Teledyne Hydrogen Monitor } \\
\text { Data Sheets }\end{array}$ & Yes & No & No & No \\
\hline $\begin{array}{l}\text { Gas Composition Teledyne Hydrogen Monitor } \\
\text { Data Logger }\end{array}$ & No & No & Yes & No \\
\hline Pressure Pressure Gauge Strip Chart & Yes & No & Yes & No \\
\hline Pressure Pressure Gauge Data Logger & No & No & Yes & No \\
\hline Pressure Pressure Gauge Data Sheets & Yes & No & No & No \\
\hline Pressure GMS - Pressure Gauge Data Logger & No & No & Yes & No \\
\hline Flow, Low Range Flow Meter Strip Chart & Yes & No & Yes & No \\
\hline Flow, Low Range Flow Meter Data Sheets & Yes & No & No & No \\
\hline Flow, Low Range Flow Meter Data Logger & No & No & Yes & No \\
\hline Flow, High Range Flow Meter Strip Chart & No & No & Yes & No \\
\hline $\begin{array}{l}\text { Ventilation System Relative Humidity Data } \\
\text { Logger }\end{array}$ & No & Yes & Yes & No \\
\hline $\begin{array}{l}\text { Acoustic Noise Microphones Strip Chart/Audio } \\
\text { Tape }\end{array}$ & No & No & No & No \\
\hline TV Camera Video Tape Installation & No & TBD & $T B D$ & No \\
\hline
\end{tabular}




\subsection{GAS RELEASE EXPERIENCE}

In the spring of 1990, an increased emphasis was placed on the characterization of gas releases from tank 241-SY-101. Since that time, these episodic releases have occurred approximately every 100 days. A summary of the events is provided in Table 4-1. This report will only summarize the data obtained during the events; reference is made to specific reports containing detailed descriptions of the events. Since the data from each event are similar, only data from selected events are illustrated in this report as an example. More complete information on sampling and analysis is provided in Section 6.0.

\subsection{GAS RELEASE EVENT OF APRIL 1990}

On April 19, 1990, tank 241-SY-101 started to release gas, and the majority of the release occurred in a 6- to 8-hr period. This event released sufficient gas to briefly pressurize the tank dome space to t0.1 in. w.g. and caused the hydrogen concentration to peak at about 3.5 vol\% in the exhaust header. The total surface level drop was 8.3 in., but the lowest level did not occur until 11 days after the event. Several instruments were employed to evaluate the concentration of hydrogen during the event. To evaluate the $\mathrm{H}_{2}$ concentration during the event, the April 1990 event used the Teledyne monitor, a gas chromatograph, and a grab sample, which were sent to a laboratory mass spectrometer. Figure 4-1 shows good agreement between the three systems. Data from the mass spectrometer evaluations showed that nitrous oxide was also released during the event. An estimation technique for the gas composition showed that it was 30 to 33 mol\% hydrogen and 20 to $25 \mathrm{~mol} \% \mathrm{~N}_{2} \mathrm{O}$ (Allemann 1991). A detailed evaluation of the April 19, 1990 event is provided in Burke et a1. (1991).

\subsection{GAS RELEASE EVENT OF AUGUST 1990}

Unlike the April 1990 event, the August 1990 event was mild. Both the surface level and pressure response indicated a much slower release of gas. The total surface drop was 5.2 in., and the peak hydrogen concentration in the exhaust header was about 1.2 percent. As with the Apri1 1990 event, the various instruments provided good agreement on the hydrogen release. Grab samples of the gas were sent to the Idaho National Engineering Laboratory (INEL) for analysis with their precision mass spectrometer. The mean composition from these analyses was 40 mol\% hydrogen $(+1.4), 32.9$ mol\% nitrous oxide $(+1.2)$, and 28 mol\% nitrogen $(+2.1)$.

The vertical temperature profiles of the tank appear to be similar both before and after the event. Before the August 1990 event, the temperature profile exhibited a pronounced bulge in the lower portion, a nearly isothermal region in the upper portion, and a steep gradient at the top surface. This was consistent with the suggestion that during a GRE, waste in the lower region moves to the upper region because of excess buoyancy. The temperature profile shows a decrease in temperature in the bulge in the lower part and an 


\begin{tabular}{|c|c|c|c|c|c|c|c|c|}
\hline Event Date & $4 / 19 / 90$ & $8 / 5 / 90$ & $10 / 24 / 90$ & $2 / 13 / 91$ & $5 / 16 / 91$ & $8 / 27 / 91$ & $12 / 4 / 91$ & $4 / 20 / 92$ \\
\hline Days since previous event & 110 & 108 & 80 & $\$ 12$ & 92 & 103 & 99 & 138 \\
\hline \multicolumn{9}{|l|}{ Surface level before event: } \\
\hline FIC & 416.70 & 415.90 & 413.30 & 409.50 & 412.00 & os & os & os \\
\hline Manual tape & 417.00 & os & 412.40 & 407.00 & 419.60 & 411.20 & 426.70 & 409.0 \\
\hline Radar (inst. 5/91) & MA & HA & Ma & MA & MA & 411.87 & 416.30 & 414.60 \\
\hline \multicolumn{9}{|l|}{ Surface level drop (in.): } \\
\hline First hour & MA & 1.3 & HA & NA & MA & MA & WA & 6.6 \\
\hline Total event & 9.3 & 5.1 & 10.2 & 5.0 & 7.2 & 6.0 & 13.0 & 9.1 \\
\hline Temperature T/C 4: Before/after $(10-20 \mathrm{~min})$ & NA & NA & $140 / 127$ & $137 / 130$ & $135.3 / 120.5$ & $133.9 / 131.3$ & $132.9 / 118.3$ & 122.1/122.1 \\
\hline Temperature T/C 16: Before/after $(10-20 \mathrm{~min})$ & MA & $125 / 133$ & $124 / 137$ & $121 / 125$ & $116.5 / 134.8$ & $117 / 121$ & $113.2 / 118.9$ & $108.5 / 129.0$ \\
\hline Maximum tank pressure (in. w.g.) & 0.1 & -2.01 & 2.3 & -2.0 & 0.25 & -2.82 & 6.84 & -2.03 \\
\hline Maximum exhaust flow $\left(\mathrm{ft}^{3} / \mathrm{min}\right)$ & 371 & 417 & 600 & 625 & 9625 & 550 & 1300 & 675 \\
\hline \multicolumn{9}{|l|}{ Estimated gas release (FATHOMS) $\left(\mathrm{ft}^{3} \mathrm{a} / 1\right.$ atm): } \\
\hline Total event & 8930 & 7000 & 9600 & 4800 & 7200 & 5940 & 11700 & MA \\
\hline \multicolumn{9}{|l|}{ Maximum $\mathrm{H}_{2}$ concentration $-\cdots$ dome: } \\
\hline Whittaker, Riser 178 (inst. 4/91) & NA & HA & HA & NA & 2.80 & 0.38 & 5.30 & Ma \\
\hline Continuous mass spec. (inst. 4/91) & NA & NA & MA & HA & 2.57 & 0.28 & os & Ma \\
\hline Grab sample mass spec. & WA & NA & MA & WA & 0.70 & MA & MA & MA \\
\hline Fathoms (230\%) & 4.9 & 1.2 & 5.3 & HA & 2.3 & NA & 6.5 & ma \\
\hline \multicolumn{9}{|l|}{ Maximum $\mathrm{H}_{2}$ concentration -- exhaust: } \\
\hline $\begin{array}{l}\text { Teledyne (data not considered reliable } \\
\text { after } 2 / 91 \text { ) }\end{array}$ & NA & MA & 4.70 & MA & 0.72 & 0.51 & 2.59 & MA \\
\hline Chromatograph & HA & WA & 4.8 & MA & MA & WA & NA & MA \\
\hline Grab sample mass spec. & NA & NA & 4.50 & 0.02 & 0.70 & MA & 2.17 & MA \\
\hline FATHOMS & 4.9 & 1.2 & 5.3 & NA & 2.3 & MA & 6.5 & MA \\
\hline
\end{tabular}

os = out of service

OS $=$ out of service
$M A$ 


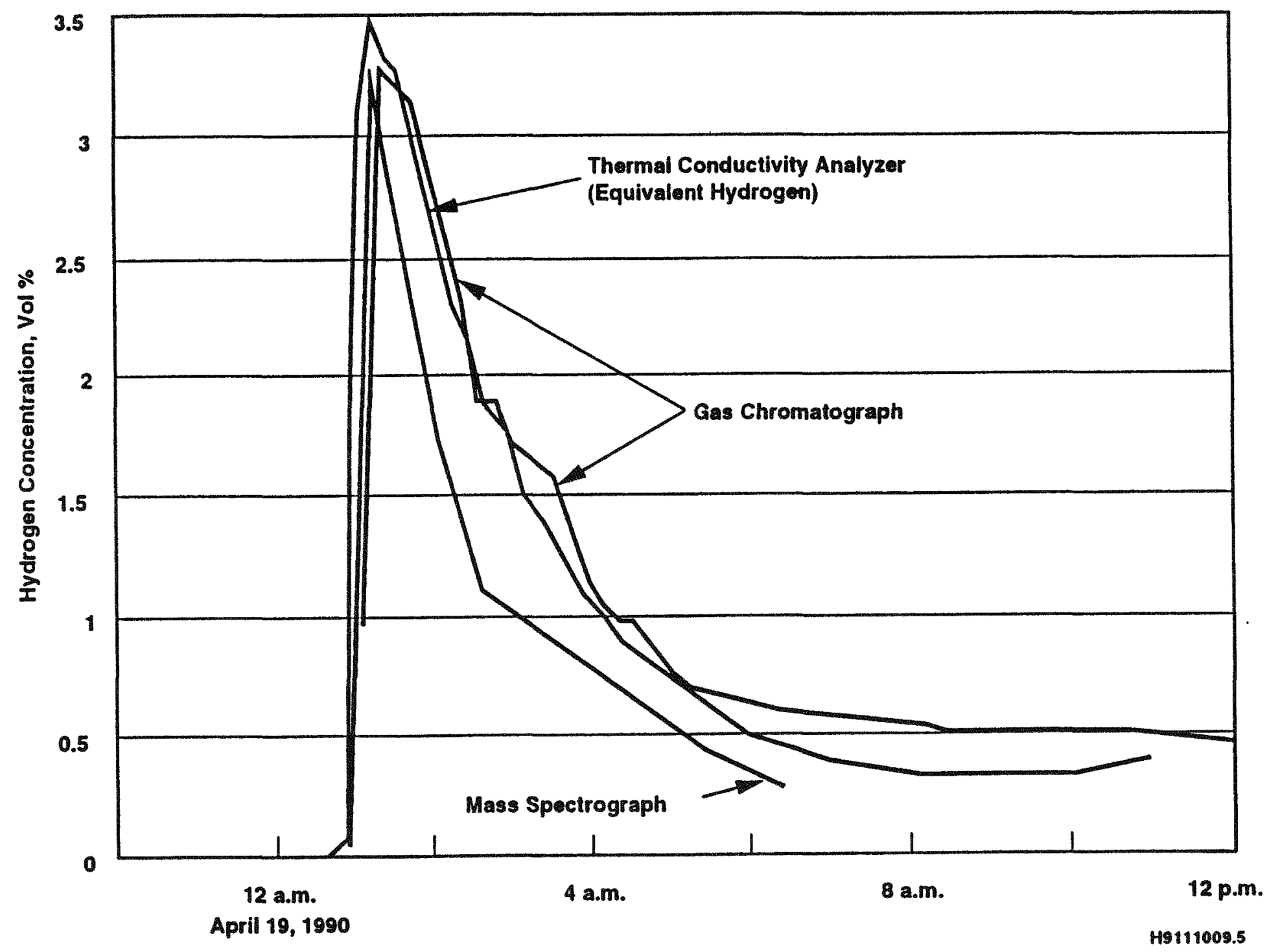


increase in temperature just below the waste surface. After the gas has been released, the temperature profile gradually reverts to the pre-event condition. A detailed evaluation of this event is given by Carothers et a1. (1990).

\subsection{GAS RELEASE EVENT OF OCTOBER 1990}

One of the improvements added to the instrumentation systems before the October 1990 event was the capability to record the temperature at 10-second intervals. Just before a high-pressure alarm signaled a release in the morning of October 24, 1990, the temperature profile underwent a rapid reversal. Temperature records showed that the upward movement of the hotter material started about 10 seconds before the colder material moved downward. The entire tank contents appeared to roll over in less than 90 seconds. This is illustrated in Figures 4-2 through 4-4. Figures 4-2 and 4-3 show the entire profile, while Figure 4-4 shows data for only two thermocouples, one at the bottom (\#4) and one at the top (\#16).

The October 24, 1990 event has been one of the largest events recorded for tank 241-SY-101 in that the event produced a large amount of hydrogen, the second largest increase in pressure, and second largest drop in surface level. Again, good agreement on the amount of hydrogen released was found for the three measurement methods. A comparison of the hydrogen release for the April, August, and October 1990 releases is shown in Figure 4-5.

Barker (1991) provides the detailed analysis of the October 1990 event.

\subsection{GAS RELEASE EVENT OF FEBRUARY 1991}

This event was rather mild, in that there was little increase in either the tank pressure or hydrogen concentration. A total drop of 6 in. was recorded over a period of 9 days. No data were obtained on gas composition. The temperature profile change for this event indicates that only a partial rollover occurred; this was similar to the August 1990 event. A report for this event was prepared and issued in December 1991 (Erhart 1991a).

\subsection{GAS RELEASE EVENT OF MAY 1991}

During this event, the tank surface dropped $7.2 \mathrm{in.}$, which is the fourth largest drop noticed to date. Before this event, the oni ine mass spectrometer and a hydrogen-specific monitor were set up to sample a probe that had been inserted into the tank dome space at riser $17 \mathrm{~B}$.

Figure 4-6 provides a comparison of the hydrogen measurements from the tank dome space and in the exhaust header. Note that the Whittaker ${ }^{2}$ unit was used for the dome space and the Teledyne unit sampler for exhaust header. For each location, there is good agreement between the hydrogen-specific monitor and the results from a mass spectrometer.

\footnotetext{
${ }^{2}$ Whittaker is a trademark of Whittaker Electronic Resources.
} 


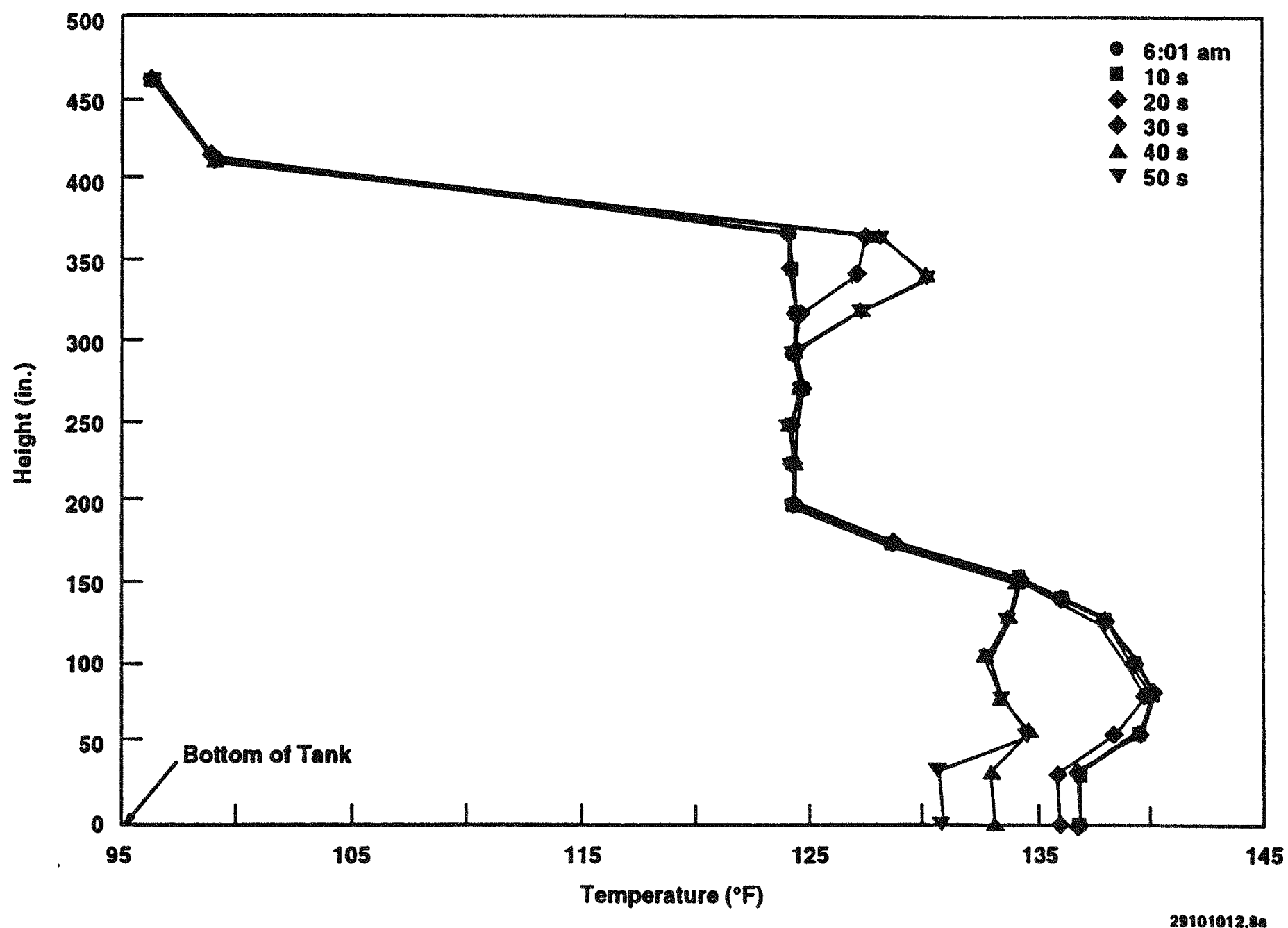

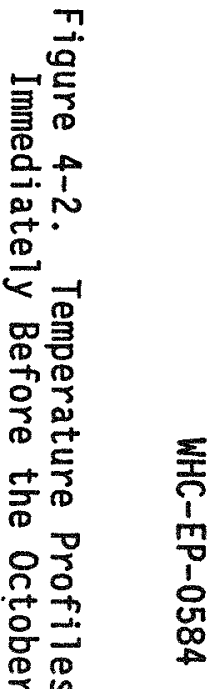

옥

홍

융 풎

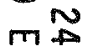

mE

密

은 


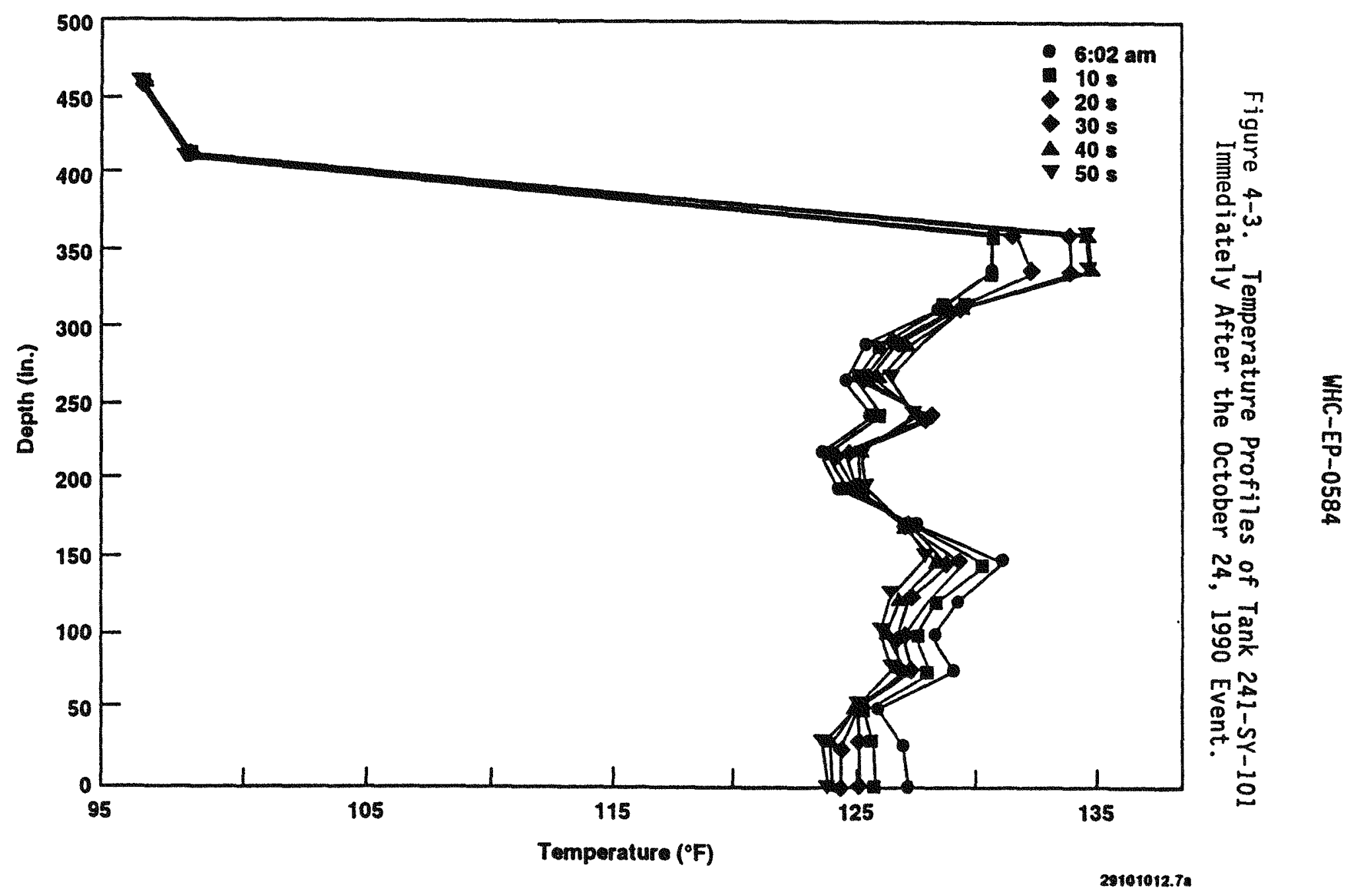




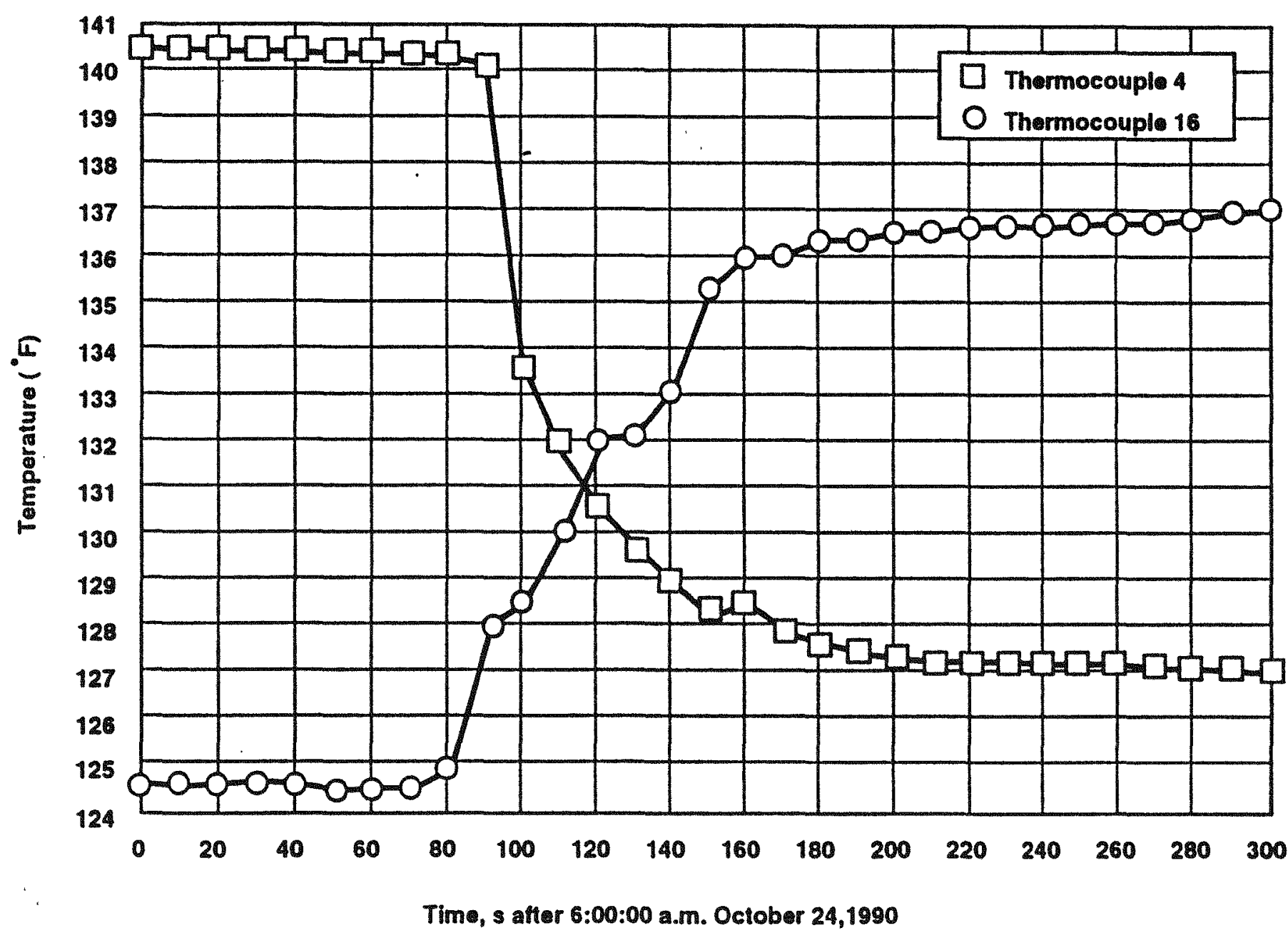

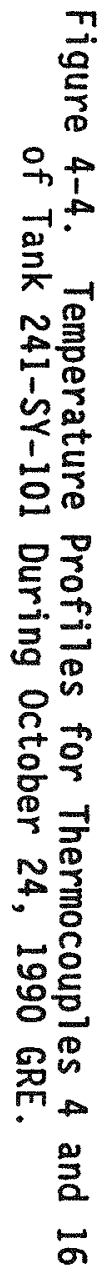




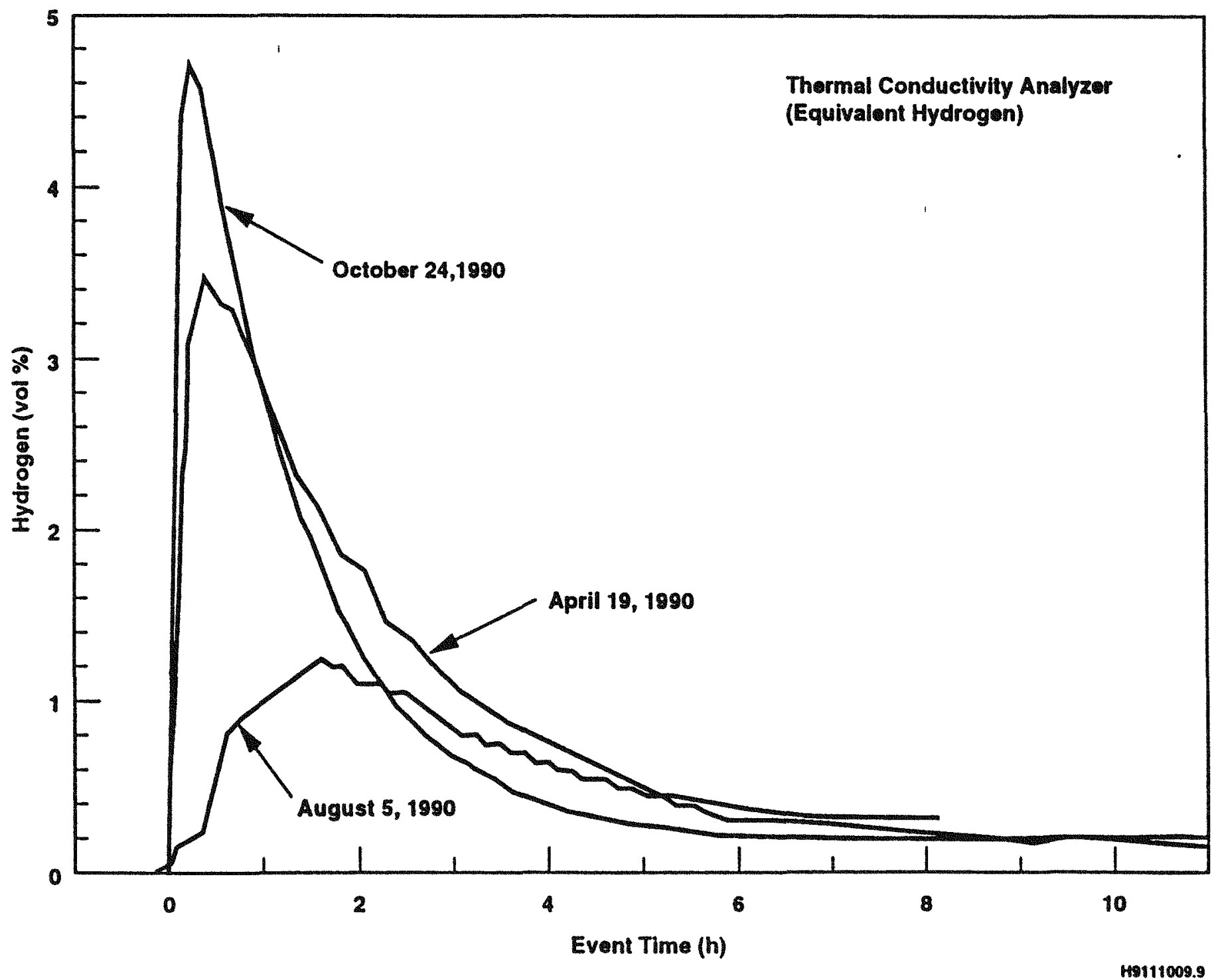




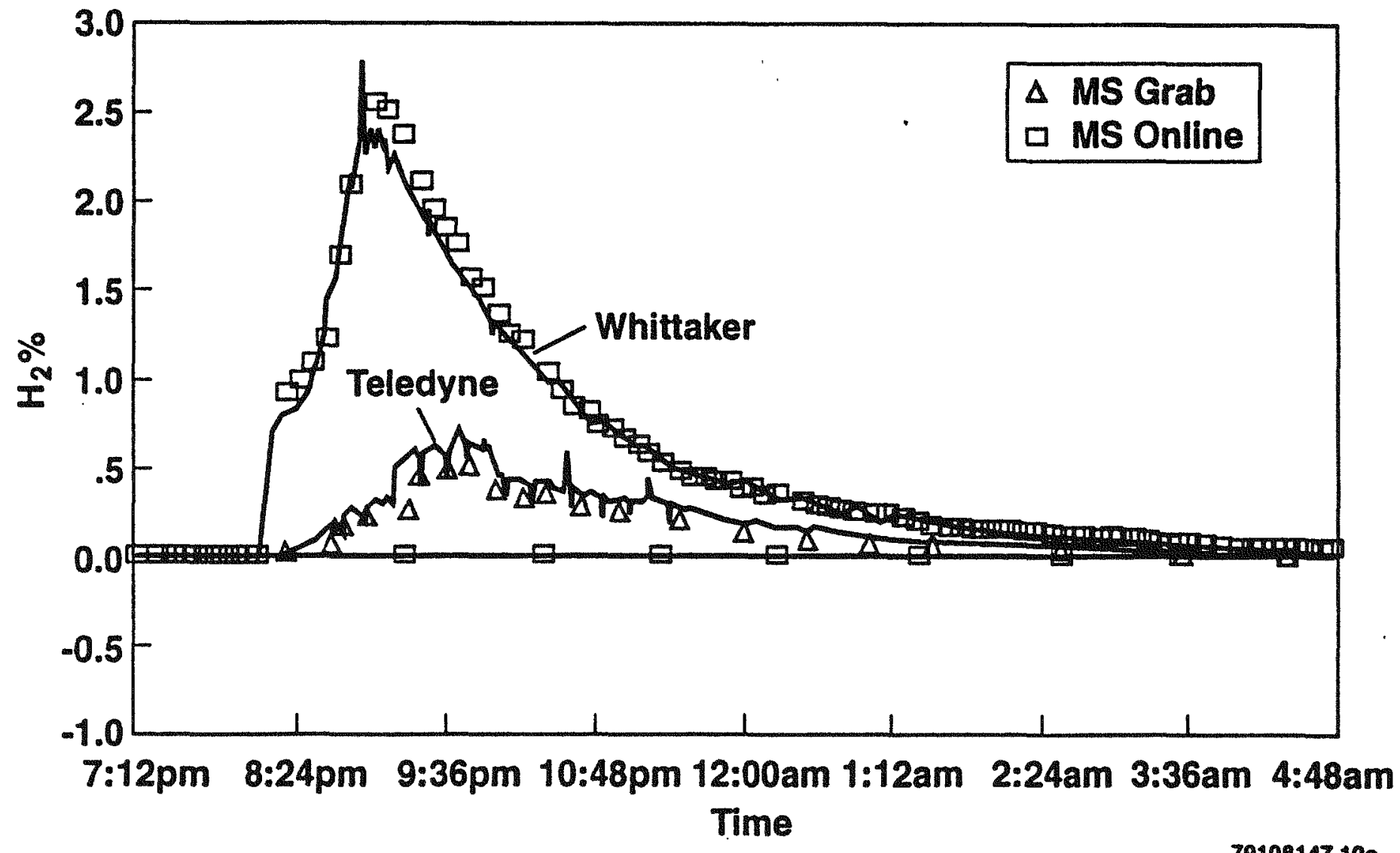

79108147.10 
While these methods do agree well with the concentration of hydrogen in the vapor space, the hydrogen monitors cannot estimate the gas composition. The gas composition is estimated by the mass spectrometer samples. Two different mass spectrometer instruments are being used. Grab samples were taken and sent to Pacific Northwest Laboratory (PNL) for high-resolution mass spectrometer analysis. The online mass spectrometer measures gases at near real time from the sample port about $18 \mathrm{in}$. above the waste.

Based on the online mass spectrometer analyses, the composition of vented gas was estimated. To do this, only the gas samples that had over 1 percent hydrogen were considered to ensure that the vent gas would be in larger quantities and the analys is would be more accurate. Because of the greater dilution in the ventilation system, none of the grab samples indicated greater than 1 percent hydrogen. Therefore, these samples are too dilute to yield meaningful gas compositions, and the online mass spectrometer was used for the May 1991 event gas composition estimates. waste.

The following is the gas composition estimated from the data for the

\begin{tabular}{lr}
\multicolumn{2}{c}{ Estimated Gas Composition } \\
\hline $\mathrm{H}_{2} \mathrm{O}$ & $15.4 \%$ \\
$\mathrm{H}_{2} \mathrm{O}$ & $17.7 \%$ \\
$\mathrm{~N}_{2}$ & $57.7 \%$ \\
$\mathrm{~N}_{2} \mathrm{O}$ & $9.1 \%$ \\
$\mathrm{CO}_{2}$ & $.1 \%$
\end{tabular}

It should be pointed out that the water may not be measured accurately with the online mass spectrometer. The mass spectrometer is not kept at the same temperature as the tank head space so the water may condense. Also, the moisture may represent some water that was evaporated into the ventilation air when the air came in contact with the waste.

The gas composition determined by the online system (August 1990 event) is different compared to that obtained for the gas from the gas sampler (described later). Ongoing work at Westinghouse Hanford Company (Westinghouse Hanford) and PNL to try to improve the understanding of the released gases, is discussed in the evaluation report for the event (Erhart 1991b).

\subsection{GAS RELEASE EVENT OF AUGUST 1991}

During the period of August 26 to 29, 1991, tank 241-SY-101 exhibited some of the characteristics associated with a GRE. This event appeared to be similar to the events in August 1990 and February 1991. There was a small increase in tank pressure and hydrogen concentration. The temperature profile did not exhibit a full reversal. The surface level drop was a total of 6 in. over a 4-day period. 
The online mass spectrometer peaked at $0.5 \%$ hydrogen and the Whittaker unit monitoring the tank dome space recorded 0.38 percent. The temperature data indicated that the waste turned over slightly during this event. Details of this GRE are given in Erhart (1992a).

\subsection{GAS RELEASE FOR DECEMBER 1991}

This event displayed the largest surface-level drop (13 in.). The release of gas pressurized the tank vapor space to +6.84 in. w.g. The tank was at above atmospheric pressure for about 2.8 minutes and exceeded the Operational Safety Limit of 5.0 in. w.g. No release of radioactive material was reported.

The maximum hydrogen $\left(\mathrm{H}_{3}\right)$ concentration detected in the tank was 5.3 vol\%. Details of this GRE are described elsewhere (Erhart 1992b).

\subsection{GAS RELEASE CHARACTERIZATION}

\subsubsection{Amount of Gas Released in an Event}

Table 4-1 also lists the total amount of gas released in various events. The total amount of gas released can be calculated using the estimates of gas composition, the ventilation flow rate, and the hydrogen release profiles. The released gas volume can also be calculated from the change in surface level of the tank. Assuming that the entire surface of the tank waste moves in a uniform manner during an event and that the gas behaves as an ideal gas, the volume of gas was calculated for two cases: (1) gas trapped underneath $250 \mathrm{in}$. of waste, and (2) gas trapped underneath $400 \mathrm{in}$. of waste. The specific gravities of the waste for these two cases were calculated from the 101-SY core sample analyses (Tingey 1992). These gas volume calculations are in general agreement with those from Barker (1991).

\subsubsection{Current Understanding of the Gas Composition}

Since 1990, there have been 345 mass spectrometer analyses of grab samples from 101-SY. These samples are from the ventilation line. A few of the data points are from INEL but the bulk have been analyzed by PNL. These mass spectrometer analyses do not report on any condensible gases such as water vapor and ammonia. These samples represent samples before, during, and after several GREs. 
The best estimate based on this information is the following:

\begin{tabular}{lr}
\multicolumn{1}{c}{ Component } & Mole\% \\
\hline Hydrogen $\left(\mathrm{H}_{2}\right)$ & 31 \\
Nitrous $\left.0 \times \mathrm{xide}_{2} \mathrm{O}\right)$ & 26 \\
Nitrogen $\left(\mathrm{N}_{2}\right)$ & 35 \\
Ammonia $\left(\mathrm{NH}_{3}\right)$ & 4 \\
Water Vapor $\left(\mathrm{H}_{2} \mathrm{O}\right)$ & 4
\end{tabular}

There were 100 grab samples that had a reported value for hydrogen. The gas composition was calculated using those samples which had hydrogen greater than $0.5 \%$. This represented 29 samples. The other samples were more dilute. The $\mathrm{H}_{2}$ to $\mathrm{N}_{2} \mathrm{O}$ ratio is of particular interest. The average value for this is 0.85 for the samples greater than $0.5 \% \mathrm{H}_{2}$. Below this value, the trend is toward higher ratios. For the purpose of safety analysis, however, the 0.85 value should be used as it represents the gas that is released immediately. This ratio is the most constant and invariate data from the tank. The ratio remains the same for a number of GREs.

The condensible gases were not measured in the grab sample data. Ammonia and water are known to be present. Their compositions were estimated on the basis of limited data.

The measured relative compositions of hydrogen, nitrogen, and nitrous oxide in the 29 samples with $>0.5 \%$ hydrogen are shown in Figure 4-7.

\subsection{VISUAL OBSERVATIONS}

Motion pictures of the upper crust surface during gas venting episodes show that much of the surface flows laterally away from the gas disengaging region. Floating solids can be seen to move away from the venting area during the vent, and then slowly migrate back towards their original position after venting is complete. Following a venting episode, the affected area reflects light like a liquid surface. Also, bubbles can be observed breaking the surface. With time, the slurry surface becomes less reflective, which is consistent with drying at the surface.

Scans of the tank surface show the presence of solid-appearing regions with a surface showing numerous ridges and valleys. Some of these regions have persisted over the time they have been observed $(\sim 1 \mathrm{yr})$ and have been relatively unaffected by the several venting events that have taken place during the past year.

Motion pictures taken during sampling activities show the presence of solid and fluid-like crust. The sludge weight sampler (Herting et al. 1992a) was able to penetrate only slightly into dry crust, but became totally submerged in wet crust. Also, when an auger sampler was lowered into wet crust, it penetrated it easily. The outside tube containing the auger moved 


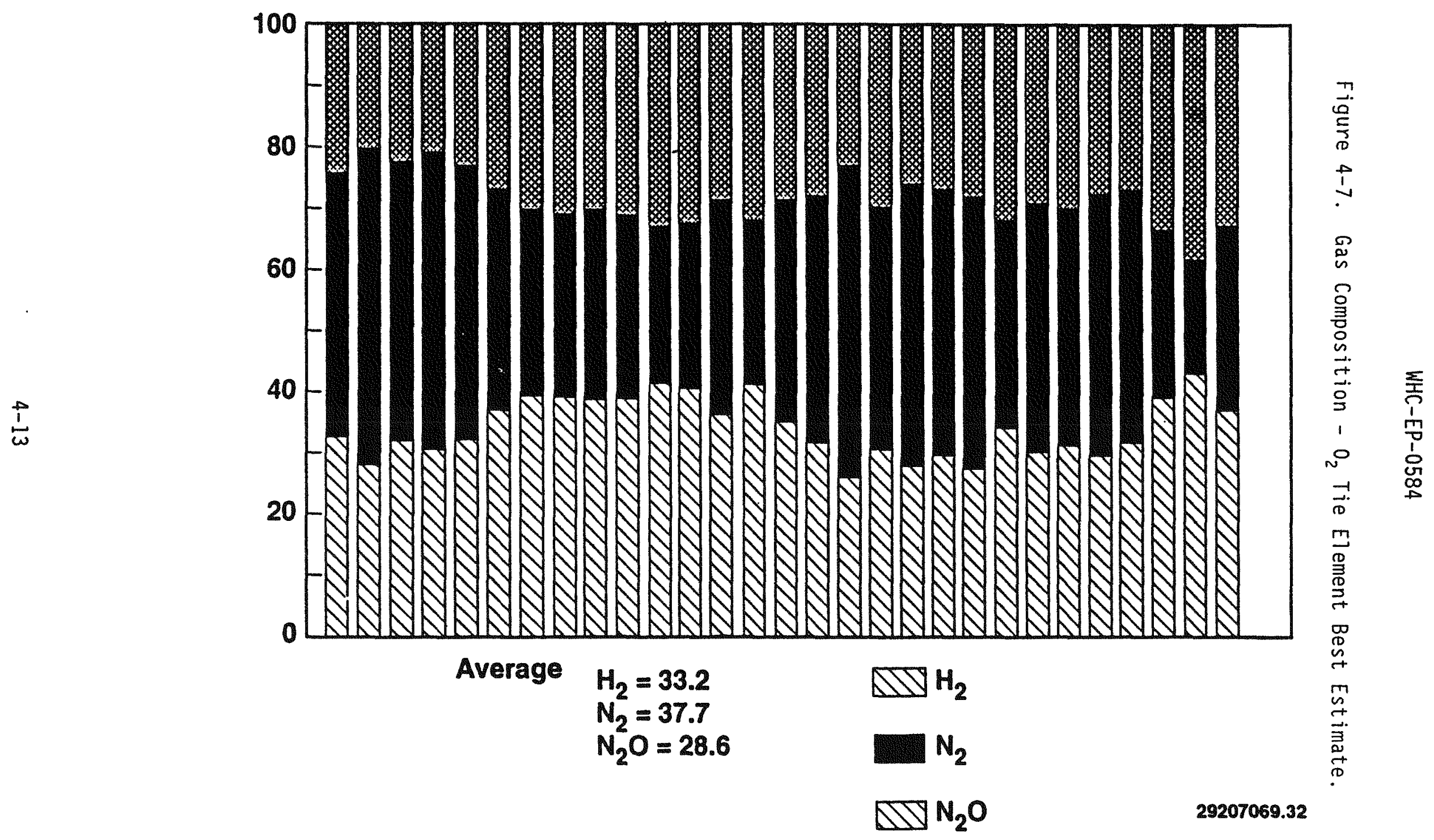


in a concentric motion, and this caused the crust to move in a way similar to cooked oatmeal. In dry crust the auger tube easily penetrated without depressing surrounding surface elements.

Video pictures taken during core sampling of waste show surface puddling of water that had been added before the drill string started to penetrate. After 2 hours, this water appeared to sink into the crust. When additional water was added, via the drill string, it did not puddle and disappeared below the drill.

The top surface had become porous enough that more water easily flowed on through. This implies that the dried top surface provides some resistance to water flow, but not for the layers underneath. 


\subsection{CORE SAMPLING DATA REQUIREMENTS}

Extruded segments of waste, about $48 \mathrm{~cm}$ (19 in.) in 1ength, will be supplied by the core drilling operation. The waste in 101-sy has crust that lies on top of a slurry/sludge. It is anticipated that there may be several distinct layers, or strata, in the slurry and sludge and at least two layers in the crust. To ensure that representative samples are obtained from the various layers, WHC-SD-WM-TP-090, Rev. 2, Analytical Chemistry Plan for Tank 241-SY-101 Core Sample, (Herting 1991), has been prepared for the handling and sample breakdown of the extruded segments.

Tank 101-SY waste must be sampled to gain further understanding of the waste and gas generation within the tank waste. The waste sampling plan has been structured to meet the requirements of Engineered Remedies and Safety as well as supply information to support activities for the Tri-Party Agreement. Information is required both on the nature of the crust as well as siurry. The data needed are the following:

Crust:

- Types of compounds present

- Reaction potential (exothermic?)

- Flammability

- Toxicological properties

- Particle size of solids

- Dissolution behavior of crust

- Density.

Slurry:

- Chemical compounds and solubility

- Density

- Gas content

- Flammability

- Heat sensitivity

- Viscosity and shear strength.

The data requests for safety, modeling, and engineered remedies tasks are listed in Table 5-1. It should be pointed out, however, that this list represents a wish list for tests and analyses, and not all of them can be carried out within the current laboratory capabilities. 
Table 5-1. Analytical Data Requests for Safety, Modeling, and Engineered Remedies.

\begin{tabular}{|l|c|c|c|}
\hline \multicolumn{1}{|c|}{ Analysis } & \multicolumn{3}{|c|}{ Region ${ }^{\mathrm{a}}$} \\
\cline { 2 - 4 } & Crust & Conv $^{\mathrm{b}}$ & Non $^{\mathrm{c}}$ \\
\hline Chemical composition & $\mathrm{X}$ & $\mathrm{X}$ & $\mathrm{X}$ \\
\hline Radiochemical composition & $\mathrm{X}$ & $\mathrm{X}$ & $\mathrm{X}$ \\
\hline Bulk density & $\mathrm{X}$ & $\mathrm{X}$ & $\mathrm{X}$ \\
\hline Liquid density & - & $\mathrm{X}$ & $\mathrm{X}$ \\
\hline Reactivity & $\mathrm{X}$ & $\mathrm{X}$ & $\mathrm{X}$ \\
\hline Depth of region & $\mathrm{X}$ & $\mathrm{X}$ & $\mathrm{X}$ \\
\hline Compressive strength & $\mathrm{X}$ & - & - \\
\hline Penetration resistance & $\mathrm{X}$ & $\mathrm{X}$ & $\mathrm{X}$ \\
\hline Dissolution properties & $\mathrm{X}$ & $\mathrm{X}$ & $\mathrm{X}$ \\
\hline Volume and weight percent settled solids & - & $\mathrm{X}$ & $\mathrm{X}$ \\
\hline Volume and weight percent centrifuged solids & - & $\mathrm{X}$ & $\mathrm{X}$ \\
\hline Solids settling rate & - & $\mathrm{X}$ & $\mathrm{X}$ \\
\hline Thermal conductivity & $\mathrm{X}$ & $\mathrm{X}$ & $\mathrm{X}$ \\
\hline Bulk heat capacity & $\mathrm{X}$ & $\mathrm{X}$ & $\mathrm{X}$ \\
\hline Shear strength & - & - & $\mathrm{X}$ \\
\hline Shear stress vs. shear rate rheogram (viscosity) & - & $\mathrm{X}$ & $\mathrm{X}$ \\
\hline Cohesiveness & - & - & $\mathrm{X}$ \\
\hline Abrasive behavior (Miller number) & - & - & $\mathrm{X}$ \\
\hline Liquid viscosity & - & $\mathrm{X}$ & $\mathrm{X}$ \\
\hline Liquid surface tension & - & $\mathrm{X}$ & $\mathrm{X}$ \\
\hline Particle wetability (e.g., contact angle) & - & $\mathrm{X}$ & $\mathrm{X}$ \\
\hline Polarized light microscopy (particle morphology) & $\mathrm{X}$ & $\mathrm{X}$ & $\mathrm{X}$ \\
\hline Particle size distribution & $\mathrm{X}$ & $\mathrm{X}$ & $\mathrm{X}$ \\
\hline Gas generation rate and composition & - & $\mathrm{X}$ & $\mathrm{X}$ \\
\hline
\end{tabular}

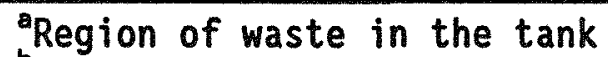

Convective region (mainly Liquid)

'Nonconvective region (mainly solids including sludge). 


\subsection{CORE SAMPLE ANALYSIS RESULTS}

\subsection{PREVIOUS DATA}

The available records indicate that the first sampling and analysis of tank 141-SY-101 total contents were performed in 1986 (Mauss 1986). Three samples were obtained, one each from the top (sample number R-6395) and the bottom (sample number $R-6394$ ), using the dip bottle-on-a-string method. The analyses of the samples included physical and chemical analyses, $x$-ray diffraction (XRD) analysis, $x$-ray fluorescent (XRF) analysis, viscosity, and percent solids determination.

The top sample was a slurry with approximately 45 percent settled solids which were dark gray and fine (clay-like) in appearance. The supernatant was clear yellow. The middle sample was a murky, brownish-gray slurry. When centrifuged, the supernatant was greenish-yellow and the solids were fine and brownish-gray. The bottom sample was thick (sludgy), with no settled solids. The sample was a green-gray color.

The top sample analyses indicated that the solids are composed primarily of organic carbon and aluminum; carbonate was present also. The slurry analyses also showed the top sample to be nontransuranic (non-TRU) waste.

The middle sample results showed the separated solids are composed of a] uminum (probably $\mathrm{NaAlO}_{2}$ and $\mathrm{Al}(\mathrm{OH})_{3}$ ), nitrate $\left(\mathrm{NaNO}_{3}\right.$ ), and organic carbon. Sodium phosphate and sodium sulfate also are present in small amounts. The middle slurry was non-TRU $(13 \mu \mathrm{Ci} / \mathrm{g})$. The bottom sample only had the total slurry analyzed. Again, the sample was found to be non-TRU $(11 \mu \mathrm{CI} / \mathrm{g})$. XRD.

The solids were analyzed by polarized light microscopy, and by XRF and

An $x$-ray analysis was performed on the water insoluble and acid insoluble solids. The presence of aluminum hydroxide $\left[\mathrm{Al}(\mathrm{OH})_{3}\right]$ indicates the water dilution caused the phase boundary to be crossed. This was because of the reduction in the sodium hydroxide ( $\mathrm{NaOH}$ ) concentration caused by the dilution.

Viscosity data (shear diagrams) were obtained on each slurry sample and a 50:50 dilution of the top sample using a rotational viscometer. In all cases, the samples exhibited pseudoplastic behavior. The viscosity increased as the depth of the sample increased. The 50:50 dilution of the middle sample decreased the viscosity significantly.

\subsection{CURRENT SAMPLING DATA}

Shortly after the October 24, 1990 GRE (window A), crust samples were obtained using the core sampler, auger, and modified siudge weight sampler. The samples were analyzed and the analytical results were published by Herting (1992).

Following the May 16, 1991 gas-release event (window C), a full-core sample (22 segments) was taken of the waste slurry extending from the surface 
of the waste to approximately 2 in. from the bottom of tank 101-SY on May 22 to 26. A three-segment core of the tank bottom region was taken on June 4, 1991 to complete the core sampling activity. Both core samples were taken through riser 22A. All the core segments were delivered to the laboratory, for core extrusion, observation, breakdown, and analysis according to test plans. The associated activities and the analytical results were reported in Herting et al. (1992a). Although Herting et al. interpreted the analytical results from the core samples to some degree, additional interpretation was provided by Reynolds (1992). This document summarizes the analytical data and interpretation from the above documents. More recently, a full core sample was also taken following the December 4, 1991, GRE (window E), which was one of the more vigorous GREs to date. Similar to the window $C$ samples, the window $E$ samples were analyzed and the analytical results reported

(Herting et a1. 1992b). Although preliminary data interpretation was made and reported, a more thorough review and interpretation of the results is still pending. Therefore, the results from the window $E$ core sample analyses will be reported in future documents.

Eight crust samples and 26 core-segment samples were taken from tank 101-SY during window $C$. More than 2,000 analytical determinations have been made on the samples.

\subsubsection{Analytical Data on Crust Samples}

The following is the summary of the analytical data and interpretation on the crust samples. The discussion includes both window $A$ and window $C$ data.

An important component of crust, from a safety evaluation perspective, is the percent moisture. The majority of the crust samples appeared wet. The remaining were harder and drier. This indicates that the crust is not uniform throughout the tank. Based on the analysis, the crust samples can be divided into three groups.

The first group of samples is dry containing 10 to 19 percent moisture. The second group contains between 20 and 29 percent moisture, with the third group containing greater than 30 percent moisture.

The first group of samples was definitely solids. In each case the sample was obtained from an object that is suspended in air (plummets or cables). The object was coated with waste and then air dried in the tank. The samples essentially were dry flakes but still contained 10 percent moisture. This perhaps indicates that the waste dries to an equilibrium moisture of 10 percent within the tank dome air.

The second group of crust samples (20 to 29 percent moisture) was more solid than fluid. The samples held their shape until crushed. Not all the samples were hard. There was a certain amount of stickiness associated with the samples.

The third group of samples ( $>30$ percent moisture) was closer to being fluids than solids. 


\section{Calorimetry}

Organics in the crust may react with the nitrate or nitrite in the crust and produce heat as well as gas. The energetics of the crust reaction have been studied (Herting et al. 1992a) and the data used in the analys is of the potential for crust combustion in case of a flammable gas burn in the tank (Fox et a1. 1992).

The amount of organics present in the crust samples was fairly constant and ranged from 1.5 to 2.2 wt\%. There seems to be a general agreement between the reactions and the total organic carbon values. It should be pointed out, however, that the exotherms start at high temperatures. The lowest exotherm measured was at $193{ }^{\circ} \mathrm{C}\left(379{ }^{\circ} \mathrm{F}\right)$ which is well above the operating temperature of tank 101-SY, and the temperatures to which the wastes will be subjected to during waste processing operations. When the crust sample was heated to $500^{\circ} \mathrm{C}\left(930^{\circ} \mathrm{F}\right)$, about 89 percent of the solids still remained after the possible presence of inerts in the sample. Such inerts will dampen a reaction by absorbing the heat and keeping the reacting chemicals apart.

\section{Crust Composition}

The solid component of the crust is primarily composed of solid components of the sodium nitrate and sodium nitrite. Appreciable amounts of sodium aluminates and sodium carbonates are present. The sodium carbonate that was identified by microscopy is the monohydrate. The monohydrate form will ascertain that there is some residual moisture in the crust under the drying conditions in the tank.

\section{Crust Thickness}

The minimum thickness of the crust at riser location $22 \mathrm{~A}$ is 4 in. as represented by the waste captured in Segment 2 . The maximum thickness was assumed to be 38 in. because of the nearly empty Segments 2 and 3 . The core samples measurements did not yield any definitive thickness values.

\subsubsection{Physical Properties of Core}

\section{Density}

A knowledge of densities is important in understanding how the tank stratifies and rolls over. Bulk densities of the extruded segments were measured by weighing and dividing by the core sampler volume. This measurement was based on an inappropriate assumption that the sampler was completely full of sample.

In addition, six segments (Tingey 1992) had densities measured by measuring the volume and weight of core samples at four temperatures, viz., $32^{\circ}, 50^{\circ}, 65^{\circ}$, and $80^{\circ} \mathrm{C}$. The measured density at $32^{\circ} \mathrm{C}$ is compared with the extruded bulk density, which was obtained at about the same temperature (refer to Table 6-1.) 
Table 6-1. Comparison of Measured Density with Extruded Bulk Density.

\begin{tabular}{|c|c|c|}
\hline Segments & Extruded Bulk Density & Measured Density \\
\hline 4 & 1.50 & 1.50 \\
\hline 8 & 1.45 & 1.53 \\
\hline 13 & 1.57 & 1.44 \\
\hline 15 & 1.63 & 1.67 \\
\hline 19 & 1.60 & 1.68 \\
\hline 22 & 1.55 & 1.71 \\
\hline
\end{tabular}

Table 6-1 shows that the measured densities, with one exception, are greater than the extruded bulk densities. The data indicate that the density of these samples is independent of temperature. The density of centrifuged solids for the segments, however, appears to be a function of temperature. The density at $80^{\circ} \mathrm{C}$ is significantly higher than at low temperatures in most cases.

A statistical test was performed on the density measurement of all the segments by applying the honest significant interval method. In this method, an interval, similar to a standard deviation, is displayed with the mean. If two intervals overlap, then it is assumed that there is no difference in the measurements. The results of this method, illustrated in Figure 6-1, clearly indicate a density difference between the convective and the nonconvective zones (Reynolds 1992).

The method also indicates that even within the supernate density data (Figure 6-2) there is a general trend for the density to be higher at the bottom than at the top. This means that in the lower regions the supernate has more dissolved solids.

The interval plot (Figure 6-3) for the solids density shows that the solids in the convective zone are denser. There is an overlap of the intervals but the trend appears to be certain.

Core sample materials were centrifuged to determine the compaction potential of the solids. Typical measured densities of the centrifuged solids component of core sample from the nonconvective slurry region (i.e., the liquid-solid mixture containing essentially all of the solid material after centrifuging) were approximately $1.8 \mathrm{gm} / \mathrm{mL}$. The typical density of the supernatant liquid was $1.46 \mathrm{gm} / \mathrm{mL}$.

\section{Viscosity} behavior.

Viscosity of the waste is important to the understanding of the tank 
Figure 6-1. Measured Density of Tank 241-SY-101 Waste.

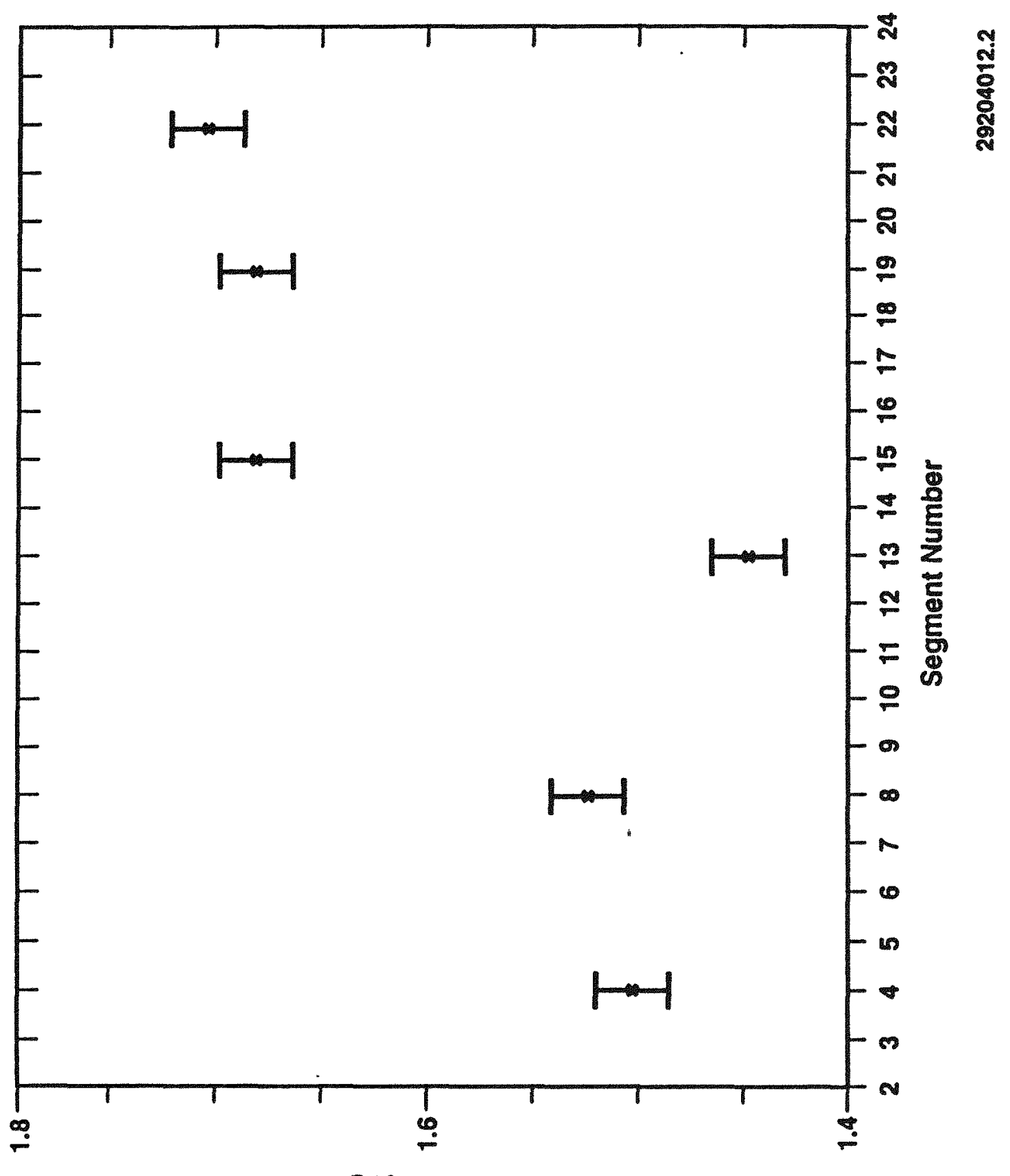

ןu/16 'Kysurg ueaw 
WHC-EP-0584

Figure 6-2. Supernate Density of Tank 241-SY-101 Waste.

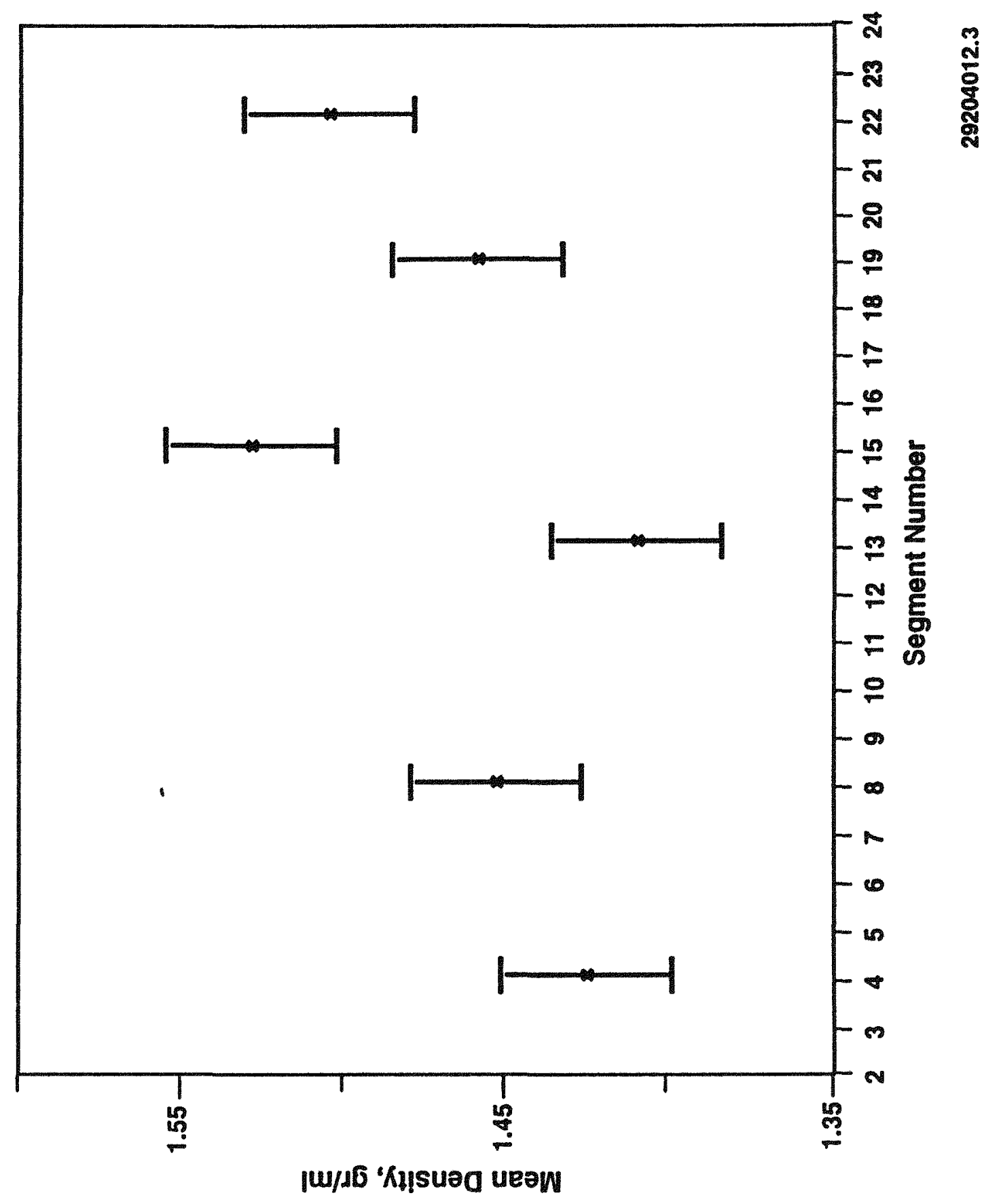


WHC-EP-0584

Figure 6-3. Density of Solids from Tank 241-SY-101 Waste.

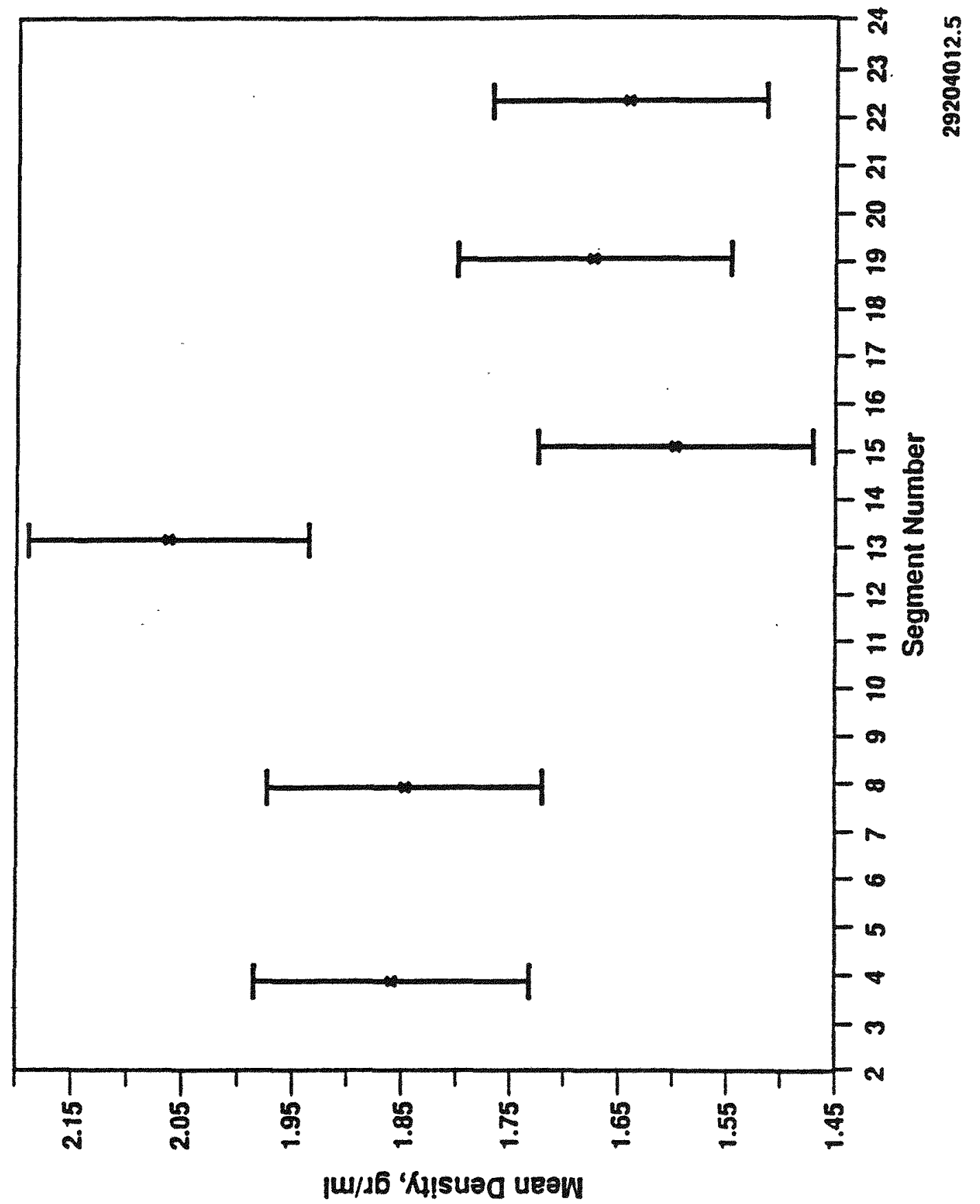


The material from the convective zone is typified by Segment 8 . This material was used in the viscosity study. The viscosity was taken at four different temperatures which bracket the temperatures in the tank. The viscosity was taken at various shear rates at these temperatures. Figure 6-4 shows how the viscosity varies with the temperature and shear rate.

The material showed essentially a Newtonian behavior. There was only a modest shear needed to start the fluid moving. The flat curves indicate that the shear rate did not affect the viscosity. The viscosity did not vary when the shear rate was increasing or decreasing.

The viscosity of the convective zone is plotted in Figure 6-5. The viscosity decreases sharply until approximately $60^{\circ} \mathrm{C}$, where the curve flattens out. The material has a viscosity of about 30 centipoise at a typical slurry temperature of $50^{\circ} \mathrm{C}$, and about 10 centipoise above $60^{\circ} \mathrm{C}$. The latter is approximately the viscosity of antifreeze.

\section{Shear Strength}

Shear strength was measured on selected segments. The shear strength measurement uses a cruciform spindle and measures the force needed to rotate the spindle. Only the force needed to break the spindle loose is recorded. Accurate shear stress measurements typically depend on the sample being in an undisturbed state. This is not totally possible on the core samples. However, the samples were disturbed as little as possible when put into the sample container. The sample container was allowed to sit several weeks for any bonds between particles to reform.

The sample size is such that only four determinations could be made on a sample. These were done at different temperatures. There was no duplication of runs to see the variation within the same sample. The sample was brought to the proper temperature, the shear vane was inserted, and one measurement was made.

Figure 6-6 shows the results of the shear strength analysis for Segments 15, 19, and 22, and the crust. Segment 15 is near the top of the nonconvective zone. Segment 19 is in the center of the nonconvective zone. Segment 22 is at the bottom of the tank. With the exception of Segment 15, the curves show a decrease in shear strength with increasing temperature up to $65{ }^{\circ} \mathrm{C}$. Then the shear strength shows a slight increase, especially for Segment 22.

The shear strength is about the same for all segments (except 15) and the crust at $65^{\circ} \mathrm{C}$.

The crust sample from a low-moisture, high-solids region showed the highest shear strength at temperatures below $65^{\circ} \mathrm{C}$. This is consistent with other observations on the crust. The shear strength values may support a harder crust at this location. 


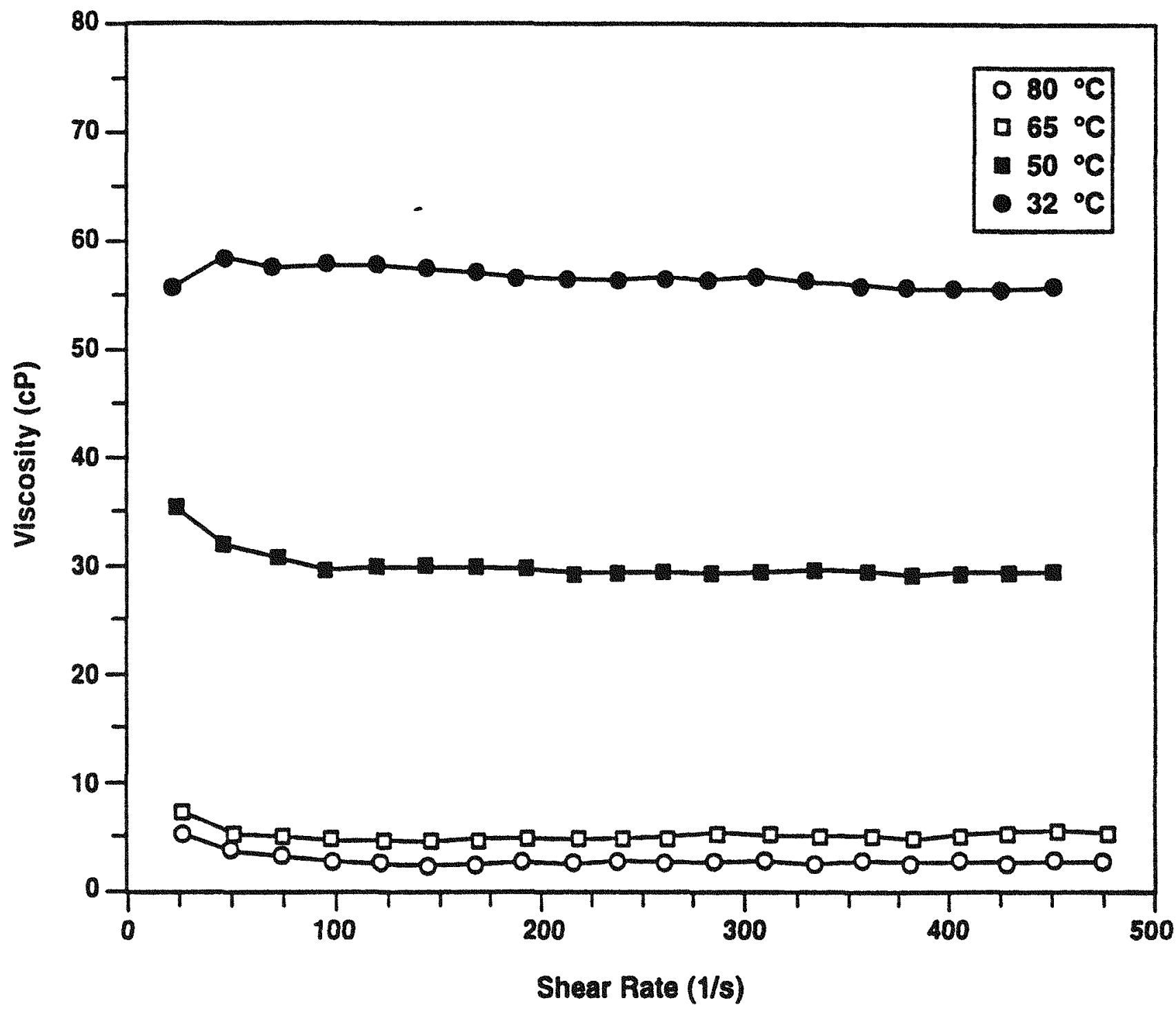

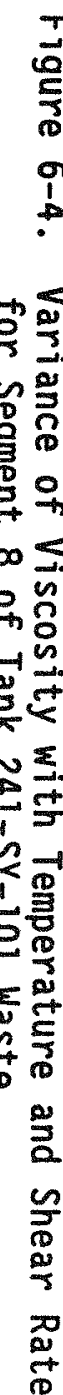

29204012.15 
Figure 6-5. Viscosity in the Convective Zone of Tank 241-SY-101 Waste.

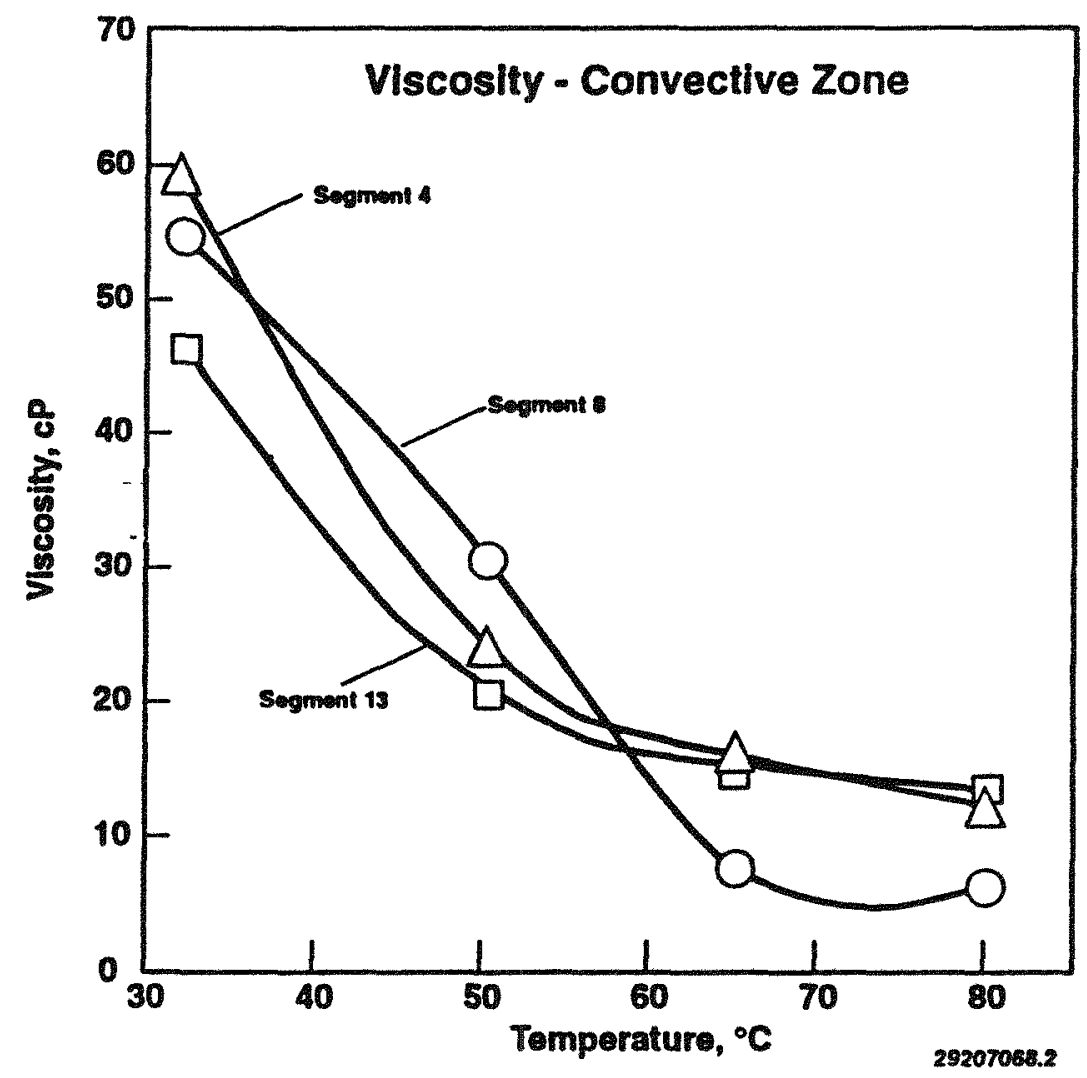


WHC-EP-0584

Figure 6-6. Shear Strength Analysis Results of Tank 241-SY-101 Waste.

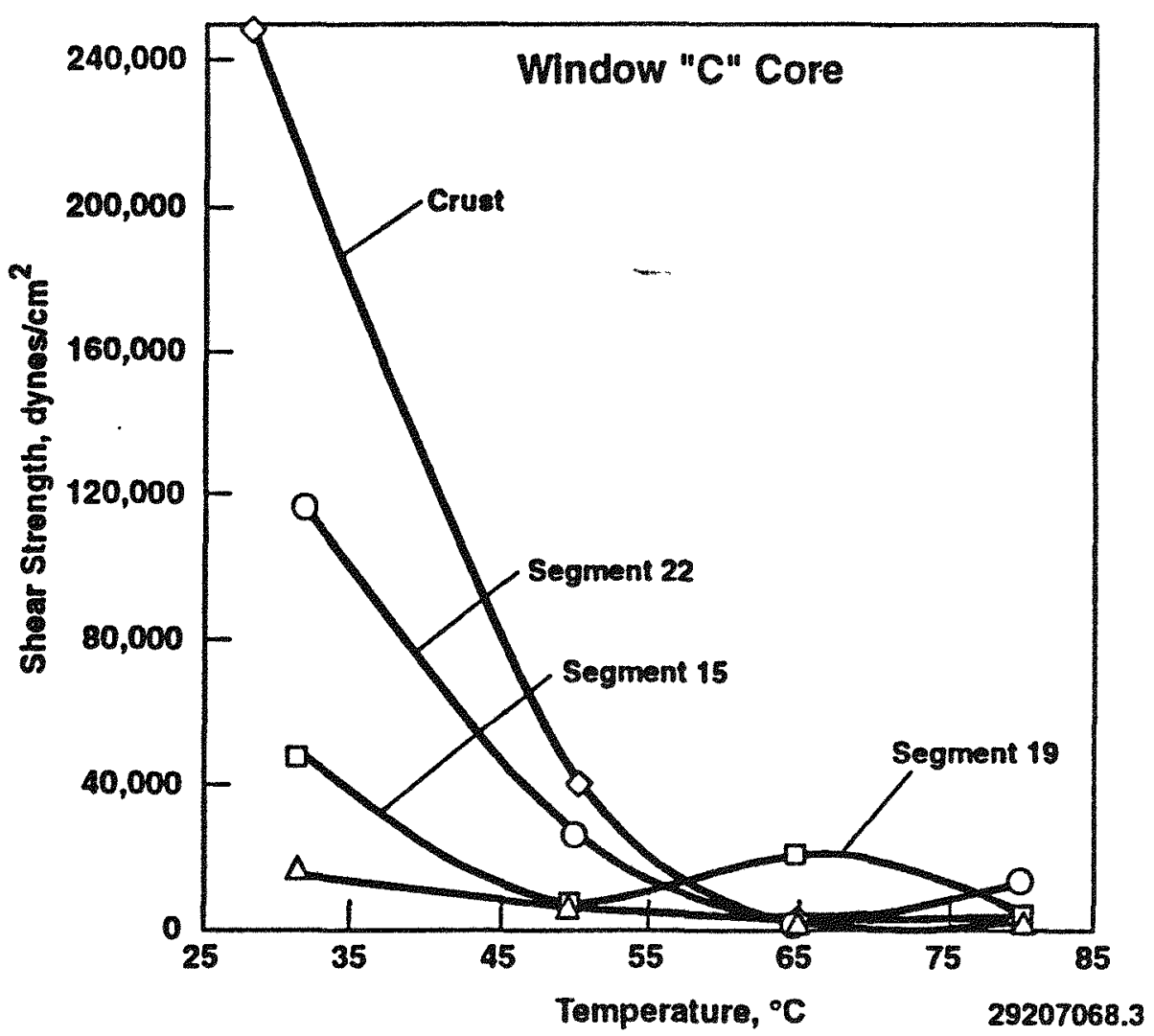


WHC-EP-0584

\section{Solids Percent}

The solids percent of the waste is one of the major differences between the convective and nonconvective zones. Solids here mean undissolved solids. A nonconvective zone has more undissolved solids than the convective zone. The difference between the zones could be seen visually when the samples were extruded.

Samples sent to PNL for physical properties analyses were tested for solids content. Samples were heated to different temperatures between 32 and $80^{\circ} \mathrm{C}$, then the settled and centrifuged solid volume was measured. Three segments from each of the convective zone and the nonconvective zone were put through this test.

Figure 6-7 displays the convective zone results.

A similar plot for nonconvective zone is shown in Figure 6-8. The nonconvective zone did not show any signs of settling, except at the highest temperature. Centrifuging did compact the solids somewhat so that there was about 20 percent supernate. The volume of centrifuged solids decreased with temperature which indicates that the solids are dissolving. However, notice that the weight percent solids dips slightly and then increases. The suggested explanation for this is that the solids dissolve as the temperature increases and then some other specie reaches saturation and precipitates.

\section{Solid Particle Size}

Particle size information was obtained as fraction of particles counted at each effective diameter. In effect, this is the number of particles in each size range:

The results indicate that the vast majority of the particles are small (60 percent are less than 1 micron). However, while the large particles may be almost insignificant in number, they represent the major portion of solids mass and volume.

Microscopic examination of the waste indicates that the larger particles are usually sodium nitrate and sodium nitrite. These chemical species are the ones which redissolve with heating and dilution. Therefore, these larger particles may be important for mitigation schemes.

The particle size information does not clearly answer whether or not the lower zones of the tank have larger particle sizes. Part of the reason may be the way the particles were harvested. The centrifuging may have sent the larger particles to the bottom of the vial where they were not measured. However, a plot of the height of waste in the tank versus largest particle sizes found (Figure 6-9) reveals a trend toward larger particles in the deeper segment in spite of a large scatter. The nonconvective zone shows no segments with the largest particle less than about 125 microns. The nonconvective zone had two segments which showed the largest particles. There is no sharp variation in particle size in going from the bottom segments to the top segments. 


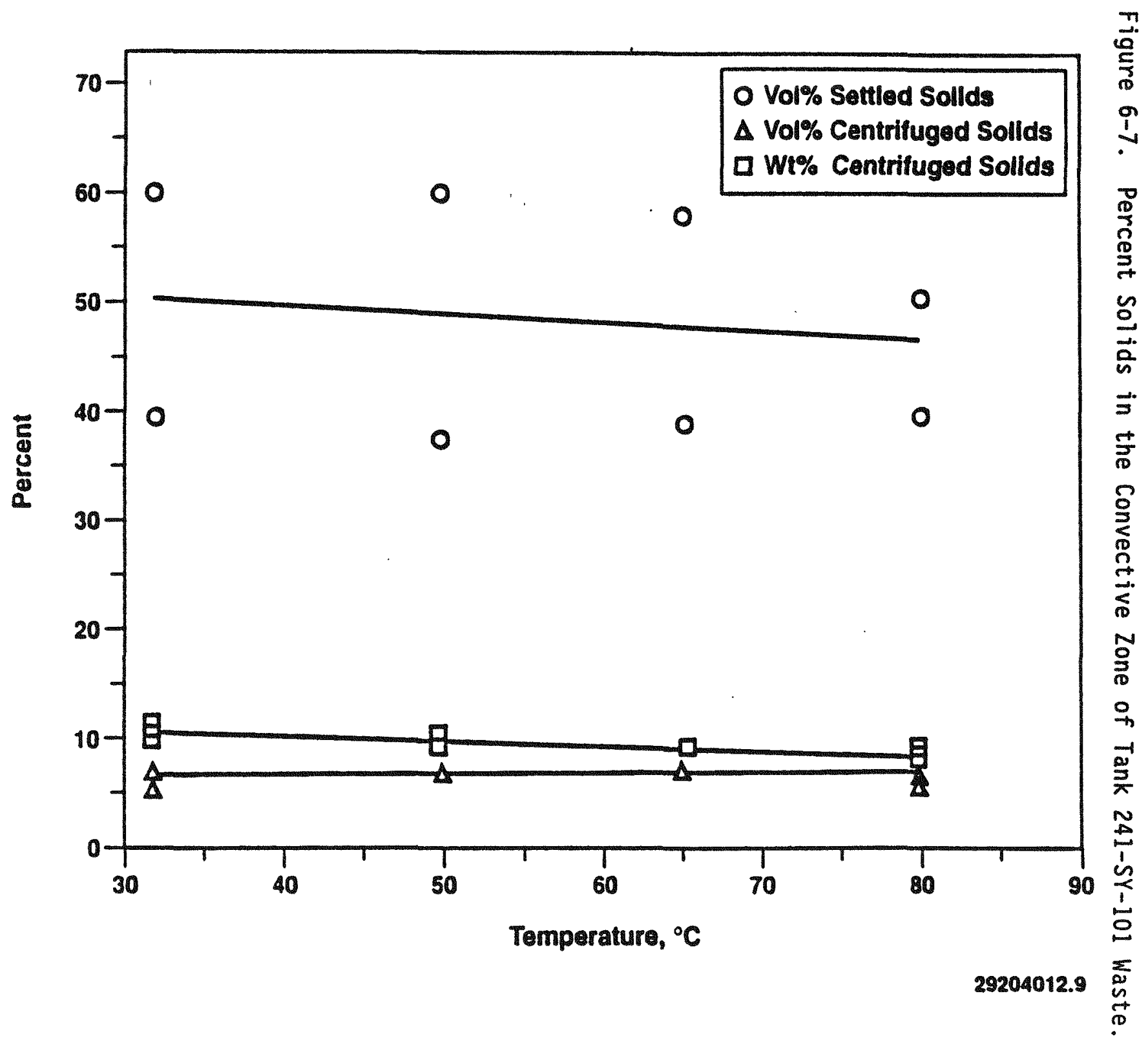




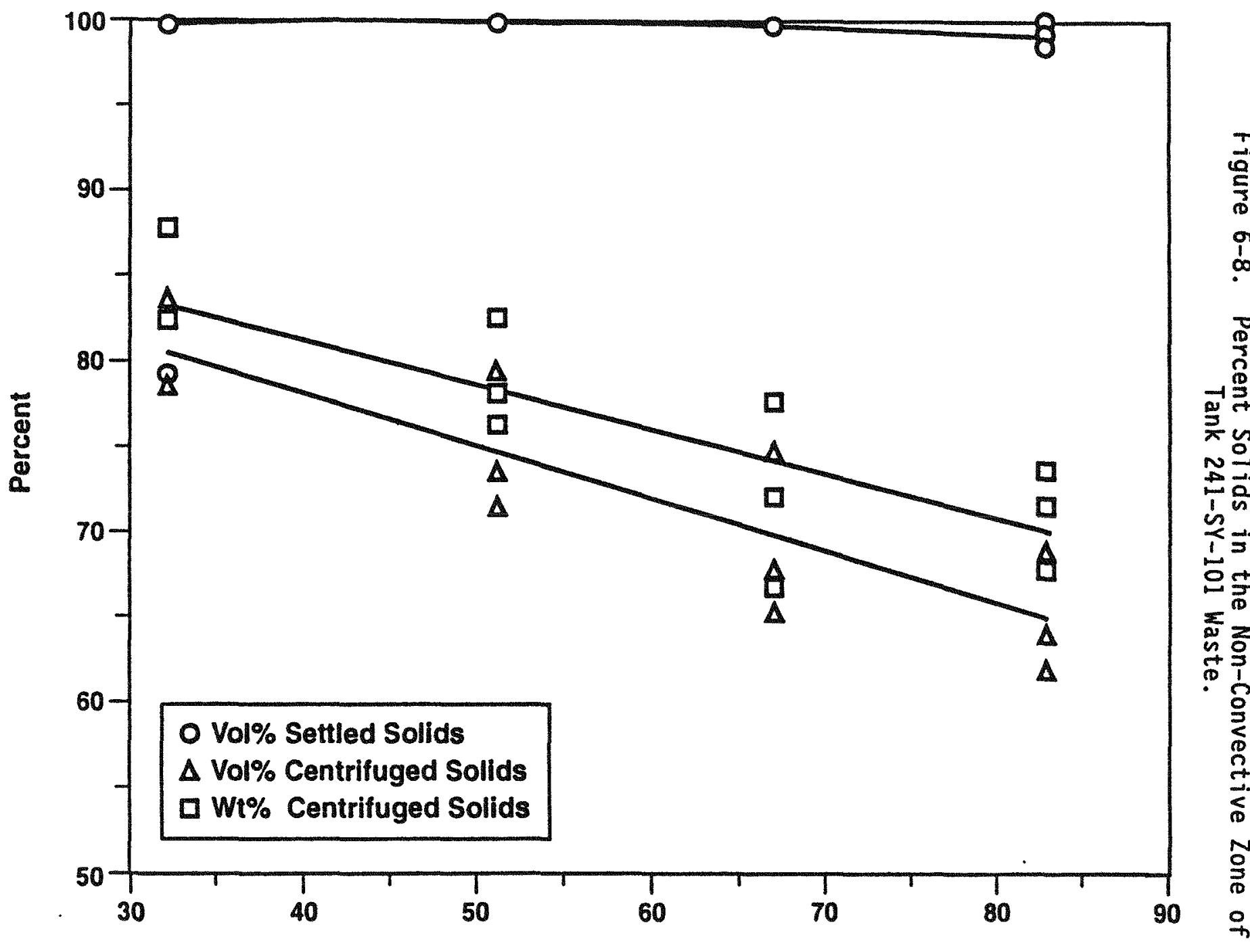

Temperature, ${ }^{\circ} \mathrm{F}$ 
WHC-EP-0584

Figure 6-9. Waste Height vs. Largest Particle Size for Tank 241-SY-101 Waste.

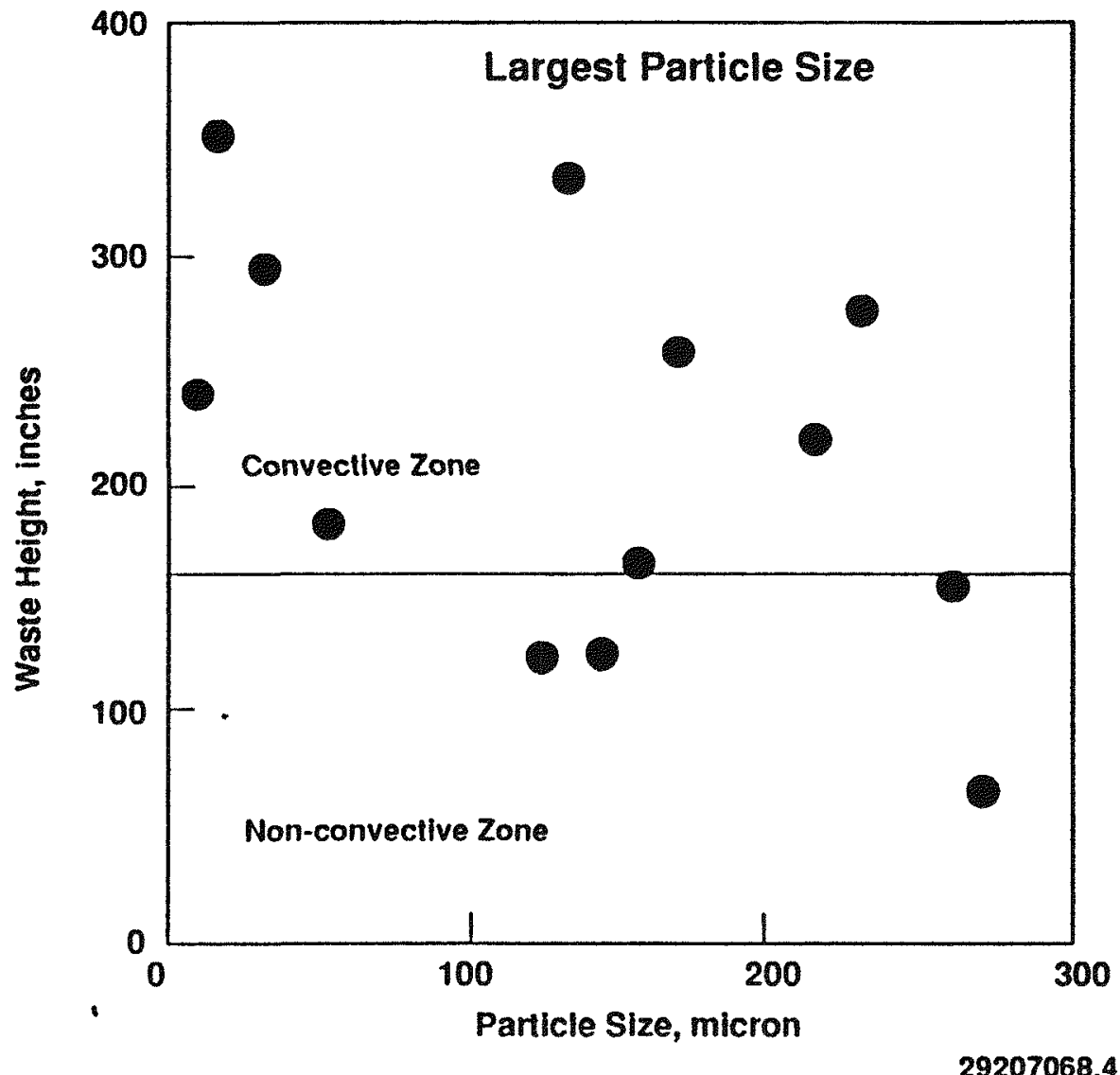




\subsubsection{Chemical Constituents}

\section{Mother Liquor}

There is reason to believe that the tank contents are mixed during the rollovers in the tank. The implication is that the liquid portion of the waste is well mixed and of constant composition. This would be especially true in the convective zone where postulated liquid motion is occurring all the time. If this is the case, then the centrifuged liquid from Segments 4 to 14T are all samples of the same mother liquor. The variation observed is perhaps a result of the combination of sampling and analytical errors. Also, the temperature of the convective zone was constant and the separation of the liquid was made at the same temperature so the temperature effects on solubility would be taken into account.

This assumption then leads to the conclusion that all of the sample information may be lumped together to get a better understanding of what the mother liquor is like. The information in the various tables reported in chapter 7 of Herting et a1. (1992a) was used in this analysis. The best estimate from the window $C$ data, for the mother liquor is tabulated below (Table 6-2) along with the specific gravity.

Table 6-2. Mother Liquor.

\begin{tabular}{|l|c|c|}
\hline \multicolumn{1}{|c|}{ Constituent } & Weight $\%$ & $95 \% \mathrm{CI}$. \\
\hline $\mathrm{H}_{2} \mathrm{O}$ & 36.1 & \pm 1.4 \\
\hline $\mathrm{TOC}$ & 1.12 & \pm 0.14 \\
\hline $\mathrm{NO}_{3}$ & 11.3 & \pm 1.8 \\
\hline $\mathrm{NO}_{2}$ & 12.1 & \pm 1.1 \\
\hline $\mathrm{Na}$ & 20.0 & \pm 0.8 \\
\hline $\mathrm{Al}$ & 3.21 & \pm 0.55 \\
\hline $\mathrm{Fe}$ & 0.0016 & \pm 0.0009 \\
\hline $\mathrm{Cr}$ & 0.0068 & \pm 0.0040 \\
\hline $\mathrm{Ca}$ & 0.0088 & \pm 0.0090 \\
\hline $\mathrm{OH}$ & 2.5 & \\
\hline $\mathrm{TIC}$ & 0.46 & \\
\hline $\mathrm{SPG}$ & 1.46 & \\
\hline
\end{tabular}

\section{Solubilities of Solids}

Reynolds (1992) evaluated the window $C$ data for solubilities of solids. The solids identified by XRD were sodium nitrite and sodium nitrate. These were also confirmed by polarized light microscopy. The microscope aiso identified $\mathrm{Na}_{2}, \mathrm{CO}_{3}, \mathrm{H}_{2} \mathrm{O}$, and $\mathrm{NaAlO}_{2}$. The carbonate identified here are water of hydration. Sodium aluminate also has other forms $[\mathrm{NaA}](\mathrm{OH})_{4}$ and 
$\mathrm{NaAlO}_{2} \cdot 2 \mathrm{H}_{2} \mathrm{O}$ ] that are associated with water. Both the carbonate and aluminate would hold a certain amount of bound water if the solids should dry out.

The data also indicate that the solids have greater amounts of TOC than the 1iquids in tank 101-SY waste.

There are a number of minor cations (e.g., iron, chromium, calcium) that appear primarily in the solids. The compounds formed by these cations are insoluble at high $\mathrm{pH}$ and thus represent the solids left when the convective zone segments are heated. Aluminum exists as the aluminate ion at high $\mathrm{pH}$. The window $C$ data show that aluminum is evenly distributed.

There are a number of anions that seem to be insoluble. Carbonate is the only one identified as a solid. However, sulfate and phosphate also would be expected to be insoluble.

It is generally believed that cesium will remain in solution due to a high solubility. However, the equilibrium constant for the $\mathrm{NaNO}_{3}=\mathrm{Na}^{+}+\mathrm{NO}_{3}^{-}$ reaction is about 50 times larger than that of a similar reaction for $\mathrm{CsNO}_{3}$. This means that cesium nitrate is less soluble than sodium nitrate. Therefore, since the sodium nitrate is identified as one of the solid species, it is possible that cesium nitrate may also be present in the solids. This is supported by the room temperature $\left(25^{\circ} \mathrm{C}\right)$ solubilities of sodium and cesium nitrates in water. At $25^{\circ} \mathrm{C}, 47.9$ grams of sodium nitrate will dissolve in 100 grams of solution as compared with only 21.5 grams of cesium nitrate.

\section{Organics}

The core sample analysis at PNL did not find any volatile organics above background in either the volatile organic analysis (VOA) or semi-VOA analysis. These findings are supported by results from cryogenic sampling of the vapor space. Therefore, the organics present are either nonvolatile or water soluble.

The PNL analyses of core samples, however, indicated that the chelators and chelator fragments make up about 65 percent of the derivatized fraction of the total nonvolatile organics recovered from the waste samples. The chelators and chelator fragments amount to $10-20 \%$ by weight of the total organics. This is not considered unusual since the complexed concentrate portion of the waste was rich in chelators. The major organics identified by the analysis are listed in Table 6-3 along with their appropriate concentrations.

Heat Load

The 241-SY Tank Farm has a heat Toad limit of $40,000 \mathrm{Btu} / \mathrm{hr}$ in any given tank. This heat load is based on the designed heat load for the tank farm ventilation system. Initial information from 101-SY indicated that the tank is near this limit. The heat load is estimated from the ${ }^{137} \mathrm{Cs}$ decay. Cesium-137 is the only radioactive species that will contribute to this heat load. All other radioactive species are present in such small amount that they do not contribute appreciably to the heat. The heat load is estimated from the measured ${ }^{137} \mathrm{Cs}$ inventory (Herting et a1. 1992a) in terms of $\mathrm{Btu} / \mathrm{hr} /$ segment. The results are shown in Table 6-4. 
Table 6-3. Heat Load Estimated from Cesium-137 Inventory.

\begin{tabular}{|l|c|}
\hline \multicolumn{1}{|c|}{ Component } & $\begin{array}{c}\text { Approximate } \\
\text { concentration } \\
(\mu \mathrm{g} / \mathrm{g})\end{array}$ \\
\hline Nitrosoiminodiacetate & 708 \\
\hline Ethylendiaminetetracetic acid (EDTA) & 237 \\
\hline Nitrilotriacetic acid (NTA) & 185 \\
\hline Ethylelnediaminetriacetic acid (ED3A) & 115 \\
\hline Butanedioic acid or succinic acid & 80 \\
\hline Citric acid (CA) & 45 \\
\hline $\begin{array}{l}\text { N-(2-Hydroxyethyl)ethylenediamine } \\
\text { triacetic acid (HEDTA) }\end{array}$ & 25 \\
\hline
\end{tabular}

Table 6-4. Cesium Inventories and Heat Load for Each Segment of Tank 241-SY-101.

\begin{tabular}{|c|c|c|}
\hline Segment & $\mu \mathrm{Ci} / \mathrm{gr}^{137} \mathrm{Cs}$ & Btu/hr/segment \\
\hline 4 & 512 & 2429 \\
\hline 5 & 319 & 1513 \\
\hline 7 & 463 & 2196 \\
\hline 8 & 277 & 1314 \\
\hline 9 & 406 & 1926 \\
\hline 11 & 471 & 2234 \\
\hline 13 & 396 & 1878 \\
\hline 14 & 406 & 1923 \\
\hline 15 & 388 & 2087 \\
\hline 16 & 401 & 2155 \\
\hline 17 & 319 & 1716 \\
\hline 18 & 366 & 1969 \\
\hline 19 & 353 & 1899 \\
\hline 20 & 387 & 2082 \\
\hline 21 & 363 & 1953 \\
\hline 22 & 358 & 1926 \\
\hline & & 31,206 \\
\hline
\end{tabular}


Notice that several segments are not included. The 16 segments above represent $304 \mathrm{in}$. of the $405 \mathrm{in.}$ in the tank when the tank was sampled. The total estimated heat load is, therefore,

$$
\frac{405}{304} \times 31,206=41,600 \frac{\mathrm{Btu}}{\mathrm{hr}} .
$$

Cesium-137 was measured on the composite samples. A similar analysis was done with this information. The results are shown in Table $6-5$. The ${ }^{137} \mathrm{Cs}$ values are the weighted average between the liquid and solids portion of the segments. The source of the information was Table 3-8 from Herting et al. (1992b).

Table 6-5. Composite Heat Estimation.

\begin{tabular}{|c|c|c|}
\hline Composite & $\mu \mathrm{Ci} / \mathrm{gr}^{137} \mathrm{Cs}$ & $\mathrm{Btu} / \mathrm{hr}$ \\
\hline 1 & 367 & 8713 \\
\hline 2 & 385 & 8223 \\
\hline 3 & 360 & 8717 \\
\hline 4 & 319 & 6866 \\
\hline \multicolumn{2}{|c|}{ TOTAL } & 32,519 \\
\hline
\end{tabular}

The composites represented 18 cores which had a height of 342 in. of the $405 \mathrm{in.}$ Therefore, the total estimated heat load for the tank is

$$
\frac{405}{342} \times 32,518=38,500 \frac{\mathrm{Btu}}{\mathrm{hr}}
$$

The mean of the two estimates is essentially equal to $40,000 \mathrm{Btu} / \mathrm{hr}$. 
WHC-EP-0584

This page intentionally left blank. 
WHC-EP-0584

\subsection{CHEMISTRY RESEARCH}

It is believed that both radiolytic and chemical processes may be contributing to gas generation in tank 101-SY. However, identifying all the chemical and radiolytic processes responsible for the generation of gases in tank 101-SY is a formidable task since many different inorganic and organic compounds are present. Some of these compounds are in solution, while others may exist as solids in the crust and/or sludge components of the waste. The chemistry is further complicated because some compounds react in the absence of radioactive materials while other reactions are initiated by the radiation emitted by ${ }^{137} \mathrm{Cs},{ }^{90} \mathrm{Sr}$, and other fission products. In any event, steps are being taken to identify the chemical and/or radiolytic processes giving rise to gas production through careful and systematic fundamental studies.

Early studies were conducted by Rockwell Hanford Operations in an attempt to understand the phenomenon of slurry growth and gas generation. In one of the most complete pieces of work, Delegard (1980) found the gas generation to be first order in the $\mathrm{NaAlO}_{2}$ concentration. The dependence of the reaction rate on the other components of the solution was more complex. In particular, the dependence of the $\mathrm{NaOH}$ concentration increased linearly to about $1 \mathrm{M}$, was a maximum at about $1.5 \mathrm{M}$, and decreased above $1.5 \mathrm{M}$. Delegard suggested an activated complex involving $A 10$ and HEDTA as a mechanism for gas generation. The temperature dependence of the gas generation rate was also investigated and found to exhibit Arrhenius behavior. The temperature dependence of the slurry growth was not investigated. The rate of $\mathrm{H}_{2}$ generation estimated from the data of Delegard is only one-sixth of the rate actually observed in tank 101-SY.

Further studies with synthetic wastes indicated that HEDTA and $\mathrm{HOACOH}$ are needed in the waste to generate gases such as $\mathrm{H}_{2}, \mathrm{~N}_{2} \mathrm{O}$, and $\mathrm{NH}_{3}$, in quantities sufficient to measure in the tank dome space. Gases were not generated when organics other than HEDTA and HOACOH were present. Slurry growth, i.e., expansion of the liquid phase without gas generation, may occur in the absence of organics, but the evidence is weak. In the case of no organics, it is uncertain as to what gases, if any, cause slurry growth.

The composition of the slurry gases released was found to vary as a function of time. The gas mixture was $\mathrm{H}_{2}$-rich at the start. The relative concentration of the $\mathrm{H}_{2}$ gas decreased with increasing time. The analyses, however, showed the same gases generated in the laboratory studies as in the tank, e.g., $\mathrm{H}_{2}, \mathrm{~N}_{2} \mathrm{O}$, and $\mathrm{NH}_{3}$. How these gases are generated under the oxidizing conditions prevalent in the tank was not determined.

Since 1990, simulant testing has been and is being conducted at PNL, Argonne National Laboratory (ANL) and Georgia Institute of Technology to understand the gas generation mechanisms in tank 101-SY.

Argonne National Laboratory is conducting studies on the radiation chemistry of synthetic waste (Meisel et a1. 1992). The ANL experiments performed to date indicate that the yield of $\mathrm{H}_{2}$ from radiolysis of aqueous solutions is substantially reduced by the presence of nitrate and nitrite in the waste solutions. Nitrate is the major scavenger for $e^{-}$and nitrite is the major scavenger for hydrogen atoms; therefore, nitrate and nitrite at high 
levels will minimize radiolytic gas production. Organic additives will increase the generation of $\mathrm{H}_{2}$ and mechanistic information is available to allow predictive modeling of trends in the rate of generation. Physical parameters such as temperature, viscosity, and pressure will not significantly affect the gas generation relative to generation under normal conditions. Radiolytic generation of $\mathrm{N}_{2} \mathrm{O}$ is inefficient in the absence of organic solutes. At the concentration level of the inorganic salts in the waste solutions, it will be difficult to find a chemical additive that could efficiently reduce the $\mathrm{H}_{2}$ yield, except perhaps by increasing the concentration of the nitrite/ nitrate components.

The work performed at ANL additionally points out that it is not likely that a chemical additive will be more efficient at scavenging $\mathrm{H}_{2}$ precursors than nitrate and nitrite, which are present at ample concentrations. In the presence of organics, oxygen produced by radiolysis is quickly destroyed. The rate of $\mathrm{N}_{2} \mathrm{O}$ generation is about 10 times higher than the $\mathrm{H}_{2}$ generation, which is fairly consistent with earlier work. The generation rate of $\mathrm{N}_{2} \mathrm{O}$ is relatively insensitive to the dose and the concentration of the organic, but sensitive to the dose rate. It should be noted, however, that $\mathrm{N}_{2} \mathrm{O}$ is generated only in the presence of organics.

Georgia Institute of Technology proposed the reactions shown in Table 7-1 as the set of reactions that can be used to explain the gases generated during the decomposition of glycolate in simulated waste. Evidence exists for many of these reactions. Steps 8 and 9 (Table 7-1) are not known, but are proposed as methods of generating $\mathrm{N}_{2}$, from the available chemicals in the system. As with no organics, no gas was evolved with EDTA under air or argon atmospheres, which was also noted in earlier experiments. With HEDTA as the organic species in solution, gas was evidenced at $0.21 \mathrm{~mL} / \mathrm{hr}$ and $0.39 \mathrm{~mL} / \mathrm{hr}$ under a helium and air atmosphere, respectively. This contradicts previous experiments in which no gas evolution was observed in the absence of air. With glycolate as the organic species, no difference was noted between the gas generation rate in helium or air. The gas generation rate was measured at $0.34 \mathrm{~mL} / \mathrm{hr}$. However, when aluminum was eliminated from the waste formation, no gases were evolved. Nitrite appears to play a more dominant role than nitrate in the mechanism for the thermal generation of gases. The elimination of nitrite reduced the gas evolution to a low level. Both chromium (III) and chromium (VI) increased the gas generation rate in the absence of air, with glycolate as the organic. Addition of copper (II) causes an increase in the amount of gas generated with formaldehyde in solution.

Chemistry research at the PNL included gas generation measurements in complex simulated waste systems with and without radiation present. Organic is required in the waste for gas production in simulated waste under both radiation and no radiation conditions. However, while the production rate with no radiation is dependent on organic concentration, the production rate is insensitive to concentration of organic with radiation present. In the absence of $\mathrm{O}_{2}$ and radiation, organic is not needed for gas generation with iron added to synthetic waste solution, with hydrogen as the product of iron corrosion. Production of both $\mathrm{H}_{2}$ and $\mathrm{N}_{2} \mathrm{O}$ is enhanced in a gamma radiation field, while $\mathrm{N}_{2}$ production appears to be insensitive to radiolysis. 
Table 7-1. Proposed Mechanism of Thermal Degradation of Glycolate.

$$
\begin{aligned}
& \text { 1. } \mathrm{Al}(\mathrm{OH})_{4}+\mathrm{NO}_{2} \rightleftarrows \mathrm{Al}(\mathrm{OH})_{3}-\mathrm{N}=0+\mathrm{OH} \\
& \text { 2. } \mathrm{Al}(\mathrm{OH})_{3}-\mathrm{O}-\mathrm{N}=\mathrm{O}+\mathrm{HO}-\mathrm{CH}_{2}-\mathrm{CO}_{2} \rightleftarrows \mathrm{Al}(\mathrm{OH})_{4}+\mathrm{O}=\mathrm{N}-\mathrm{O}-\mathrm{CH}_{2}-\mathrm{CO}_{2} \\
& \text { 3. } \mathrm{O}=\mathrm{N}-\mathrm{O}-\mathrm{CH}_{2}-\mathrm{CO}_{2} \rightarrow \mathrm{NO}+\mathrm{O}=\mathrm{CH}_{2}+\mathrm{CO}_{2} \\
& \text { 4. } \mathrm{O}=\mathrm{N}-\mathrm{O}-\mathrm{CH}_{2}-\mathrm{CO}_{2}+\mathrm{OH} \rightarrow \mathrm{NO}+\mathrm{H}-(\mathrm{CO})-\mathrm{CO}_{2}+\mathrm{H}_{2} \mathrm{O} \\
& \text { 5. } 2 \mathrm{NO} \rightleftarrows \mathrm{N}_{2} \mathrm{O}_{2}^{2} \\
& \text { 6. } \mathrm{N}_{2} \mathrm{O}_{2}+\mathrm{H}_{2} \mathrm{O} \rightleftarrows \mathrm{HN}_{2} \mathrm{O}+\mathrm{OH} \\
& \text { 7. } \mathrm{HN}_{2} \mathrm{O}_{2} \rightarrow \mathrm{N}_{2} \mathrm{O}+\mathrm{OH} \\
& \text { 8. } \mathrm{N}_{2} \mathrm{O}+\mathrm{Al}(\mathrm{OH})_{3}-\mathrm{O}-\mathrm{N}=0 \rightarrow \mathrm{N}_{2}+\mathrm{Al}(\mathrm{OH})_{3}-\mathrm{O}-\mathrm{N}=0 \\
& \text { 9. } \mathrm{N}_{2} \mathrm{O}+\mathrm{NO}_{2} \rightarrow \mathrm{N}_{2}+\mathrm{NO}_{3} \\
& \text { 10. } \mathrm{CH}_{2}=\mathrm{O}+\mathrm{OH} \rightleftarrows \mathrm{HO}-\mathrm{CH}_{2}-\mathrm{O} \\
& \text { 11. } \mathrm{HO}-\mathrm{CH}_{2}-\mathrm{O}+\mathrm{OH} \rightleftarrows \mathrm{O}-\mathrm{CH}_{2}-\mathrm{O}+\mathrm{H}_{2} \mathrm{O} \\
& \text { 12. } \mathrm{O}-\mathrm{CH}_{2}-\mathrm{O}+\mathrm{H}_{2} \mathrm{O} \rightarrow \mathrm{H}_{2}+\mathrm{H}-\mathrm{COO}+\mathrm{OH} \\
& \text { 13. } \mathrm{H}-(\mathrm{CO})-\mathrm{CO}_{2}+\mathrm{OH} \rightleftarrows \mathrm{O}-\mathrm{CH}(\mathrm{OH})-\mathrm{CO}_{2} \rightleftarrows(\mathrm{O})_{2} \rightleftarrows(0)_{2}-\mathrm{CH}-\mathrm{CO}_{2} \\
& \text { 14. }(\mathrm{O})_{2}-\mathrm{CH}-\mathrm{CO}_{2}+\mathrm{H}_{2} \mathrm{O} \rightarrow \mathrm{H}_{2}+\mathrm{O}_{2} \mathrm{C}-\mathrm{CO}_{2}+\mathrm{OH}
\end{aligned}
$$

The Pittsburgh Research Center of the U.S. Bureau of Mines (BOM) has studied the flammability of various mixtures of hydrogen, nitrous oxide, and air. The tests were performed in a 120-L spherical chamber using electric sparks and stronger pyrotechnic ignitors.

The BOM data indicated that below $20 \% \mathrm{H}_{2}$, there is no significant difference in the flammability for $\mathrm{H}_{2}$-air or $1: 1$ or $3: 2$ ratios of $\mathrm{H}_{2} / \mathrm{N}_{2} \mathrm{O}$ plus air mixtures. At higher $\mathrm{H}_{2}$ concentrations, the $\mathrm{H}_{2}-\mathrm{N}_{2} \mathrm{O}$-air mixtures are more hazardous, with higher maximum pressures and rates of pressure rise, as expected. Small amounts of $\mathrm{N}_{2} \mathrm{O}$ (relative to the air) do not appear to have much effect on the $f 1$ ammability, but high concentrations of $\mathrm{N}_{2} \mathrm{O}$ (relative to the air) markedly increase the explosion hazard. A stoichiometric mixture of $50 \% \mathrm{H}_{2}$ and $50 \% \mathrm{~N}_{2} \mathrm{O}$ (with no air) appears to have resulted in a detonation when initiated with a spark in the 120-L chamber.

The lean flammability limits (LFL) measured in the 120-L chamber using spark ignition were the same for al1 three mixtures $\left(\mathrm{H}_{2}-\mathrm{air}\right.$ and $1: 1$ and $3: 2$ ratios of $\mathrm{H}_{2} / \mathrm{N}_{2} \mathrm{O}$ plus air). For quiescent initial conditions, the LFL for upward flame propagation was: $\mathrm{LFL}_{\text {upward }} \approx 5 \% \mathrm{H}_{2}$, and the lean flammability limit for downward propagation was: $L_{\mathrm{F}} \mathrm{L}_{\text {downward }}=8 \% \mathrm{H}_{2}$. The quiescent mixtures of $\mathrm{H}_{2}$-air or $\mathrm{H}_{2}-\mathrm{N}_{2} \mathrm{O}$-air showed only very low pressure rises over the 
4 to $8 \% \mathrm{H}_{2}$ range, but the turbulent (fan on during tests) mixtures showed considerably higher pressures. The LFLs for the turbulent mixtures were: $L F L_{\text {ypward }}=4 \% \mathrm{H}_{2}$ and $L F L_{\text {downuard }}=6 \% \mathrm{H}_{2}$. The effects of strong pyrotechnic ignitors were comparable to the effects of turbulence.

Some tests were made at an elevated temperature of $54{ }^{\circ} \mathrm{C}$ and with added water vapor, and the data at low $\mathrm{H}_{3}$-concentrations were not significantly different from the ambient temperature, dry data.

The addition of small amounts of ammonia $\left(\mathrm{NH}_{3}\right)$ to the $\mathrm{H}_{2}-\mathrm{N}_{2} \mathrm{O}$-air system does not appear to increase the explosion hazard over and above what would be expected for its added fuel contribution to the mixture.

Both nitrogen and argon were tested as inert gases, and nitrogen was found to be more effective in inhibiting the $\mathrm{H}_{2}-\mathrm{N}_{2} \mathrm{O}$ flammability. However, small amounts of air added to the system significantly reduced the effectiveness of the inert nitrogen. 


\subsection{MODELING ACTIVITIES}

Several analytical models have been developed to understand the accumulation and release of flammable gases from tank 101-SY. In general, these models are attempts to represent observed or hypothesized tank conditions, applying empirical data where available.

The majority of the models employed to date vary in detail and scope; in many cases addressing only limited aspects of the relevant issue. An integrated model or system of models to represent the entire range of phenomenology has also been developed.

This section summarizes significant models and analyses developed through 1991 and the early part of 1992. For a more detailed look at these models, the reader is advised to refer to the references listed in this section.

\subsection{BACKGROUND}

Direct sampling of tank 101-SY contents has confirmed indirect evidence from the vertical temperature profile in the tank that the waste in tank 101-SY, between GREs exists in several physical layers:

- An upper layer, known as the crust, which contains a large fraction of solids, but is of low enough density of float, and which has thermal insulating properties relative to the liquid layer beneath.

- A convective liquid layer of nearly uniform temperature.

- A thick, nonconvective layer of liquid and settled solid particles, known as the slurry layer; this layer may contain a sublayer of denser and more viscous material known as sludge, which is located at the bottom of the tank.

This view of the tank contents is illustrated in Figure 8-1.

The episodic gas release behavior is consistent with a phenomenology as follows:

- Gases generated in the slurry are retained and accumulated, thereby causing the tank contents volume to increase and the slurry layer density to decrease. The volume increase is apparent as a rising surface level of the tank contents.

- The density of the slurry, or parts of it, becomes less than the density of the overlying liquid.

- The unstable density relationship causes a rollover of all or a part of the tank contents. The initial instability, triggering upward displacement of the slurry at some point, is augmented, once started, because of gas bubble expansion with the decreasing hydrostatic pressure at increasing elevations. 
- The rollover hydraulics carry liquid, gas, and solids from the slurry layer into the liquid layer and into or through the crust. Bursts of slurry gas are released as slurry upwellings reach the surface.

- After the initial upwellings, gases continue to evolve by effervescence through the liquid and crust.

- Over a period of time, the heavier components of the slurry settle through the liquid, and the slurry layer is reformed. It appears that a large fraction of the slurry gas is retained in the slurry at this time.

\subsection{MODELING OF GAS GENERATION AND ACCUMULATION}

\subsubsection{Gas Generation}

Laboratory and theoretical data indicate that radiolysis plus chemical reactions can account for the gas quantities which appear to be produced (Meisel et a1. 1992). At this time, these data do not account for the relative quantities of the gas constituents, and they are not sufficient to indicate quantitative differences between the various waste layers in the tank. Laboratory data show temperature sensitivity of relevant chemical reactions, as well as radiation sensitivity, but the laboratory data are not at this time correlated to operational data.

Operational data provide no basis on which to differentiate gas generation in the various waste layers, nor to distinguish time or temperature dependence. For analytical purposes, the gas generation has been modeled as being constant in both space and time.

The use of a constant value for the gas generation rate, without functional dependence on temperature, radiation level, or waste constituents or physical states, does not mean that such dependencies do not exist. Current operational, laboratory, and theoretical data do not establish values for such dependencies, but if future operations or mitigation programs cause large changes in waste parameters, significant changes in gas generation rates could occur. For example, an increased temperature might cause an increased gas generation rate.

A reference value for the gas generation rate has been calculated from recent operational data, i.e., the time period 1989-1992. The calculation is dependent on assumptions regarding gas retention, which are

- Gas release from the convective liquid and crust layers is continuous (i.e., any gas accumulation in these layers is constant, at equilibrium)

- Gas release from the slurry is zero in the time period between GREs. 


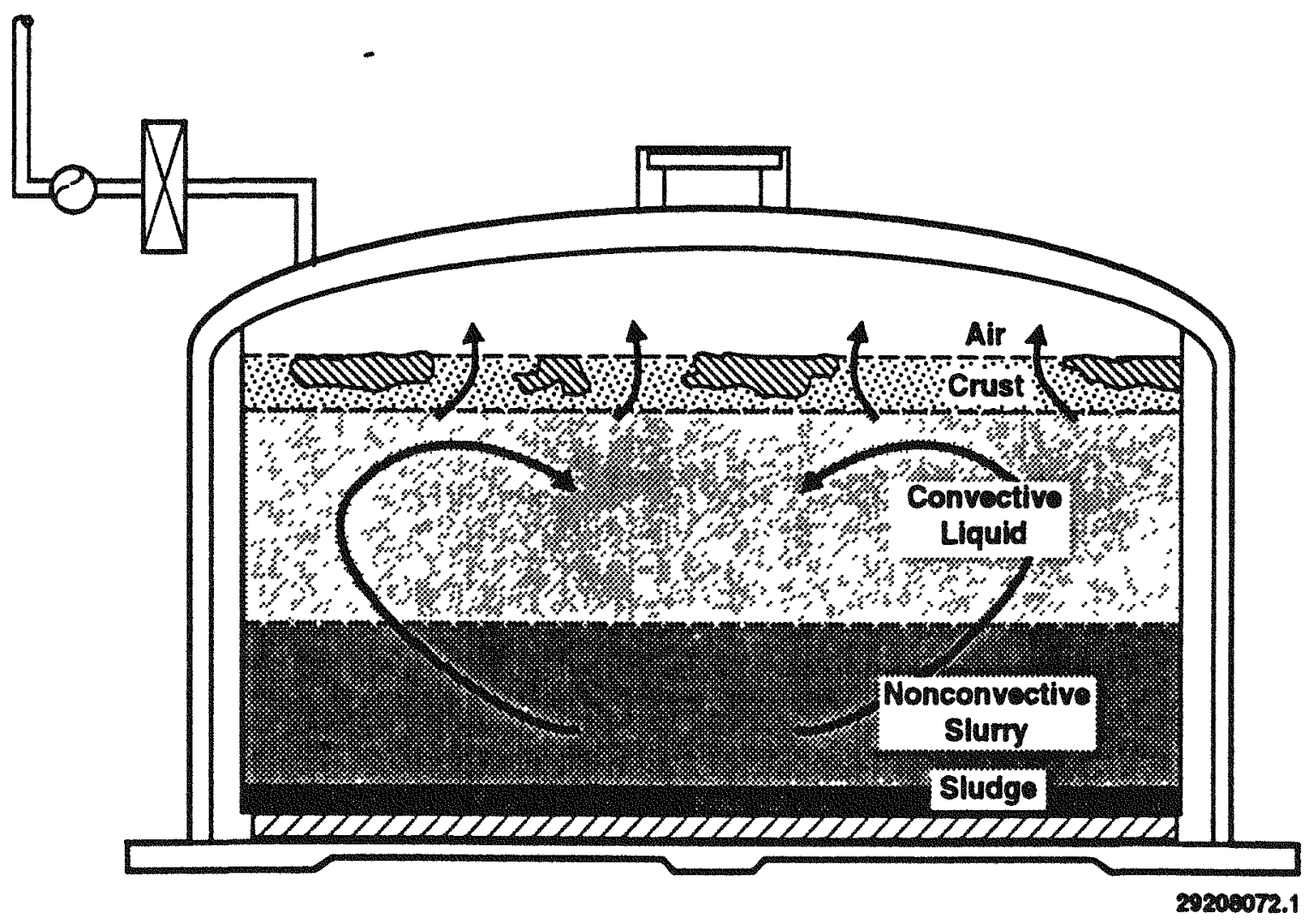

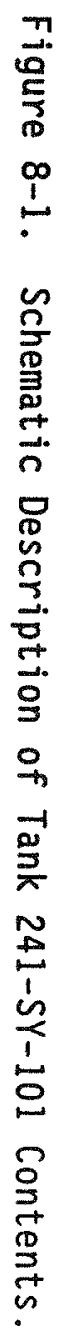


WHC-EP-0584

Based on a surface-level growth rate of $0.09 \mathrm{in.} /$ day from recent operational data, the annual gas generation in the slurry (released during GREs) was calculated to be $25,600 \mathrm{ft}^{3}$. This value agrees with the observed release during GREs from Apri1 1990 through December 1991 of 18,000 to $26,000 \mathrm{ft}^{3} / \mathrm{yr}$ (Babad et a7. 1992). The continuously released gas from the convective liquid and crust layers is estimated at $77 \mathrm{ft}^{3} / \mathrm{day}$, which is expected to appear at a concentration of $89 \mathrm{ppm}$ in a ventilation flow of $600 \mathrm{ft}^{3} / \mathrm{min}$.

\subsubsection{Gas Accumulation and Release}

Uncertainties in physical properties are significant to the calculated results, and sensitivity studies are necessary to assess the importance of key uncertainties.

Simplified models have been used to estimate the maximum quantity of gas that could accumulate in the slurry, and the maximum amount which could be retained following a GRE. The simplified model assumes the following:

- The maximum gas accumulation in the slurry is that quantity which reduces the average slurry density to the neutral buoyancy point (i.e., when the slurry layer becomes buoyant, it must roll over and release some or all of the accumulated gas).

- The minimum gas release in a GRE is that quantity which would allow the slurry, at the lower hydrostatic pressure corresponding to its position if it were floating on top of the convective layer, to become heavier than the convective liquid (i.e., for the slurry to be reestablished at the tank bottom, it must release at least enough gas to permit the nongaseous components to sink).

Gas accumulation in the slurry layer was calculated on the basis of measured data from tank 101-SY core samples. Centrifuging of core samples compacted the so-called centrifuged solids to an average density of $1.8 \mathrm{~g} / \mathrm{mL}$. This was taken as a representative value for the compaction of the slurry in tank 101-SY. Any gas content remaining after sample preparation and centrifuging was assumed to be negligible, either because the gas quantity is virtually zero or any retained gas is so tightly held that it would not be subject to episodic release. The gas void content to bring this solid/liquid mixture to neutral buoyancy is 19 vol\%. The corresponding calculated neutrally buoyant gas accumulation in the slurry layer is $13,700 \mathrm{ft}^{3}$ (in situ). Converting to atmospheric pressure (and neglecting temperature change), the buoyant gas content is $29,000 \mathrm{ft}^{3}$ of gas at 1 atmosphere pressure.

Alternate interpretations of available data may indicate that the solid/ liquid slurry density, void-free, might be below $1.7 \mathrm{~g} / \mathrm{mL}$ or as high as $1.93 \mathrm{~g} / \mathrm{mL}$. The corresponding range of potential maximum gas accumulation is approximately 21,000 to $37,000 \mathrm{ft}^{3}$ of gas at one atmosphere pressure.

The calculated minimum gas release for the base case, if 100 percent of the slurry was involved in the GRE, is about 9,000 $\mathrm{ft}^{3}$ (at one atmosphere). 
A summary of potential gas inventory data as calculated by the above simplified model has recently been reported.

\subsection{MODELING OF THE ROLLOVER PHENOMENON}

The idea that the tank 101-SY episodic gas release behavior could be explained by a hydraulic rollover phenomenon was previously suggested.

Several analytical models have been used for scoping assessments of this sort of behavior. All of the models show that the observed tank behavior is consistent, in general characteristics, with such a conceptual model. The models concerning the rollover phenomenon are described in the following section.

\subsubsection{The TEMPEST Model}

Hydrodynamic simulations of the postulated rollover mechanisms have been computed by the transient thermal hydraulics computer code, TEMPEST

(Allemann et a1. 1992). These simulations were preliminary investigations designed to evaluate basic features of the rollover mechanisms and how they relate to observed data in tank 101-SY. The preliminary investigations were accomplished using computational features available in the TEMPEST code. No model development of the TEMPEST code for this problem has been done to date. Features in the TEMPEST code were tested in related tank studies for Westinghouse Hanford and used in this work.

The simulation results, in conjunction with other aspects of the project investigating rollover mechanisms, were intended to further understanding of the hydrodynamics of the tank and to guide the planning of additional simulation work and the development of physical models describing the state of the material in the tank. Simulations accomplished to date have been used to identify the ability of the TEMPEST code to calculate rollover phenomena inherent in physically unstable thermal hydraulics for cylindrical geometries and to develop insights into rollover mechanisms using those abilities.

Preliminary simulations of hydrodynamics in a numerical model of tank 101-SY were carried out for a postulated gas-volume induced rollover process. These simulations were conducted for several situations, including a settling solids field and an incompressible (nonexpanding) rising bubble field.

The supernatant liquid in the tank initially was modeled as a constant property fluid with the exception of density, which is dependent on temperature. Density also is a function of concentration of the constituents transported in it. The TEMPEST code has the capability of treating the base fluid as having a volumetric concentration dependent viscosity, but that feature was not enabled in these simulations.

The slurry layer was assumed to be a layer of particles with an interstitial quantity of supernatant fluid. Solids in the layer initially were at rest subject to a maximum concentration at which particle settling is zero. The layer was assumed to be shearable. Convective transport of the 
solids was by solution of a constituent transport equation. A settling velocity component was included; this settling velocity component was a specified value and was modified during computation according to local concentration. The modification was such that as the local concentration increased, the settling velocity of the solids constituent decreased towards zero at a maximum packing factor. The functional dependence of settling velocity with local volumetric concentration was specified before computation of a simulation case. The specific gravity of the solids phase modeled in this work was 2.3. This modeling approach was a first approximation to a largely unknown material state for the slurry layer in the tank.

The gas phase also was modeled as a constituent in the computation. As a first approximation within the current capabilities of the TEMPEST code, the gas phase was assumed to be a continuous distribution of incompressible bubbles. TEMPEST does not model for compression-expansion behavior of a gas component in the fluid. In the solution of a constituent transport equation for the gas, the bubbles were assigned a rise velocity. In the preliminary analysis reported here, the rise velocity was arbitrarily assumed to be $0.01 \mathrm{ft} / \mathrm{s}(0.3 \mathrm{~cm} / \mathrm{s})$. This rise velocity was modified during calculations according to a volumetric concentration function similar to that performed for a solids phase settling. This function is required to prevent overpacking of the gas phase in the upper region of the computation domain during a simulation. Property-based calculations involving the gas phase were performed assuming the gas to be hydrogen at one atmosphere.

Calculations were conducted according to several scenarios designed to attain an understanding of the computation process and an understanding of the physics being simulated. Material in the tank initially was assumed to be at rest with a sludge layer existing in the lower $15 \mathrm{ft}$. The fraction of solids and gas phases in the sludge layer were adjusted by trial and error to attain a solids mass fraction of 0.44 and a net positive density of approximately 6 percent. The amount of net positive density initially was chosen arbitrarily because it was not known in a real material state of the sludge layer what amount would be required to induce the rollover event.

The temperature profiles generated by the TEMPEST code are in good agreement with measured data from tank 101-SY during the GRE of October 1990.

TEMPEST model analyses demonstrate the ability of this model to represent qualitatively the observed behavior of tank 101-SY rollover events. This agreement indicates that the prediction of certain physical principles governing the hydrodynamics and heat transfer in this problem can be computed to give characteristic similarity with data. This similarity provides confidence in the TEMPEST code as a useful analysis tool, al though more accurate representations of physical material states can and should be programmed.

\subsubsection{The GOTH Mode1}

A three-phase (solid, liquid, gas) three-dimensional numerical computation model has been developed to simulate the behavior of the contents of tank 101-SY during a GRE (Thurgood 1992). The objective of this simulation is to represent the tank behavior phenomenologically. The thermal-hydraulic 
computer program used as the basis for the model is the GOTHIC computer program which is the most enhanced version of the FATHOMS computer program. (FATHOMS is also used by Westinghouse Hanford, in a different version, to simulate the mixing of hydrogen in the air space above the waste in the tank and the removal of hydrogen from the tank by the tank ventilation system.) This thermal-hydraulics program simulates two-phase flow, laminar shear stress, and conduction within the fluid and turbulent shear stress and energy transport. The modified version of GOTHIC is referred to as GOTH to keep its identity separate from GOTHIC.

The GRE is initiated when sufficient buoyancy develops in the slurry to cause a portion, or all of the slurry layer, to rise buoyantly. That is, material that was in the bottom nonconvective layer rises to the top and the convective supernatant replaces it. As the lower material rises, the gas within it expands because of the change in hydrostatic pressure. This expansion, combined with the disturbance of the material caused by the rollover, results in some of the entrapped gas being released from the slurry, flowing around or through the crust into the air space at the top of the tank. The gases are then removed from the tank by the tank ventilation system.

The GOTHIC program solves the conservation equations for mass, momentum and energy for multicomponent, two-phase flow. Conservation equations are solved for three fields:

- Steam/gas mixture

- Continuous liquid

- Liquid droplet suspended in Steam/gas mixture.

The program calculates the relative velocities between these fields, including the effects of two-phase slip on pressure drop and heat transfer between phases and between solid surfaces and the fluid. It includes the calculation of laminar and turbulent shear stresses and fluid conduction and turbulent heat transport. The three fields may be in thermal nonequilibrium since separate energy equations are solved for each field. The volume and mass of each phase and the concentration of each component of the gas mixture is calculated for each computational cell because separate conservation of mass equations are solved for each phase and for each component of the noncondensible gas mixture. Each phase can travel at its own velocity because separate momentum equations are solved for each phase. Therefore, the program can calculate the settling of liquid droplets and the rise of gas bubbles.

Some features were added to GOTHIC for simulation of a GRE. The first modification was to implement a particle field into the code. GOTHIC has a droplet field (1iquid droplets suspended in the gas phase) which is not required for the waste tank simulation. Since the droplet field is not required for the tank simulation, a particle field was introduced into the code by converting the droplet field into a particle field. Second, the laminar shear stress model in GOTHIC is for Newtonian fluids only. The materials in the tank exhibit non-Newtonian behavior which is a function of both temperature and particle concentration. A non-Newtonian model for calculating the viscosity was added. 
The initial GOTH study showed, by numerical experimentation, that relatively small particle sizes are required in order to obtain the slow settling rates needed to allow the thermal inversion and gas release rates to occur over the relatively long time periods that they do. A particle size of 0.001 in. (25 microns) was used in these calculations. Initial measurements from the tank sample indicate that mean particle sizes may be even smaller, with larger particle sizes being in the range of 100 to 300 microns.

The GOTH computer code was used to generate a rollover event. Because the effect of the dispersed phase viscosity is included, the model is not limited to particulate flows, but can also be applied to droplet and bubbly flows.

\subsection{ROLLOVER FEATURE MODELS}

\subsubsection{Rayleigh-Taylor Instability}

Los Alamos National Laboratory evaluated the rollover with a model based upon a linear, inviscid theory for Rayleigh-Taylor (RT) instability. An idealized system consisting of two isothermal layers and the crust ${ }^{3}$ was considered. The two layers correspond to the slurry and liquid layers in the tank; the sludge layer and the actual temperature gradients were ignored. During the time between events, gas generated in the slurry layer is assumed to remain there, either in solution or trapped by the solids in the layer. ${ }^{4}$

A system is said to be potentially RT unstable when the acceleration vector points toward the lighter layer. When the only force acting is gravity, this means that the configuration with a liquid layer on top of a lighter liquid or gas layer is unstable and the layers will invert. often restoring forces exist and include surface or interfacial tension or, in solids, material strength. The effects of viscosity and heat and mass transfer can also reduce the sensitivity to instability. The effect of restoring forces was neglected in the model here.

The instability can be triggered when the critical density ratio is exceeded, i.e., when the liquid density is greater than the density of the slurry. Without any gas in the slurry, it is considerably heavier than the liquid layer and no instability is possible.

The data on crust drop together with the average gas-generation rate using an arbitrary datum beginning after the March 1989 GRE, were used to calculate an index of instability for each event.

${ }^{3}$ The crust plays no role in the actual rollover. It can affect the time for gas to move from beneath the crust into the dome region.

${ }^{4}$ Gas produced in the liquid 7ayer is assumed to move freely out of the layer and through the crust into the dome. Gas that evolves continuously does not pose a safety problem because of the low steady-state concentrations. 
If the system responds only to the RT instability, then this index should never exceed 1 before an event because this would correspond to a global instability. That is, the entire volume of the slurry is at the critical density ratio. On the other hand, events can occur at a lower value of the instability index; these would be interpreted as partial releases where a nonuniform distribution of gas in the slurry results in a local release. Figure 8-2 shows the instability index assuming that the crust level after the Apri1 1990 event, $z_{c}(m i n)$, represents the minimum amount of retained gas. The peak value of $I_{R T}$ is close to one, with events occurring at an index value as low as 0.8 .

The Los Alamos National Laboratory (LANL) analysis made no attempt to calculate the dynamics of a tank rollover. The assessment does indicate, qualitatively, that an unstable density condition, i.e., an RT instability, may be a sufficient condition to initiate a rollover. It also illustrates the variability of rollover events.

\subsubsection{Neutral Buoyancy Model of Rollover Initiation}

As a possible explanation of the variability in the timing and magnitude of the episodic gas releases, the effect of pressure and gas volume gradients in the slurry layer were investigated in a simple one-dimensional model. This model assumed that gas is generated at a uniform rate in the liquid phase of the slurry, and is released whenever the slurry achieves a net positive buoyancy for the entire slurry layer above some level.

The model assumes the slurry bed has sufficient mechanical (shear) strength to act as a barrier, preventing the rise of lower level buoyant slurry through heavier overlying layers. The slurry is assumed to have no tensile strength. The slurry then behaves as follows.

1. Starting with a uniform gas content (input), the slurry grows lighter, by expulsion of liquid from the settled bed, and first becomes buoyant at the top surface of the slurry.

2. The slurry layer above the neutral buoyancy point in the bed is assumed to release gas from all layers above the neutral buoyancy level.

3. Release of gas from the top layer(s) permits the slurry bed to resettle on top, and a period of time elapses until gas buildup lower in the bed produces enough buoyancy to balance the heavier slurry above.

4. The layers below the neutral buoyancy point are assumed to be unaffected by the gas release above, except that the releases are followed by resettiing of the solids, increasing the weight of solids which must be overcome by buoyant forces. 
WHC-EP-0584

Figure 8-2. Calculated Instability Index.

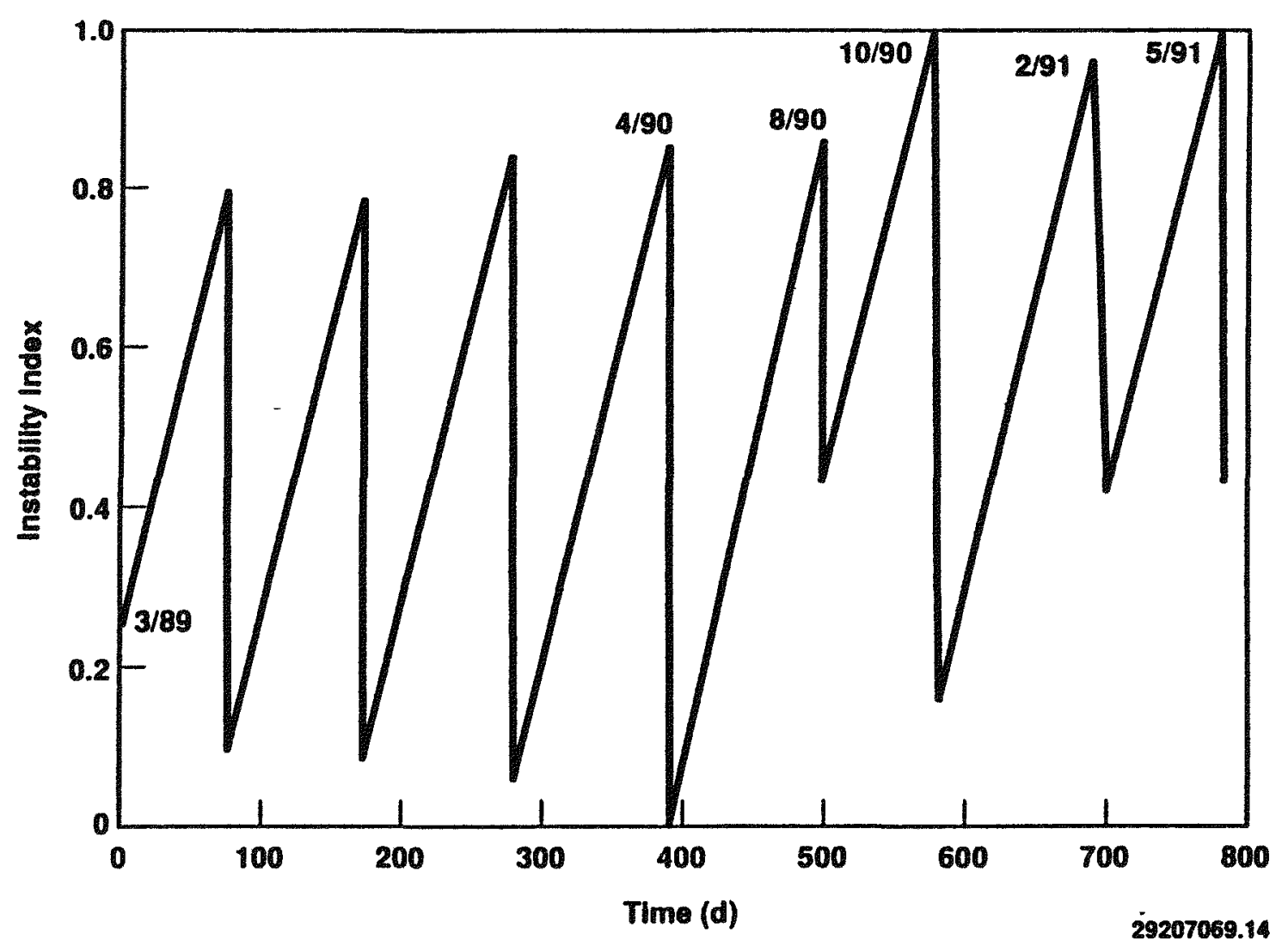


5. The neutral buoyancy point works its way to the bottom. If the gas release at each slurry rise were assumed to be 100 percent, the process would simply repeat, but if the release is less than 100 percent, the system continues to remember its history, and subsequent releases are affected by the gas which remains in the slurry.

A scoping calculation was performed using preliminary rough approximations of characteristic tank 101-SY data, and starting with a uniform gas volume of 7.5 percent in the slurry. Slurry rise events (burps) were calculated as a function of time. The calculated behavior is qualitatively consistent with observations.

\subsubsection{The GOB Theory of Partial Rollover Gas Release}

A proposed theory of partial rollover that can explain many of the quantitative and qualitative observations is called the gob theory (Allemann 1992). In this theory, a portion of the bottom sludge in the tank retains enough of the gas being produced by the waste that this portion (gob) breaks loose from the siudge mass or layer as buoyancy overcomes the cohesive forces and viscosity. The gob then rises rapidly to the top of the bulk waste and almost instantly releases the largest bubbles of gas that have already coalesced. The gas remaining in the gob in smaller size bubbles, percolates (fizzes) out at a slower rate until the amount of gas can no longer hold the cohesive solid fraction afloat. Then the gob material begins to sink, and the remaining gas is recompressed by hydrostatic pressure.

The gob theory of episodic gas release from tank 101-SY is consistent with observed phenomena of long-term gas release rate-associated liquid level drops in the tank and percolation bubble size. Qualitatively, the theory models: (1) the temperature profile overturn and beginning of the profile reconstruction, (2) the temperature balance during a release, (3) the association of a series of upwellings during a release, and (4) the varied release sizes. The results show the sensitivity of the phenomenon to the physical properties of the waste slurry. For more details on the model, refer to Allemann (1992).

\subsection{MODELING OF HYDROGEN IN THE TANK DOME SPACE AND VENTILATION SYSTEM}

\subsubsection{FATHOMS Analyses}

Analytical modeling has been performed to determine the hydrogen inventory in the dome of tank 101-SY for various ventilation rates and slurry gas injection profiles.

The FATHOMS computer code is a state-of-the art computer program for modeling multiphase flow (Burgess and Holman 1991). It solves, by finite difference analysis, the conservation equations for mass, momentum, and energy for multicomponent, two-phase flow. It features a flexible noding scheme that 
allows it to be run in a lumped parameter mode or in a one-, two- or threedimensional mode. The code is a direct extension of the general thermalhydraulic analysis code COBRA-NC (Wheeler et a1. 1986), which was developed by PNL.

The basic FATHOMS model simulates the tank 101-SY ventilation system. The fan is assumed to run at a constant speed, and loss factors are used to establish steady-state flows for various branches of the ventilation system consistent with measured data (i.e., tank pressures and flow rates). The ventilation system flow rate for tank $101-5 y$ is assumed to be $\sim 620 \mathrm{ft}^{3} / \mathrm{min}$, with total flow from all tanks at $\sim 1,000 \mathrm{ft}^{3} / \mathrm{min}$. The volume representing tank 101-SY is further subdivided to allow 3-D modeling of the dome space. The model assumes that al1 air in-leakage occurs at the dome center.

Parametric analyses of the hydrogen quantity in the dome space, as a function of time, was performed for a variety of slurry gas release profiles, including a profile representative of the October 1990 GRE.

These analyses showed that the peak $\mathrm{H}_{2}$ quantity in the dome space is only mildly sensitive to the ventilation rate, although the time for which a given quantity is exceeded is sensitive to ventilation.

Parallel calculations with a fine mesh representation of the dome space, as well as the coarse mesh, showed the coarse mesh to be reasonably close, and to overcalculate the hydrogen peak. These calculations also showed mixing in the dome space to be rapid, with a time scale short compared to the ventilation exchange time. For more details, refer to Burgess and Holman (1991).

\subsubsection{Hydrogen Mixing Studies-Transient Reactor Analys is Code Model}

The LANL modeled the tank 101-SY dome space and ventilation system for analysis of slurry gas quantities and concentrations, and the dynamics of postulated flammable gas burns.

The analytical tools used were the coupled Hydrogen Mixing Studies (HMS) and Transient Reactor Analysis Code (TRAC) computer codes. The HMS is a finite-volume computer code that solves the transient, three-dimensional, compressible fluid Navier-Stokes equations with multiple species coupled with chemical kinetics. This code was developed at LANL to be a best estimate tool for predicting the transport, mixing, and combustion of hydrogen gas in nuclear reactor containments. The HMS was used to model the release of hydrogen and nitrous oxide into the vapor space of tank 101-SY. These released gases were then postulated to be transported and mixed in the cover gas volume according to local dynamics (such as convection and turbulent diffusion) before their ignition was postulated. After hydrogen ignition, the flows were driven by the coupled fluid-dynamics/chemical kinetics algorithm. The TRAC is a finite-volume/lumped-parameter thermal-hydraulics code developed at LANL for deriving advanced best-estimate predictions of postulated accidents involving light-water reactors. The network flow capability of TRAC was used to model the ventilation system associated with SY Tank Farm. In this context, tanks 102-SY and 103-SY were modeled using the lumped volume 
capability, while the ventilation system, including the in-leakage ports to each tank, were modeled using the one-dimensional finite-volume capability of TRAC.

The two codes were numerically coupled at the physical representation of the boundary to tank 101-SY. This is, HMS-provided TRAC pressures, temperatures, and gas composition at computational cells adjacent to the physical connections for the ventilation system and the in-leakage port. The TRAC used these values to compute flow rates throughout the entire system, excluding tank 101-SY. The resulting TRAC velocities representing the response of the ventilation system were then used as inflow or outflow boundary conditions for HMS.

The HMS computes the fluid dynamics and species transport, including turbulence effects and combustion phenomena. Source or sink terms are included to represent the species mass created or destroyed by chemical reactions.

Convective heat exchange between the burning gas mixture and the waste surface is given by Newton's heating and cooling law, where the heat-transfer coefficient is calculated according to a modified Reynolds analogy.

Radiation heat transfer from the flame is modeled in a relatively simple fashion. It is assumed that 15 percent of the total chemical energy of combustion is radiated from a point source at the computation cell center. This energy is radiation spherically away from each computational cell where combustion occurs to solid surfaces such as the crust, with the appropriate geometric view factors.

A one-step chemical kinetics model is used that simplifies the actual chemical processes. In this model, the only reactions modeled are

$$
\mathrm{H}_{2}+\mathrm{N}_{2} \mathrm{O} \rightarrow \mathrm{H}_{2} \mathrm{O}+\mathrm{N}_{2}+77.4 \mathrm{kcal} / \mathrm{mole} \mathrm{H}_{2} \text { consumed }
$$

$\mathrm{H}_{2}+1 / 2 \mathrm{O}_{2} \rightarrow \mathrm{H}_{2} \mathrm{O}+57.8 \mathrm{kcal} / \mathrm{mole}_{2}$ consumed.

As the flame sweeps across the waste surface, the shear stress on the surface could be sufficiently high to cause particle entrainment into the dome atmosphere. An entrainment model was used (Iversen 1984) to predict wind pickup of small particles from dry particulate beds. Because the waste surface is wet (i.e., saturated with water), this model is extremely conservative for modeling waste entrainment.

The TRAC code solves the two-phase, two-fluid mass, energy, and momentum conservation equations in lumped-parameter and one-, two-, and threedimensional geometries. The code was originally developed for light-water reactor nuclear safety studies. It is directly applicable to the Hanford Site waste tank ventilation system, because of its networking capability

(i.e., linking together complicated piping networks with different and coupled components) and its fast running speed.

The coupling of the HMS and TRAC computer codes was accomplished by forcing consistent boundary conditions to be imposed at the physical locations where the two computer models interacted. For this calculation, the locations where the two computer models interacted were: (1) where the ventilation 
ductwork left tank 101-SY, and (2) where the inflow leakage paths are above tank 101-SY. At these locations, TRAC determined the velocity or volumetric flow rate leaving tank 101-SY, while HMS determined the pressure and temperature in the vicinity of the exit or entrance to tank 101-SY.

\subsection{PHYSICAL MODELING}

- An illustrative physical model of a rollover phenomenon was demonstrated in 1990. Gas generation was produced by ordinary yeast, acting on sugar in aqueous solution. Slurry materials compatible with the yeast were added. Demonstrations were made, for example, using slurries of corn meal and cream of wheat.

Undisturbed, these models displayed a characteristic gas accumulation, rollover, and gas release behavior strikingly similar to the apparent behavior of tank 101-SY. Moreover, continuous stirring of the mixture, keeping the solids in suspension, prevented gas accumulation and the resulting rollover; gas release was essentially continuous.

The concept of mobilizing the settled solids to prevent gas accumulation was explored further by jet mixing tests in a sector model representing tank 101-SY. Water was used as the liquid medium. Calcium hydroxide (1 ime) was selected to simulate the settled solids. Tests demonstrated effective suspension of settled solids, and mixing of the solid and liquid components throughout the model. These analyses concluded that similar jet pump mixing would be effective in tank 101-SY.

Physical modeling is continuing in support of the planned mixer pump mitigation test in tank 101-SY. 


\subsection{CONCLUSIONS}

Since the declaration of the USQ, tank 101-SY is being monitored for several types of data. The data include surface levels, temperatures, released gas composition, tank pressure, ventilation flow rate, relative humidity, acoustic noise and video images. The data acquisition is performed by four main computer systems. Two of these are used for all tank farms, while the other two are specific for tank 101-SY.

The data monitoring primarily indicated that a tank waste rollover immediately precedes a gas release event. The crust is not continuous through the surface and is cracked and fragmented. Gas is continuously released from the upper convective liquid layer through the crust. The humidity in the tank dome space changes little from winter to summer months. The approximate slurry gas composition is $30 \% \mathrm{H}_{2}, 30 \% \mathrm{~N}_{2} \mathrm{O}$, and $30 \% \mathrm{~N}_{2}$ with ammonia, water vapor, and other gases comprising the remaining 10 percent.

In addition to data monitoring, core samples are being obtained and analyzed for various physical and chemical properties. These data indicated that the crust is wetter than previously assumed. The driest crust was found to contain at least 10 percent moisture. As expected, the density of core segments increases from the top of the waste tank to the bottom with a corresponding increase in suspended solids.

To add to the understanding of the tank behavior, laboratory research is being performed on simulated wastes and the physical processes are being modeled. The research studies revealed that both radiolytic and chemical processes may be contributing to gas generation in tank 101-SY. Organics are needed in the waste to generate gases such as $\mathrm{H}_{2}, \mathrm{~N}_{2} \mathrm{O}$ and $\mathrm{NH}_{3}$, in quantities sufficient to measure in the tank dome space. Flammability studies on mixtures of $\mathrm{H}_{2}, \mathrm{~N}_{2} \mathrm{O}$ and air indicated that the lean flammability limits (LFLs) using spark ignition are the same for all three mixtures $\left(\mathrm{H}_{2}\right.$-air and $1: 1$ and $3: 2$ ratios of $\mathrm{H}_{2} / \mathrm{N}_{2} \mathrm{O}$ plus air). For quiescent initial conditions, the LFL for upward flame propagation (LFL $\mathrm{Lpward}_{\text {d }}$ ) is approximately $5 \% \mathrm{H}_{2}$, and the LFL for downward flame propagation ( $L F L_{\text {downwerd }}$ ) $=8 \% \mathrm{H}_{2}$. The LFLs for the turbulent mixtures are $L F L_{\text {upparc }}=4 \% \mathrm{H}_{2}$ and $\left[\mathrm{LH}_{\mathrm{C}}\right.$ dounward $=6 \% \mathrm{H}_{2}$. The turbulent mixtures showed considerabty higher pressures compared to the quiescent mixtures over the $4 \%$ to $8 \% \mathrm{H}_{2}$ range.

Thermocalorimetric data analysis on synthetic crust concluded that a hydrogen burn in tank 101-SY would not result in the initiation of a selfpropagating reaction in the crust and that consumption of crust would be limited to a thin layer and surface projections. Actual crust samples have been shown to be less energetic than synthetic samples.

Modeling studies on crust burn concluded that a global burn of the crust is highly unlikely even if the gas mixture in the tank dome space were to be ignited, and that a below-the-crust burn of the $\mathrm{H}_{2} / \mathrm{N}_{2} \mathrm{O}$ mixture is also highiy improbable.

Modeling studies on the accumulation and release process of flammable gases helped in the understanding of the process. Gases generated in the slurry are retained and continue to accumulate resulting in an increase of 
tank contents volume and a decrease of the slurry layer density. The slurry layer density eventually becomes less than the density of the overlying liquid causing a rollover. Once the slurry loses enough gas to increase its density to above that of the convective liquid, the slurry settles down to its original position and the cycle repeats.

Modeling studies on the rollover phenomenon consistently predicted the observed tank behavior in a qualitative manner. However, the models need to be improved to quantitatively describe the rollover process. Studies should be extended to include parameter uncertainties and also sensitivity to parameter variations.

Finally, additional data are needed for a better understanding of the tank behavior before, during, and after a GRE. Understanding the tank contents and behavior will be helpful in predicting future events and in planning for remediation. This knowledge also is helpful in a better definition of the window criteria for work to be performed on the tank following a gas release. 


\subsection{REFERENCES/BIBLIOGRAPHY}

Allemann, R. T., 1991, Slurry Growth Gas Composition, WHC-SA-1216-FP, Pacific Northwest Laboratory, Richland, Washington.

Allemann, R. T., Z. I. Antoniak, L. L. Eyler, L. M. Liljegren, and J. S. Roberts, 1992, PNL-8011, Conceptual Models for Waste Tank Mechanistic Analysis - Status Report - January 1991, Pacific Northwest Laboratory, Richland, Washington.

Allemann, R. T., 1992, PNL-SA-20353, Physical Mechanisms Contributing to the Episodic Gas Release From Hanford Tank 241-SY-101, April 1992, Pacific Northwest Laboratory, Richland, Washington.

Babad, H., G. D. Johnson, D. A. Reynolds, and D. M. Strachan, 1992, Understanding of Cyclic Venting Phenomena in Hanford Site High Level Waste Tank: The Evaluation of Tank 241-SY-101, WHC-SA-1364-FP, Westinghouse Hanford Company, Richland, Washington.

Barker, J. J., 1991, Evaluation of October 24, 1990 Tank 241-SY-101 Gas Release Event, WHC-SD-WM-PE-041, Rev. 0, Westinghouse Hanford Company, Richland, Washington.

Burgess, D. M., and J. L. Holman, 1991, Ventilation Flow Recommendations for Waste Tank 241-SY-101, WHC-EP-0406, Westinghouse Hanford Company, Richl and, Washington.

Burke, T. M., K. G. Carothers, S. M. Joyce, and A. L. Pajunen, 1991, Evaluation of April 19, 1990 Tank 241-SY-101 Gas Release Event, WHC-SD-WM-PE-039, Westinghouse Hanford Company, Richland, Washington.

Carothers, K. G., T. M. Burke, and D. A. Reynolds, 1990, Evaluation of August 5, 1990 Tank 241-SY-101 Gas Release Event, WHC-SD-WM-PE-040, Rev. 0, Westinghouse Hanford Company, Richland, Washington.

Delegard, C., 1980, Laboratory Studies of Complexed Waste Slurry Volume Growth in Tank 241-SY-101, RHO-LD-124, Rockwell Hanford Operations, Richland, Washington.

Erhart, M. F., 1991a, Evaluation of February 1991 Tank 241-SY-101 Gas Release Event, WHC-SD-WM-PE-043, Rev. 1, Westinghouse Hanford Company, Richland, Washington.

Erhart, M. F., 1991b, Evaluation of May 1991 Tank 241-SY-101 Gas Release Event, WHC-SD-WM-PE-044, Rev. 0, Westinghouse Hanford Company, Richland, Washington.

Erhart, M. F., 1992a, Evaluation of August 1991 Tank 241-5Y-101 Gas Release Event, WHC-SD-WM-PE-045, Rev. 1, Westinghouse Hanford Company, Richland, Washington. 
Erhart, M. F., 1992b, Evaluation of December 1991 Tank 241-SY-101 Gas Release Event, WHC-SD-WM-PE-046, Rev. 0, Westinghouse Hanford Company, Rich1and, Washington.

Fox, G. L., T. R. Beaver, D. B. Bechtold, and A. K. Postma, 1992, Tank 241-SY-101 Crust Burn Analysis, WHC-SD-WM-SAR-046, Revision 1, Westinghouse Hanford Company, Richland, Washington.

Herting, D. L., 1991, Analytical Chemistry Plan for Tank 241-SY-101 Core Sample, WHC-SD-WM-TP-090, Rev. 2, Westinghouse Hanford Company, Richland, Washington.

Herting, D. L., 1992, Analysis of November 1990 Crust Samples from Tank 241-SY-101, WHC-SD-WM-DTR-022, Rev. 0, Westinghouse Hanford Company, Richl and, Washington.

Herting, D. L., D. B. Bechtold, B. A. Crawford, T. L. Welsh, and L. Jensen, 1992a, Laboratory Characterization of Samples Taken in May 1991 From Hanford Waste Tank 241-SY-101, WHC-SD-WM-DTR-024, Rev. 0, Westinghouse Hanford Company, Richland, Washington.

Herting, D. L., D. B. Bechtold, B. E. Hey, B. D. Keele, L. Jensen, and T. L. We1sh, 1992b, Laboratory Characterization of Samples Taken in December 1991 (Window E) from Hanford Waste Tank 241-SY-101, WHC-SD-WM-DTR-026, Rev. 0, Westinghouse Hanford Company, Richland, Washington.

Lechelt, J. A., 1991, Data Management Plan for Tank 241-SY-101 Monitoring Systems, WHC-SD-WM-PLN-018, Rev. 0, Westinghouse Hanford Company, Richland, Washington.

Mauss, B. M., 1986, letter to L. M. Sasaki, "101-SY Samples: Laboratory Anaiysis and Results," 65453-86-079, Rockwel1 Hanford Operations, Richland, Washington.

Meisel, D., H. Diamond, C. D. Jonah, M. C. Sauer, Jr., J. C. Sullivan, F. Barnabas, E. Cerny, and Y. Di Cheng, 1992, Radiolytic and Radiolytically-Induced Generation of Gases in Simulated Mixed Waste Solutions, TRAC-0378, Waste Management 1992, Tucson, Arizona.

Reynolds, D. A., 1992, Window C Core Sample Results and Interpretation, WHC-EP-0589, Westinghouse Hanford Company, Richland, Washington.

Thurgood, M. G., 1992, NAI 9101-1, Simulation of Gas Release Event in Tank 101-SY Using the GOTH Computer Program.

Tingey, J. M., 1992, PNL-8054, Physical Characterization of Tank 101-SY Core Samples From Window C, Pacific Northwest Laboratory, Richland, Washington. 


\section{WHC-EP-0584}

We1ty, R. K., and N. J. Vermeulen, 1991, Waste Storage Tank Status and Leak Detection Criteria, WHC-SD-WM-TI-357, Rev. 10, Westinghouse Hanford Company, Richland, Washington.

Wheeler, C. L., M. G. Thurgood, and T. L. George, 1986, COBRA-NC: A Thermal Hydraulics Code for Transient Analysis of Nuclear Reactor Components, NUREG/CR 3262, U.S. Nuclear Regulatory Commission, Washington, DC. 
WHC-EP-0584

This page intentionally left blank. 


\section{DISTRIBUTION}

\section{Number of Copies}

\section{OFFSITE}

U.S. Department of EnergyHeadquarters

J. C. Tseng (10)

Argonne National Laboratory/

Chemistry Division 9700 South Cass Avenue Argonne, Illinois 60439-4831

E. P. Horwitz

D. Meisel

Carnegie-Mellon University/Chemical Engineering Design Science Incorporated 163 Witherow Road

Sewickley, Pennsylvania 15143

\section{G. Powers}

The Florida State University/Department of Chemistry

Tallahassee, Florida 32306

G. R. Choppin

Georgia Institute of Technology

225 North Avenue

Boggs Chemistry Building

Atlanta, Georgia 30332

E. C. Ashby

A. Schneider 5005 Hidden Branches Drive Dunwoody, Georgia 30338

Hazards Research Corporation 200 Valley Road

Mt. Arlington, New Jersey 07856

C. Grelecki

W. W. Schulz

727 Sweetleaf Drive Wilmington, Delaware 19808 
DISTRIBUTION (continued)

Number of Copies

\section{OFFSITE}

1

Lawrence Livermore National Laboratory P.0. Box 808, L-221

Livermore, California 94550

B. Hudson

3

Los Alamos National Laboratory

P.0. Box 1663, MSC 920

Los Alamos, New Mexico 87545

S. F. Agnew

T. Larson

D. Oakley

3

Science Applications International

J. 0 . Bunting

R. Daniels

H. Sutter

2

Oak Ridge National Laboratory

P.0. Box 2008, MS 6268

Oak Ridge, Tennessee 37831-6268

D. 0. Campbe11

T. Kress

1

Sandia National Laboratory

P.0. Box 5800

Albuquerque, New Mexico 87185

S. Slezak

1

Rice University

5211 Paisley

Houston, Texas 77096

A. S. Veletos

2

Massachusetts Institute of Technology Department of Nuclear Engineering 77 Massachusetts Ave., Room 24-109

Cambridge, Maryland 02139

C. Forsberg

M. Kazimi 


\section{DISTRIBUTION (continued)}

Number of Copies

\section{OFFSITE}

Harvard University

295 Upland Avenue

Newton Highlands, Maryland 02161

M. First

1

Air Products \& Chemicals, Inc. 7201 Hamilton B7vd

Allenton, Pennsylvania 18195-1501

G. Schumauch

1

C. Abrams

1987 Virginia

Idaho Falls, Idaho 83404

1

F. Carlson

6965 North 5th West

Idaho Falls, Idaho 83401

1

Los Alamos National Laboratory

409 12th Street, SW, Suite 310

Washington, D.C. 20024-2188

D. Oakley

1

University of Washington/Chemistry

Department

Building 10

Seattle, Washington 98195

B. R. Kowalski

1

Vanderbilt University

P.0. Box 1596, Station B

Nashville, Tennessee 37235

F. L. Parker

1

Washington State University/Department

of Chemical Engineering

Pullman, Washington 99164

W. J. Thomson 


\section{DISTRIBUTION (continued)}

Number of Copies

OFFSITE

1

ONSITE

8

7

49
Westinghouse Savannah River Company Box 616

Building 773A, Room B132

Aiken, South Carolina 29802

N. Bibler

U.S. Department of Energy

Richland Operations office

G. J. Bracken

A4-02

R. F. Christensen

A4-02

J. M. Clark

R. E. Gerton

A4-02

J. P. Hamric

W. A. Rutherford

Public Reading Room (2)

A4-02

A7 -32

A4-02

Pacific Northwest Laboratory

R. T. Allemann

KT-15

S. A. Bryan

P7-25

B. M. Johnson

$\mathrm{K} 1-78$

M. R. Kreiter

K7-90

G. B. Mellinger

P7-18

L. R. Pederson

K2-44

D. M. Strachan

K2-38

Westinghouse Hanford Company

T. M. Anderson

R. P. Anantatmula (10)

B3-01

R1-51

H. Babad

H4-23

D. C. Board

S1-57

T. M. Burke

HO-34

G. M. Christensen

H4-23

W. L. Cowley

G. L. Fox

H5-31

J. C. Fulton

D. G. Hamrick

[5-0]

R2-31

C. E. Hanson

R1-51

D. L. Herting

H5-09

R. D. House

T6-50

M. M. Is I am

R2-83

R1-49 
DISTRIBUTION (continued)

Number of Copies

ONSITE

Westinghouse Hanford Company (continued)

J. Jo

G. D. Johnson

N. W. Kirch

W. L. Knecht

B. G. Lauzon

J. A. Lechelt

R. M. Marusich

J. P. Menard

G. J. Miskho

A. F. Noonan

D. M. Ogden

M. A. Payne

R. S. Popielarczyk

J. G. Propson

I. E. Reep

D. A. Reynolds

D. C. Richardson

C. P. Schroeder

M. H. Shannon

D. E. Simpson

D. D. Stepnewski

J. D. Thomson

A. E. Wilder

D. D. Wodrich

Central Files

EDMC

Information Release (3)

R2-11

H4-23

R2-11

HO-34

R1-08

R2-11

H5-32

R2-40

R2-50

R2-12

HO-34

R2-50

R1-30

R2-18

H4-23

R2-11

R2-31

L7-06

H5-30

B3-55

H5-32

R1-30

R1-51

R2-23

L8-04

H4-22

H4-17

TFIC

R1-20 
WHC-EP-0584

This page intentionally left blank.

Distr-6 